\title{
Value and Momentum Everywhere
}

\author{
Asness, Clifford S.; Moskowitz, Tobias; Heje Pedersen, Lasse
}

Document Version

Accepted author manuscript

Published in:

Journal of Finance

DOI:

10.1111/jofi.12021

Publication date:

2013

License

Other

Citation for published version (APA):

Asness, C. S., Moskowitz, T., \& Heje Pedersen, L. (2013). Value and Momentum Everywhere. Journal of Finance, 68(3), 929-985. https://doi.org/10.1111/jofi.12021

Link to publication in CBS Research Portal

\section{General rights}

Copyright and moral rights for the publications made accessible in the public portal are retained by the authors and/or other copyright owners and it is a condition of accessing publications that users recognise and abide by the legal requirements associated with these rights.

Take down policy

If you believe that this document breaches copyright please contact us (research.lib@cbs.dk) providing details, and we will remove access to the work immediately and investigate your claim. 


\section{Value and Momentum Everywhere \\ Clifford S. Asness, Tobias J. Moskowitz, and Lasse Heje Pedersen}

Journal article (Post print version)

This is the peer reviewed version of the following article Asness, CS, Moskowitz, T \& Heje

Pedersen, L 2013, 'Value and Momentum Everywhere' Journal of Finance, vol 68, nr. 3, s. 929-

985., which has been published in final form at 10.1111/jofi.12021.

This article may be used for non-commercial purposes in accordance with Wiley Terms and

Conditions for Self-Archiving.

Uploaded to Research@CBS: March २०16 


\title{
Value and Momentum Everywhere
}

\author{
Clifford S. Asness, Tobias J. Moskowitz, and Lasse Heje Pedersen*
}

Current Version: June 2012

\begin{abstract}
We study the returns to value and momentum strategies jointly across eight diverse markets and asset classes. Finding consistent value and momentum premia in every asset class, we further find strong common factor structure among their returns. Value and momentum are more positively correlated across asset classes than passive exposures to the asset classes themselves. However, value and momentum are negatively correlated both within and across asset classes. Our results indicate the presence of common global risks that we characterize with a three factor model. Global funding liquidity risk is a partial source of these patterns, which are identifiable only when examining value and momentum simultaneously across markets. Our findings present a challenge to existing behavioral, institutional, and rational asset pricing theories that largely focus on U.S. equities.
\end{abstract}

\footnotetext{
*Asness is at AQR Capital Management. Moskowitz is at the University of Chicago Booth School of Business and NBER and is a consultant to AQR Capital. Pedersen is at the New York University Stern School of Business, Copenhagen Business School, AQR, CEPR, FRIC, and NBER. We thank Aaron Brown, John Cochrane, Kent Daniel, Gene Fama, Kenneth French, Cam Harvey (the editor), Ronen Israel, Robert Krail, John Liew, Harry Mamaysky, Michael Mendelson, Stefan Nagel, Lars Nielsen, Otto Van Hemert, Jeff Wurgler, and an anonymous referee for helpful comments, as well as seminar participants at the University of Chicago, Princeton University, Duke University, the Danish Society of Financial Analysts with Henrik Amilon and Asbjørn Trolle as discussants, and the NBER Summer Institute Asset Pricing Meetings with Kent Daniel as a discussant. We also thank Radhika Gupta, Kelvin Hu, Sarah Jiang, Adam Klein, Ari Levine, Len Lorilla, Wes McKinney, and Karthik Sridharan for research assistance. AQR Capital invests in, among other things, value and momentum strategies. The views expressed here are those of the authors and not necessarily those of any affiliated institution.
} 
Two of the most studied capital market phenomena are the relation between an asset's return and the ratio of its "long-run" (or book) value relative to its current market value, termed the "value" effect, and the relation between an asset's return and its recent relative performance history, termed the "momentum" effect. The returns to value and momentum strategies have become central to the market efficiency debate and the focal points of asset pricing studies, generating numerous competing theories for their existence. We offer new insights into these two market anomalies by examining their returns jointly across eight diverse markets and asset classes. Chiefly, we find significant return premia to value and momentum in every asset class and strong co-movement of their returns across asset classes, both of which challenge existing theories for their existence. We provide a simple three factor model that captures the global returns across asset classes, the FamaFrench U.S. stock portfolios, and a set of hedge fund indices.

The literature on market anomalies predominantly focuses on U.S. individual equities, and often examines value or momentum separately. In the rare case where value and momentum are studied outside of U.S. equities, they are also typically studied in isolation-separate from each other and separate from other markets. We uncover unique evidence and features of value and momentum by examining them jointly across eight different markets and asset classes (individual stocks in the U.S., U.K., Europe, and Japan, country equity index futures, government bonds, currencies, and commodity futures). ${ }^{1}$ Although some of these markets have been analyzed in isolation, our joint approach provides unique evidence on several key and novel questions about these pervasive market phenomena.

Specifically, how much variation exists in value and momentum premia across markets and asset classes? How correlated are value and momentum returns across these diverse markets and asset classes with different geographies, structures, investor types, and securities? What are the economic drivers of value and momentum premia and their correlation structure? What is a natural benchmark model for portfolios of global securities across different asset classes?

\footnotetext{
${ }_{1}^{1}$ Early evidence on U.S. equities finds value stocks on average outperform growth stocks (Stattman (1980), Rosenberg, Reid, and Lanstein (1985), and Fama and French (1992)) and stocks with high positive momentum (high 6-12 month past returns) outperform stocks with low momentum, (Jegadeesh and Titman (1993) and Asness (1994)). Similar effects are found in other equity markets (Fama and French (1998), Rouwenhorst (1998), Liew and Vassalou (2000), Griffin, Ji, and Martin (2003), Chui, Wei, and Titman (2010)), and in country equity indices (Asness, Liew, and Stevens (1997) and Bhojraj and Swaminathan (2006)). Momentum is also found in currencies (Shleifer and Summers (1990), Kho (1996), and LeBaron (1999)) and commodities (Erb and Harvey (2006) and Gorton, Hayashi, and Rouwenhorst (2008)).
} 
We find consistent and ubiquitous evidence of value and momentum return premia across all the markets we study, including value and momentum in government bonds and value effects in currencies and commodities, which are all novel to the literature. Our broader set of portfolios generates much larger cross-sectional dispersion in average returns than those from U.S. stocks only, providing a richer set of asset returns that any asset pricing model should seek to explain. Most strikingly, we discover significant co-movement in value and momentum strategies across diverse asset classes. Value strategies are positively correlated with other value strategies across otherwise unrelated markets, and momentum strategies are positively correlated with other momentum strategies globally. However, value and momentum are negatively correlated with each other within and across asset classes.

The striking co-movement pattern across asset classes is one of our central findings and suggests the presence of common global factors related to value and momentum. This common risk structure implies a host of results we investigate further. For example, using a simple three factor model, consisting of a global market index, a zero cost value strategy applied across all asset classes, and a zero cost momentum strategy across all assets, we capture the co-movement and the cross section of average returns both globally across asset classes and locally within an asset class. We further show that the global three factor model captures well the returns to the Fama and French U.S. stock portfolios as well as a set of hedge fund indices. Our use of a simple three factor model in pricing a variety of assets globally is motivated by finance research and practice becoming increasingly global and the desire to have a single model that describes returns across asset classes rather than specialized models for each market. We show that separate factors for value and momentum best explain the data, rather than a single factor, since both strategies produce positive returns on average yet are negatively correlated. ${ }^{2}$

We then investigate the source of this common global factor structure. We find only modest links to macroeconomic variables, such as business cycle, consumption, and default risk. However, we find significant evidence that liquidity risk is negatively related to value and positively related to momentum globally across asset classes. Pastor and Stambaugh (2003) and Sadka (2006) find that measures of liquidity risk are positively related to momentum in U.S. individual stocks. We show that this link is also present in other markets and asset classes and show that value returns are significantly negatively related to liquidity risk globally, implying that part of the negative correlation between value and momentum is driven by opposite signed exposure to liquidity risk.

\footnotetext{
${ }^{2}$ A single factor would require significant time variation in betas and/or risk premia to accommodate these facts. We remain agnostic as to whether our factors capture such dynamics or represent separate unconditional factors.
} 
Separating market from funding liquidity (see Brunnermeier and Pedersen (2009)) we further find that the primary link between value and momentum returns comes from funding risk, whose importance has increased over time, particularly after the funding crisis of 1998. Importantly, these results cannot be detected by examining a single market in isolation. The statistical power gained by looking across many markets at once-a unique feature of our analysis-allows these factor exposures to be revealed.

In terms of economic magnitudes, however, liquidity risk can only explain a small fraction of value and momentum return premia and co-movement. While liquidity risk may partly explain the positive risk premium associated with momentum, because value loads negatively on liquidity risk, the positive premium associated with value becomes an even deeper puzzle. Moreover, a simple equal weighted combination of value and momentum is immune to liquidity risk and generates substantial abnormal returns. Hence, funding liquidity risk can only provide a partial and incomplete explanation for momentum, but cannot explain the value premium or the value and momentum combination premium.

The evidence we uncover aims to shed light on explanations for the existence of value and momentum premia. For example, strong correlation structure among these strategies in otherwise unrelated asset classes may indicate the presence of common global risk factors for which value and momentum premia provide compensation. Conversely, such correlation structure is not a prediction of existing behavioral models (e.g., Daniel, Hirshleifer, and Subrahmanyam (1998), Barberis, Shleifer, and Vishny (1998), and Hong and Stein (1999)).

In addition to assuaging data mining concerns, evidence of consistent value and momentum premia across diverse asset classes may be difficult to reconcile under rational asset pricing theories that rely on firm investment risk or firm growth options as explanations for the value and momentum premia, $^{3}$ which are predominantly motivated by firm equity. These theories seem ill equipped to explain the same and correlated effects we find in currencies, government bonds, and commodities.

We also highlight that studying value and momentum jointly is more powerful than examining each in isolation. The negative correlation between value and momentum strategies and their high positive expected returns implies that a simple combination of the two is much closer to the efficient frontier than either strategy alone, and exhibits less variation across markets and over time. The return premium to a combination of value and momentum applied across all asset classes, therefore,

\footnotetext{
${ }^{3}$ See Gomes, Kogan, and Zhang (2003), Zhang (2005), Li, Livdan, and Zhang (2009), Belo (2010), Li and Zhang (2010), Liu and Zhang (2008), Berk, Green, and Naik (1999), Johnson (2002), Sagi and Seasholes (2007), Liu, Whited, and Zhang (2009).
} 
presents an even bigger challenge for asset pricing theories to accommodate (e.g., the Hansen and Jagannathan (1997) bound).

Our work also relates to the recent literature on global asset pricing. Fama and French (2012) examine the returns to size, value, and momentum in individual stocks across global equity markets and find consistent risk premia across markets. Considering both global equities and other global asset classes Frazzini and Pedersen (2010) find consistent returns to "betting against beta,” Koijen, Moskowitz, Pedersen, and Vrugt (2012) document global “carry” returns, and Moskowitz, Ooi, and Pedersen (2012) present global evidence of "time series momentum.” Time series momentum is a timing strategy using each asset's own past returns, which is separate from the cross-sectional momentum strategies we study here. Focusing on this different time series phenomenon, Moskowitz, Ooi, and Pedersen (2012) examine returns to futures contracts on equity indices, bonds, currencies, and commodities-ignoring individual stocks, which comprise half our study here-and address a different set of questions. Our focus is on the interaction between cross-sectional momentum and value strategies and their common factor structure globally, where we find striking co-movement across assets and a link to liquidity risk.

The link to funding liquidity risk may also be consistent with global arbitrage activity in the face of funding constraints influencing value and momentum returns (Brunnermeier and Pedersen (2009)). Why does momentum load positively on liquidity risk and value load negatively? A simple and natural story might be that momentum represents the most popular trades, as investors chase returns and flock to the assets whose prices appreciated most recently. Value, on the other hand, represents a contrarian view. When a liquidity shock occurs, investors engaged in liquidating sell offs (due to cash needs and risk management) will put more price pressure on the most popular and crowded trades, such as high momentum securities, as everyone runs for the exit at the same time (Pedersen (2009)), while the less crowded contrarian/value trades will be less affected.

Vayanos and Wooley (2012) offer a model of value and momentum returns due to delegated management that may be consistent with these results. They argue that flows between investment funds can give rise to momentum effects from inertia due to slow moving capital, and eventually push prices away from fundamentals causing reversals or value effects. Correlation of value and momentum across different asset classes could also be affected by funds flowing simultaneously across asset classes, which could in turn be impacted by funding liquidity. However, matching the magnitude of our empirical findings remains an open question.

The paper proceeds as follows. Section I outlines our data and portfolio construction. Section II examines the performance of value and momentum across asset classes and documents their global 
co-movement. Section III investigates the source of common variation by examining macroeconomic and liquidity risk, and Section IV offers an empirically motivated three factor model to describe the cross section of returns across asset classes. Section V briefly discusses the robustness of our results to implementation issues. Section VI concludes by discussing the implications of our findings.

\section{Data and Portfolio Construction}

We describe our data and methodology for constructing value and momentum portfolios across markets and asset classes.

\section{A. Data}

Global Individual Stocks. We examine value and momentum portfolios of individual stocks globally across four equity markets: U.S., U.K., continental Europe (excluding the U.K.), and Japan. The U.S. stock universe consists of all common equity in CRSP (sharecodes 10 and 11) with a book value from Compustat in the previous six months, and at least 12 months of past return history from January 1972 to July 2011. We exclude ADR's, REITS, financials, closed end funds, foreign shares, and stocks with share prices less than $\$ 1$ at the beginning of each month. We limit the remaining universe of stocks in each market to a very liquid set of securities that could be traded for reasonably low cost at reasonable trading volume size. Specifically, we rank stocks based on their beginning of month market capitalization in descending order and include in our universe the number of stocks that account cumulatively for $90 \%$ of the total market capitalization of the entire stock market. ${ }^{4}$ This universe corresponds to an extremely liquid and tradeable set of securities. For instance, over our sample period this universe corresponds to the largest $17 \%$ of firms on average. For the U.S. stock market at the beginning of the sample period (January 1972) our universe consists of the 354 largest firms and by the end of our sample (July 2011) the universe is the 676 largest names. Hence, our sample of U.S. equities is significantly larger and more liquid than the Russell 1000.

For stocks outside of the U.S., we use Datastream data from the U.K., continental Europe (across all European stock markets, excluding the U.K.), and Japan. We restrict the universe in each market using the same criteria used for U.S. stocks. On average over the sample period, our universe represents the largest 13\%, 20\%, and 26\% of firms in the U.K., Europe, and Japan, respectively. Data on prices and returns comes from Datastream, and data on book values is from Worldscope.

Most studies of individual stocks examine a much broader and less liquid set of securities. We restrict our sample to a much more liquid universe (roughly the largest $20 \%$ of stocks in each market)

\footnotetext{
${ }^{4}$ This procedure is similar to how MSCI defines its universe of stocks for its global stock indices.
} 
to provide reasonable and conservative estimates of an implementable set of trading strategies and to better compare those strategies with the set of strategies we employ in index futures, currencies, government bonds, and commodity futures, which are typically more liquid instruments. Our results are conservative since value and momentum premia are larger among smaller, less liquid securities over the sample period we study. ${ }^{5}$

All series are monthly and end in July 2011. The U.S. and U.K. stock samples begin in January 1972. The Europe and Japan stock samples begin in January 1974. The average (minimum) number of stocks in each market over their respective sample periods is 724 (354) in the U.S., 147 (76) in the U.K., 290 (96) in Europe, and 471 (148) in Japan.

Global Equity Indices. The universe of country equity index futures consists of the following 18 developed equity markets: Australia, Austria, Belgium, Canada, Denmark, France, Germany, Hong Kong, Italy, Japan, Netherlands, Norway, Portugal, Spain, Sweden, Switzerland, U.K., and U.S. Returns and price data as well as book values are obtained from MSCI. The sample covers the period January 1978 to July 2011, with the minimum number of equity indices being eight and all 18 indices represented after 1980. The returns on the country equity index futures do not include any returns on collateral from transacting in futures contracts, hence these are comparable to returns in excess of the risk free rate.

Currencies. We obtain spot exchange rates from Datastream covering the following 10 currencies: Australia, Canada, Germany (spliced with the Euro), Japan, New Zealand, Norway, Sweden, Switzerland, U.K., and U.S. The data cover the period January 1979 to July 2011, where the minimum number of currencies is seven at any point in time and all 10 currencies are available after 1980. We compute returns from currency forward contracts, where currency returns are all dollar denominated and implicitly include the local interest rate differential.

Global Government Bonds. Bond index returns come from Datastream, short rates and 10 year government bond yields are from Bloomberg, and inflation forecasts are obtained from investment bank analysts' estimates as compiled by Consensus Economics. We obtain government bond data for the following 10 countries: Australia, Canada, Denmark, Germany, Japan, Norway, Sweden,

\footnotetext{
${ }^{5}$ Hong, Lim, and Stein (2000), Grinblatt and Moskowitz (2004), Fama and French (2012), and Israel and Moskowitz (2012) show that value and momentum returns are inversely related to the size of securities over the time period studied here, though Israel and Moskowitz (2012) show this relation is not robust for momentum in other sample periods. Value and momentum returns have also been shown to be stronger in less liquid emerging markets (Rouwenhorst (1999), Erb and Harvey (2006), Griffin, Ji, and Martin (2003)). A previous version of this paper used a broader and less liquid set of stocks that exhibited significantly stronger value and momentum returns.
} 
Switzerland, U.K., and U.S. over the period January 1982 to July 2011, where the minimum number of country bond returns is six at any point in time and all 10 country bonds are available after 1990.

Commodity Futures. We cover 27 different commodity futures obtained from several sources. Data on Aluminum, Copper, Nickel, Zinc, Lead, and Tin are from the London Metal Exchange (LME). Brent Crude and Gas Oil are from the Intercontinental Exchange (ICE). Live Cattle, Feeder Cattle, and Lean Hogs are from the Chicago Mercantile Exchange (CME). Corn, Soybeans, Soy Meal, Soy Oil, and Wheat are from the Chicago Board of Trade (CBOT). WTI Crude, RBOB Gasoline, Heating Oil, and Natural Gas are from the New York Mercantile Exchange (NYMEX). Gold and Silver are from the New York Commodities Exchange (COMEX). Cotton, Coffee, Cocoa, and Sugar are from New York Board of Trade (NYBOT), and Platinum data are from the Tokyo Commodity Exchange (TOCOM). The sample covers the period January 1972 to July 2011, with the minimum number of commodities being 10 at any point in time and all 27 commodities available after 1980.

Returns for commodity futures are calculated as follows. Each day we compute the daily excess return of the most liquid futures contract, which is typically the nearest or next nearest-to-delivery contract, and then compound the daily returns to a total return index from which we compute returns at a monthly horizon. Bessembinder (1992), de Roon, Nijman, and Veld (2000), Moskowitz, Ooi, and Pedersen (2012), and Koijen, Moskowitz, Pedersen, and Vrugt (2012) compute futures returns similarly. All returns are denominated in U.S. dollars and do not include the return on collateral associated with the futures contract.

\section{B. Value and Momentum Measures}

To measure value and momentum, we use the simplest and, to the extent a standard exists, most standard measures. We are not interested in coming up with the best predictors of returns in each asset class. Rather, our goal is to maintain a simple and fairly uniform approach that is consistent across asset classes and minimizes the pernicious effects of data snooping. As such, if data snooping can be avoided, our results may therefore understate the true gross returns to value and momentum available from more thoughtfully chosen measures.

For individual stocks, we use the common value signal of the ratio of the book value of equity to market value of equity, or book-to-market ratio, BE/ME (see Fama and French $(1992,1993)$ and 
Lakonishok, Shleifer, and Vishny (1994)) of the stock. ${ }^{6}$ Book values are lagged six months to ensure data availability to investors at the time, and the most recent market values are used to compute the ratios. For the purposes of this paper, using lagged or contemporary prices, rather than market values matched contemporaneously in time as in Fama and French (1992), is not important. When using more recent prices in the value measure, the negative correlation between value and momentum is more negative and the value premium is slightly reduced, but our conclusions are not materially affected. A combination of value and momentum-one of the themes in this paper-obtains nearly identical pricing results whether lagging price in the value measure or not. Asness and Frazzini (2012) investigate this issue more thoroughly and argue that using contemporaneous market values can be important and ease interpretation when examining value in the presence of momentum, as we do in this paper. Gerakos and Linnainmaa (2012) decompose value into book and market components and find that the market value of equity drives most of the relevant pricing information.

For momentum, we use the common measure of the past 12 month cumulative raw return on the asset (see Jegadeesh and Titman (1993), Asness (1994), Fama and French (1996), and Grinblatt and Moskowitz (2004)), skipping the most recent month's return, MOM2-12. We skip the most recent month, which is standard in the momentum literature, to avoid the one month reversal in stock returns, which may be related to liquidity or microstructure issues (Jegadeesh (1990), Lo and MacKinaly (1990), Boudoukh, Richardson, and Whitelaw (1994), Asness (1994), Grinblatt and Moskowitz (2004)). ${ }^{7}$

For all other asset classes, we attempt to define similar value and momentum measures. Momentum is straightforward since we can use the same measure for all asset classes, namely the return over the past 12 months skipping the most recent month. While excluding the most recent month of returns is not necessary for some of the other asset classes we consider because they suffer

\footnotetext{
${ }^{6}$ While research has shown that there are other value measures that are more powerful for predicting stock returns (e.g., Lakonishok, Shleifer, and Vishny (1994), Asness, Porter, and Stevens (2000), Piotroski (2000)), we maintain a basic and simple approach that is somewhat consistent across asset classes.

${ }^{7}$ Novy-Marx (2011) shows that the past 7 to 12 month return is a better momentum predictor in U.S. stocks than the past 2 to 6 month return, though the past 2 to 6 month return is still a positive predictor. We use the more standard momentum measure based on the past 2 to 12 month return for several reasons. First, as Novy-Marx (2011) shows, the benefit of using returns from the past 7 to 12 months as opposed to the entire 2 to 12 month past return is negligible in U.S. stocks. Second, Goyal and Wahal (2012) examine the power of past 7-to-12 versus past 2 to 6 month returns across 36 countries and find that there is no significant difference between these past return predictors in 35 out of 36 countries - the exception being the U.S.. Third, MOM2-12 is the established momentum signal that has worked well out of sample across time and geography and been studied by many authors. While we believe using MOM2-12 is the most prudent and reasonable measure to use for these reasons, using other momentum signals, such as MOM7-12, should not alter any of our conclusions.
} 
less from liquidity issues (e.g., equity index futures and currencies), we do so to maintain uniformity across asset classes. Momentum returns for these asset classes are in fact stronger when we don't skip the most recent month, hence our results are conservative.

For measures of value, attaining uniformity is more difficult because not all asset classes have a measure of "book value.” For these assets, we try to use simple and consistent measures of value. For country indices, we aggregate up the individual stocks' $B E / M E$ ratios by computing the average value weighted $B E / M E$ among the index constituents of the country. This number matches very closely the $B E / M E$ ratios reported by MSCI for our country indices over our sample period. For commodities, we define "book value" as the spot price five years ago, which we divide by the most recent spot price to get our value measure, which is essentially the negative of the spot return over the last five years. Similarly, for currencies, our value measure is the negative of the five year return on the exchange rate, taking into account the interest earned measured using local 3 month LIBOR rates. The currency value measure is equivalently the five year deviation from uncovered interestrate parity, or, assuming that real rates are constant across countries, it is a five year change in purchasing power parity. For bonds, we similarly use the negative of the past five year return as our value measure. The use of past five year returns as measures of value is motivated by DeBondt and Thaler (1985), who use similar measures for individual stocks to identify “cheap” and "expensive” firms. Fama and French (1996) show that the negative of the past five year return generates portfolios that are highly correlated with portfolios formed on BE/ME, and Gerakos and Linnainmaa (2012) document a direct link between past returns and $B E / M E$ ratios. Theory also suggests a link between long-term returns and book-to-market value measures (e.g., Daniel, Hirshleifer, and Subrahmanyam (1998), Barberis, Shleifer, and Vishny (1998), Hong and Stein (1999), and Vayanos and Wooley (2011)).

In the Internet Appendix accompanying this paper, Table A1 shows that individual stock portfolios formed from the negative of past five year returns are highly correlated with those formed on $B E / M E$ ratios in our sample. For example, among U.S. stocks the returns to a value factor formed from the negative of the past five year return is 0.83 correlated with the returns formed from $B E / M E$ sorts. In the U.K., Europe, and Japan the correlation between portfolio returns formed on negative past five year returns and $B E / M E$ ratios is similarly high. Globally, a value factor averaged across all four stock markets estimated from negative past five year return sorts has a 0.86 correlation with a value factor formed from $B E / M E$ sorts. Hence, using past five year returns to measure value seems reasonable. 


\section{Value and Momentum Portfolios: 48 New Test Assets}

Using the measures above, we construct a set of value and momentum portfolios within each market and asset class by ranking securities within each asset class by value or momentum and sorting them into three equal groups. We then form three portfolios—high, middle, and low-from these groups, where for individual stocks we value weight the returns in the portfolios by their beginning of month market capitalization, and for the non-stock asset classes we equal weight securities. ${ }^{8}$ Given that our sample of stocks focuses exclusively on very large and liquid securities in each market, typically the largest quintile of securities, further value weighting the securities within this universe creates an extremely large and liquid set of portfolios that should yield very conservative results compared to typical portfolios used in the literature. Thus, we generate three portfolios—low, middle, and high — for each of the two characteristics—value and momentum - in each of the eight asset classes, producing $3 \times 2 \times 8=48$ test portfolios.

\section{Value and Momentum Factors}

We also construct value and momentum factors for each asset class, which are zero cost longshort portfolios that use the entire cross section of securities within an asset class. For any security $i=1, \ldots, N$ at time $t$ with signal $S_{\text {it }}$ (value or momentum), we weight securities in proportion to their cross-sectional rank based on the signal minus the cross-sectional average rank of that signal. Simply using ranks of the signals as portfolio weights helps mitigate the influence of outliers, but portfolios constructed using the raw signals are similar and generate slightly better performance. Specifically, the weight on security $i$ at time $t$ is

$$
w_{i t}{ }^{S}=c_{t}\left(\operatorname{rank}\left(S_{i t}\right)-\sum_{i} \operatorname{rank}\left(S_{i t}\right) / N\right) \text {, }
$$

where the weights across all stocks sum to zero, representing a dollar neutral long-short portfolio. We include a scaling factor $c_{t}$ such that the overall portfolio is scaled to one dollar long and one dollar short. The return on the portfolio is then,

$$
r_{t}^{S}=\Sigma_{i} w_{i t}^{S} r_{i t} \text {, where } S \in \text { (value, momentum). }
$$

We also construct a 50/50 equal combination (COMBO) factor of value and momentum, whose returns are

$$
r_{t}^{\text {СOMBO }}=0.5 r_{t}^{\text {VALUE }}+0.5 r_{t}^{\text {MOM }}
$$

\footnotetext{
${ }^{8}$ Weighting the non-stock asset classes by their ex ante volatility gives similar results. In addition, rebalancing back to equal weights annually rather than monthly produces similar results.
} 
These zero cost signal weighted portfolios are another way to examine the efficacy of value and momentum across markets and are used as factors in our pricing model. Although these factors are not value weighted, the set of securities used to generate them are extremely large and liquid. As we will show, the signal weighted factor portfolios outperform simple portfolio sort spreads because security weights are a positive (linear) function of the signal, as opposed to the coarseness of only classifying securities into three groups. In addition, the factors are better diversified since all securities in the cross section are given non-zero weight.

\section{Value and Momentum Returns and Co-movement}

Table I shows the consistent performance of value and momentum, and their combination, within each of the major markets and asset classes we study. Other studies examine value and momentum in some of the same asset classes, but to our knowledge we are the first to study them in combination and simultaneously across asset classes. In addition, we also discover new evidence for value and momentum premia in asset classes not previously studied-both value and momentum in government bonds and value effects in currencies and commodities. Our emphasis, however, is on the power of applying value and momentum everywhere at once.

\section{A. Return Premia}

Table I reports the annualized mean return, $t$-statistic of the mean, standard deviation, and Sharpe ratio of the low (P1), middle (P2), and high (P3) portfolios for value and momentum in each market and asset class as well as the high minus low (P3-P1) spread portfolio and the signal weighted factor portfolio from equation (2). Also reported are the intercepts or alphas, and their $t$-statistics (in parentheses) from a time series regression of each return series on the return of the market index for each asset class. The market index for the stock strategies is the MSCI equity index for each country, for country index futures it is the MSCI World Index, and for currencies, fixed income, and commodities, the benchmark is an equal weighted basket of the securities in each asset class. The last two columns of Table I report the same statistics for the 50/50 combination of value and momentum for the P3-P1 spread and signal weighted factors and the last row for each asset class reports the correlation of returns between value and momentum for both the P3-P1zero cost spread portfolio and the signal-weighted factor returns.

Panel A of Table I reports results for each of the individual stock strategies. Consistent with results in the literature, there is a significant return premium for value in every stock market, with the strongest performance in Japan. Momentum premia are also positive in every market, especially in 
Europe, but are statistically insignificant in Japan. As the last row for each market indicates, the correlation between value and momentum returns is strongly negative, averaging about -0.60 . Combining two positive return strategies with such strong negative correlation to each other increases Sharpe ratios significantly. In every market, the value/momentum combination outperforms either value or momentum by itself. Hence, many theories attempting to explain the observed Sharpe ratio for value or momentum have a higher hurdle to meet if considering a simple linear combination of both.

In addition, the combination of value and momentum is much more stable across markets. For instance, previous research attempting to explain why momentum does not seem to work very well in Japan (see Chui, Titman, and Wei (2010) for a behavioral explanation related to cultural biases) should confront the fact that value has performed exceptionally well in Japan during the same time period, and the fact that value and momentum are -0.64 correlated in Japan over this period. So, rather than explain why momentum did not work in Japan, it would be nearly equally appropriate to ask why value did so well (see Asness (2011)). Moreover, an equal combination of value and momentum realizes an even higher Sharpe ratio than value alone in Japan, suggesting that a positive weight on momentum in Japan improves the efficient frontier, which is also confirmed from a static portfolio optimization.

The last set of rows of Panel A of Table I show the power of combining value and momentum portfolios across markets. We report an average of value, momentum, and their combination across all four regions (“Global stocks”) by weighting each market by the inverse of their ex post sample standard deviation. ${ }^{9}$ Value applied globally generates an annualized Sharpe ratio not much larger than the average of the Sharpe ratios across each market, indicating strong covariation among value strategies across markets. Likewise, momentum applied globally does not produce a Sharpe ratio much larger than the average Sharpe ratio across markets, indicating strong correlation structure among momentum portfolios globally, too.

Panel B of Table I reports the same statistics for the non-stock asset classes. There are consistent value and momentum return premia in these asset classes as well, including some not

\footnotetext{
${ }^{9}$ We compute the monthly standard deviation of returns in each market and weight each market by the inverse of this number, rescaled to sum to one, to form a global portfolio across all markets. Each market's dollar contribution to the global portfolio is therefore proportional to the reciprocal of its measured volatility, but each market contributes an equal fraction to the total volatility of the portfolio, ignoring correlations. Weighting by total market cap or equal weighting produces nearly identical results, but we use the equal volatility weighting scheme to be consistent with what we do for the non-equity asset classes.
} 
previously examined (e.g., bonds, value in currencies and commodities). ${ }^{10}$ While value and momentum returns vary somewhat across the asset classes, the combination of value and momentum is quite robust due to a consistent negative correlation between value and momentum within each asset class that averages -0.54 . We also examine a diversified portfolio of value, momentum, and their combination across all asset classes. Since, the volatilities of the portfolios are vastly different across asset classes - for example, commodity strategies have about four times the volatility of bond strategies-we weight each asset class by the inverse of its ex-post sample volatility, so that each asset class contributes roughly an equal amount to the ex post volatility of the diversified portfolio. ${ }^{11}$ The diversified portfolio across all asset classes yields small improvements in Sharpe ratios, which suggests the presence of correlation structure in value and momentum returns across these different asset classes. Models that give rise to value and momentum returns in equities, such as the production or investment based theories of Berk, Green, and Naik (1999), Johnson (2002), Gomes, Kogan, and Zhang (2003), Zhang (2005), Sagi and Seasholes (2007), Liu, Whited, and Zhang (2009), Li, Livdan, and Zhang (2009), Belo (2010), Li and Zhang (2010), Liu and Zhang (2008), may not easily apply to other asset classes that yield the same and correlated effects.

Combining the stock (Panel A) and non-stock (Panel B) value and momentum strategies across all asset classes produces even larger Sharpe ratios, with the 50/50 value and momentum combination portfolio producing an annual Sharpe ratio of 1.42. This Sharpe ratio presents an even greater challenge for asset pricing models, which already struggle to explain the magnitude of the U.S. equity premium and value and momentum premia in U.S. stocks. Considering value and momentum together and applying them globally across all asset classes, the Sharpe ratio hurdle these pricing models need to explain is several times larger than those found in U.S. equity data alone.

\section{B. Alternative Measures}

We use a single measure for value and for momentum for all eight markets we study. We choose the most studied or simplest measure in each case and attempt to maintain uniformity across asset classes, in order to minimize the potential for data mining. Using these simple, uniform measures results in positive risk premia for value and momentum in every asset class we study, though some of the results are statistically insignificant. In particular, our weakest results pertain to

\footnotetext{
${ }^{10}$ The somewhat weaker returns for the non-stock asset classes would be partially attenuated if transactions costs are considered, since trading costs are typically higher for individual stocks than the futures contracts we examine outside of equities. Therefore, net of trading cost returns would elevate the relative importance of the non-stock strategies. We discuss implementation issues briefly in Section V.

${ }^{11}$ Using ex ante rolling measures of volatility and covariances yields similar results.
} 
bonds, which do not produce statistically reliable premia. However, data mining worries may be weighed against the potential improvements from having better measures of value and momentum. For example, take value strategies among bonds. Using our current measure of value, the five year change in yield, we are only able to produce a Sharpe ratio of 0.18 and an alpha of $1.9 \%$ that is not statistically significant ( $t$-statistic of 1.68). However, Panel C of Table 1 reports results for value strategies among bonds that use alternative measures, such as the real bond yield, which is the yield on 10 year bonds minus the five year forecast in inflation, and the term spread, which is the yield on 10 year bonds minus the short rate. As Panel $\mathrm{C}$ of Table 1 shows, these alternative value measures produce Sharpe ratios of 0.73 and 0.55 , respectively, and the $t$-statistics of their alphas are significant at 2.36 and 2.78 .

Moreover, we are able to produce even more reliable risk premia when using multiple measures of value that diversify away measurement error or noise across variables. ${ }^{12}$ Creating a composite average index of value measures using all three measures above, produces even stronger results, where the value strategy generates a Sharpe ratio of 0.91 to 1.10 with $t$-statistics of their alphas being 4.40 and 5.48. These alternative measures of value also blend nicely with our original measure for momentum, where in each case the 50/50 value/momentum combination portfolios also improve with these alternative measures.

Hence, our use of single, simple, and uniform value and momentum measures may understate the true returns to these strategies in each asset class. Nevertheless, we stick with these simple measures to be conservative and to mitigate data mining concerns, even though in the case of bonds the results appear to be insignificant with such simple measures.

\section{Co-movement Across Asset Classes}

Table II reports the correlations of value and momentum returns across diverse asset classes to identify their common movements. The strength of co-movement may support or challenge various theoretical explanations for value and momentum, and may ultimately point to underlying economic drivers for their returns. The correlations are computed from the returns of the signal weighted zero cost factor portfolios from equation (2), but results are similar using the top third minus bottom third P3-P1 portfolio returns.

Panel A of Table II reports the correlations among value strategies and among momentum strategies globally across asset markets. We first compute the average return series for value and

\footnotetext{
${ }^{12}$ Israel and Moskowitz (2012) show how other measures of value and momentum can improve the stability of returns to these styles among individual equities.
} 
momentum across all stock markets and across all non-stock asset classes separately. For example, we compute the volatility weighted average of all the individual stock value strategies across the four equity markets—U.S., U.K., Europe, and Japan—and the weighted average of value strategies across the non-equity asset classes-index futures, currencies, bonds, and commodities. We do the same for momentum. We then compute the correlation matrix between these average return series. The diagonal of the correlation matrix is computed as the average correlation between each individual market's return series and the average of all other return series in other markets. For instance, the first entry in the covariance matrix is the average of the correlations between each equity market's value strategy and a portfolio of all other equity market value strategies: an average of the correlation of U.S. value with a diversified value strategy in all other individual equity markets (U.K., Europe, and Japan), correlation of U.K. value with a diversified value strategy in U.S., Europe, and Japan, correlation of Europe value with a diversified value strategy in U.S., U.K., and Japan, and correlation of Japan value with a diversified value strategy in U.S., U.K., and Europe. In general, we obtain more powerful statistical findings when looking at the correlations of the average return series rather than the average of individual correlations, since the former better diversifies away random noise from each market, a theme we emphasize throughout the paper. ${ }^{13}$ Correlations are computed from quarterly returns to help mitigate any non-synchronous trading issues across markets, due to illiquid assets that do not trade continuously or time zone differences. An F-test on the joint significance of the correlations is also performed.

Panel A of Table II shows a consistent pattern, where value in one market or asset class is positively correlated with value elsewhere, momentum in one market or asset class is positively correlated to momentum elsewhere, and value and momentum are negatively correlated everywhere across markets and asset classes. The average individual stock value strategy is 0.68 correlated with other stock market value strategies, and is 0.15 correlated with the average non-stock value strategy. The average individual stock momentum strategy is 0.65 correlated with other stock market momentum strategies and 0.37 correlated with the average non-stock momentum strategy. The strong correlation structure among value and momentum strategies across such different assets is interesting

\footnotetext{
${ }^{13}$ In the Internet Appendix to the paper, we report in Table A2 the average of the individual correlations among the stock and non-stock value and momentum strategies, where we first compute the pair-wise correlations of all individual strategies (e.g., U.S. value with Japan value) and then take the average for each group. We exclude the correlation of each strategy with itself (removing the 1's) when averaging and also exclude the correlation of each strategy with all other strategies within the same market (i.e., exclude U.S. momentum when examining U.S. value's correlation with other momentum strategies). While these individual correlations are consistently weaker than those obtained from taking averages first and then computing correlations, the average pairwise correlations also exhibit strong co-movement among value and momentum across diverse assets.
} 
since these asset classes face different types of investors, institutional and market structures, and information environments.

Value and momentum are also negatively correlated across asset classes. A value strategy in one stock market is on average -0.53 correlated with a portfolio of momentum strategies in other stock markets. In addition, value in one asset class is negatively correlated with momentum in another asset class. For example, the average stock value strategy is -0.26 correlated with the average nonstock momentum strategy, non-stock value strategies are on average -0.16 correlated with stock momentum strategies, and non-stock value is on average -0.13 correlated with non-stock momentum in other asset classes. This correlation structure-value being positively correlated across assets, momentum being positively correlated across assets, and value and momentum being negatively correlated within and across asset classes — cannot be explained by the correlation of the passive asset classes themselves. The value and momentum strategies we examine are long-short and market neutral with respect to each asset class, and yet exhibit stronger correlation across asset classes than do passive exposures to these asset classes.

Panel B of Table II breaks down the correlations of the average stock strategies with each of the non-stock strategies. Nearly all of the value strategies across asset classes are consistently positively correlated, all of the momentum strategies are consistently positively correlated, all of the correlations between value and momentum are consistently negatively correlated, and most of these correlations are statistically different from zero.

For robustness, we also show that defining value differently produces similar negative correlation numbers between value and momentum strategies. Our value measure for equities, $B E / M E$, uses the most recent market value in the denominator which yields a -0.53 correlation between value and momentum in Table II Panel A. However, lagging prices by one year in the $B E / M E$ measure (i.e., using $\mathrm{ME}$ from one year prior) so that the value measure uses price data that does not overlap with the momentum measure, still produces a negative correlation between value and momentum of -0.28 , which is highlighted in Table A3 of the Internet Appendix. While these correlations are smaller in magnitude, they are still significantly negative.

In addition, using the negative of the past five year return of a stock as a value measure for equities, which is what we use for the non-equity asset classes, also generates negative correlations between value and momentum of similar magnitude (-0.48 as highlighted in Table A4 of the Internet Appendix). This provides more evidence that past five year returns capture similar effects as $B E / M E$ (Gerakos and Linnainmaa (2012) reach a similar conclusion). Hence, simply using recent prices or 
using past five year returns as a value measure does not appear to be driving the negative correlation between value and momentum returns, which appears to be robust across different value measures.

Figure 1 examines the first principal component of the covariance matrix of the value and momentum returns. The top figure plots the eigenvector weights associated with the largest eigenvalue from the covariance matrix of the individual stock value and momentum strategies in each stock market. The bottom figure plots the eigenvector weights for all asset classes, which include a global individual stock value and momentum factor across all countries. Both figures show that the first principal component loads in one direction on all value strategies and loads in exactly the opposite direction on all momentum strategies, highlighting the strong and ubiquitous negative correlation between value and momentum across asset classes as well as the positive correlation among value strategies and among momentum strategies across asset classes. The first principal component, which is essentially long momentum and short value (or vice versa) in every asset class, accounts for $54 \%$ of the individual stock strategies' covariance matrix and $23 \%$ of the all-asset-class covariance matrix. The commonality among value and momentum strategies across vastly different assets and markets with widely varying information, structures, and investors, points to common global factor structure among these phenomena.

Table A5 in the Internet Appendix also shows that correlations across markets and asset classes for the value/momentum combination strategies are lower than they are for value or momentum alone, indicating that the negative correlation between value and momentum offsets some of the common variation when combined together in a portfolio. In other words, it appears that value and momentum load oppositely on some common sources of risk.

Figure 2 illustrates succinctly the return and correlation evidence on value and momentum globally by plotting the cumulative returns to value, momentum, and their combination in each asset market and across all asset markets. The consistent positive returns and strong correlation structure across assets, as well as the negative correlation between value and momentum in every market, is highlighted on the graphs.

\section{Relation to Macroeconomic and Liquidity Risk}

In this section we investigate possible sources driving the common variation of value and momentum strategies across markets and asset classes. 


\section{A. Macroeconomic Risk Exposure}

Table III reports results from time series regressions of value and momentum returns for U.S. stocks, global stocks, non-stock asset classes, and all asset classes combined on various measures of macroeconomic risks. ${ }^{14}$

The first two columns of Table III report the time series regression coefficients of U.S. value and momentum returns on U.S. macroeconomic variables: long-run consumption growth, a recession indicator, GDP growth, as well as the U.S. stock market return in excess of the T-bill rate and the Fama and French (1993) bond market factor returns TERM and DEF. Consumption growth is the real per capita growth in nondurable and service consumption obtained quarterly and long-run consumption growth is the future three year growth rate in consumption, measured as the sum of log quarterly consumption growth 12 quarters ahead as in Parker and Julliard (2005) and Malloy, Moskowitz, and Vissing-Jorgensen (2009). GDP growth is the real per-capita growth in GDP. These macroeconomic data are obtained from the National Income and Product Accounts (NIPA). The recession indicator is defined using ex-post peak $(=0)$ and trough dates $(=1)$ from the NBER.

As Table III shows, U.S. stock value strategies are positively related to long-run consumption growth in U.S. data, consistent with the findings of Parker and Julliard (2005), Bansal and Yaron (2004), Malloy, Moskowitz, and Vissing-Jorgensen (2009), and Hansen, Heaton, and Li (2008). U.S. stock momentum strategy returns are not related to long-run consumption growth. Value and momentum are slightly negatively related to recessions and GDP growth, but none of these relationships are statistically significant. TERM and DEF are positively related to value and the default spread is negatively related to momentum.

The next six columns of Table III report regression results for value and momentum in global stocks, all non-stock asset classes, and all asset classes on global macroeconomic variables. Here, we use global long-run consumption growth, which is a GDP weighted average of 12-quarter ahead nondurable and service per capita consumption growth in the U.S., U.K., Europe, and Japan. Global macroeconomic data are obtained from Economic Cycle Research Institute (ECRI), which covers production and consumption data as well as business cycle dates using the same methodology as the NBER for about 50 countries over time. Similarly, a global recession variable is the GDP weighted average of recession indicators in each country and global GDP growth is the average across

\footnotetext{
${ }^{14}$ Chordia and Shivakumar (2002) claim that a conditional forecasting model of macroeconomic risks can explain momentum profits in U.S. stocks, but Griffin, Ji, and Martin (2003) show that neither an unconditional or conditional model of macroeconomic risks can explain momentum in equities globally across 40 countries, including the U.S. We examine the relation between macroeconomic risks and value and momentum strategies globally across asset classes to shed new light on this question.
} 
countries weighted by beginning of year GDP. For the market return, we use the MSCI World Index in excess of the U.S. T-bill rate. Finally, since we do not have data to construct TERM and DEF internationally, we use the U.S. versions.

As Table III shows, the global macroeconomic variables are generally not significantly related to value and momentum returns, with a couple of exceptions. Momentum is negatively and significantly related to recessions, especially among non-stock asset classes. The default spread is positively related to global stock value, but is negatively and insignificantly related to value returns in other asset classes. DEF is consistently negatively related to momentum returns in all asset classes.

\section{B. Liquidity Risk Exposure}

Table IV reports results from regressions that add various liquidity risk proxies to the macroeconomic variables above.

\section{B.1. Measuring funding and market liquidity risk}

To measure liquidity risk exposure, we regress value and momentum returns on shocks to liquidity. We follow Moskowitz and Pedersen (2012) to define our liquidity shocks. We consider both funding liquidity shocks (e.g., Brunnermeier and Pedersen (2009)) and market liquidity shocks. The funding liquidity variables are the Treasury-Eurodollar (TED) spread (the average over the month of the daily local 3 month interbank LIBOR interest rate minus the local 3 month government rate), the LIBOR minus term repo spread (the spread between the local 3 month LIBOR rate and the local term repurchase rate), and the spread between interest rate swaps and local short term government rates (Swap-T-bill) in each of the four markets. We sign every variable so that it represents liquidity. Hence, we take the negative of the TED spread and the other spreads so that they capture liquidity, since a wider spread represents worse liquidity.

The funding series are available for the common period January 1987 to July 2011. We define shocks to these variables as the residuals from an AR(2) model, following Korajczyk and Sadka (2008) and Moskowitz and Pedersen (2012). ${ }^{15}$ The market liquidity variables are the on-the-run minus off-the-run 10 year government Treasury note spread (see Krishnamurthy (2002)) in each of the four markets (U.S., U.K., Japan, and Europe, using Germany as a proxy), the Pastor and Stambaugh (2003) liquidity measure (their factor, not their factor mimicking portfolio, specifically their innovations obtained from Rob Stambaugh's webpage), and the illiquidity measure of Acharya

\footnotetext{
${ }^{15}$ There is no special or theoretical reason to use an $\operatorname{AR}(2)$. An $\operatorname{AR}(3)$, AR(1) or first differences yields similar results.
} 
and Pedersen (2005), motivated by Amihud's (2002) measure. We construct the Pastor and Stambaugh (2003) and Acharya and Pedersen (2005) measures in other countries by following their methodologies applied to stocks in those markets. Once again, these variables are signed so that they represent liquidity, hence we take the negative of the Acharya and Pedersen (2005) measure, which is based off of Amihud's (2002) illiquidity measure.

In addition, we take the first principal component of the correlation matrix of all funding liquidity shocks, all market liquidity shocks, and all liquidity shocks and construct an index of shocks for funding, market, and all liquidity. ${ }^{16}$ The principal component of the correlation, rather than covariance, matrix is used because the liquidity variables have different volatilities and scale.

Figure 3 plots the time series of the index of all global liquidity shocks monthly from January 1987 to July 2011. The plot shows that our constructed global liquidity shocks capture a dozen of the largest known liquidity events in global markets over the last 25 years, including the 1987 stock market crash, decimalization, September 11, 2001, the quant meltdown of August 2007, Bear Stearns, and the Lehman Brothers bankruptcy.

\section{B.2. Value and Momentum Returns and Liquidity Risk}

Table IV reports regression results of value and momentum returns on the liquidity shocks, but also controlling for the macro variables above. We only report the coefficient estimates on the liquidity shocks for brevity and because the coefficient estimates on the macro variables do not change much with the addition of the liquidity variables. We examine each liquidity shock singularly in separate regressions. Panel A of Table IV reports results using the U.S. liquidity shock measures. The dependent variables are the global value and momentum "everywhere" factor returns, the 50/50 combination between them, and the difference between value and momentum returns to test for differences in liquidity exposure between value and momentum. The first four rows of Panel A of Table IV show that funding liquidity risk is consistently negatively related to value returns and significantly positively related to momentum returns. Value performs poorly when funding liquidity rises, which occurs during times when borrowing is easier, while momentum performs well during

\footnotetext{
${ }^{16}$ A previous version of this paper also included the liquidity measures of Sadka (2006) and Adrian and Shin (2009) and found similar results. However, because the Sadka (2006) and Adrian and Shin (2009) measures require data not available in other equity markets, such as tick and trade data and balance sheet information from prime brokers, we cannot compute them internationally and hence omit them. See Amihud, Mendelson, and Pedersen (2005) for a survey of liquidity and liquidity risk measures.
} 
these times. The opposite exposure to funding liquidity shocks for value and momentum contributes partly to their negative correlation. ${ }^{17}$

The next four rows examine market liquidity shocks in the U.S. market. Here, we find little relation between market liquidity shocks and value and momentum returns. The Acharya and Pedersen (2005) liquidity measure is marginally negatively related to value and positively related to momentum, but overall the relation between market liquidity shocks and value and momentum returns is weak. Pastor and Stambaugh (2003) (and Sadka (2006)) find a positive and significant relation between U.S. equity momentum returns and their market liquidity shocks. We find the same sign as Pastor and Stambaugh (2003) for our global momentum returns across asset classes over our sample period, but do not detect a significant relation. In addition to our momentum returns covering a wider set of asset classes and a different time period than Pastor and Stambaugh (2003), we also use their factor and not their factor mimicking portfolio. They show that the latter exhibits a much stronger relation to momentum, while the former exhibits a weak relation to momentum, consistent with our global results.

Panel B of Table IV reports the regression results using the global funding and market liquidity shocks. Global funding liquidity shocks negatively impact value returns and positively affect momentum returns, but global market liquidity shocks do not seem to have much impact, consistent with the U.S. liquidity measures. Furthermore, the global measures, especially the funding liquidity index, seem to provide more statistical significance. The opposite signed loadings on liquidity risk for value and momentum may partially explain why the two strategies are negatively correlated.

However, the opposite signed loadings on a single factor, such as liquidity risk, cannot explain why both value and momentum earn positive risk premia. On the one hand, part of the returns to momentum can be explained as compensation for liquidity risk exposure since momentum loads positively on liquidity shocks and liquidity risk carries a positive risk premium. On the other hand, value loads negatively on liquidity risk, which makes its positive return an even deeper puzzle.

Why does momentum load positively and value load negatively on liquidity risk? One simple and intuitive story might be that momentum captures the most popular trades, being long the assets whose prices have recently appreciated as fickle investors have flocked to these assets. Value, on the

\footnotetext{
${ }^{17}$ Another interpretation of these funding shocks is that they proxy for changes in risk aversion or risk premia. So, in addition to funding liquidity being tight when spreads are wide, it may also be the case that risk aversion or risk premia in the economy are particularly high. Under this alternative view, however, it would seem that both value and momentum returns would decline with rising spreads, whereas we find that value and momentum returns move in opposite directions with respect to these shocks. In addition, the market portfolio and macroeconomic variables are included in the regression which may account for changing risk or risk premia.
} 
other hand, expresses a contrarian view, where assets have experienced price declines over several years. When a liquidity shock occurs, investor liquidations (from cash needs, redemptions, risk management, "running for the exit" at the same time; see Pedersen (2009)) puts more price pressure on the more "crowded trades." These liquidations may affect crowded high momentum securities more than the less popular contrarian/value securities. Further investigation into the opposite signed exposure of value and momentum to liquidity risk is an interesting research question, but is beyond the scope of this paper.

Finally, as Table IV shows, because of the opposite signed exposure of value and momentum to funding liquidity shocks, the 50/50 equal combination of value and momentum is essentially immune to funding shocks, and yet, as we have shown, generates huge positive returns. Thus, while exploring liquidity risk's relation to value and momentum more deeply may be interesting, liquidity risk by itself cannot explain why a combination of value and momentum is so profitable, and hence can only partially explain part of the cross-sectional landscape of returns.

\section{B.3. The power of averaging across markets}

A key feature of the analysis in Tables III and IV is that we examine the average returns to value and momentum across a wide set of markets and asset classes simultaneously. The power of looking at the universal average return to value and momentum greatly improves our ability to identify common factor exposure. For example, if we examine each individual value and momentum strategy's exposure to liquidity risk separately, we do not find nearly as strong a pattern and, in fact, might have concluded there exists little evidence of any reliable relation to liquidity risk.

Figure 4 reports the $t$-statistics of the liquidity betas of each of our individual market or asset class value and momentum strategies. The average $t$-statistic of the liquidity betas for value is -0.95 and for momentum is 1.81 -hardly convincing. In contrast, when we regress the average value and momentum return series across all markets and asset classes on global liquidity shocks, we get a $t$ statistic for the liquidity beta of -3.25 for value and 4.43 for momentum. The average liquidity beta among the individual strategies is not nearly as strong as the liquidity beta of the average. Averaging across all markets and asset classes mitigates much of the noise not related to value or momentum, such as idiosyncratic regional or market noise, allowing for better identification of a common factor such as liquidity risk to emerge. Restricting attention to one asset class at a time, or to one strategy within an asset class, the patterns above are difficult to detect. The scope and uniformity of studying value and momentum everywhere at once is what allows these patterns to be identified. 


\section{Asset Pricing Tests}

The strong common factor structure evidenced in Section II and the link to liquidity risk in Section III suggests examining formally asset pricing tests to assess the economic significance of these patterns and how much of the return premia to value and momentum can be captured by this common variation.

\section{A. Explaining Value/Momentum in One Market with Value/Momentum in Other Markets}

We first examine how well value and momentum in one market or asset class are explained by value and momentum returns in other asset classes. Specifically, we run the following regression,

$$
R_{i, t}^{p}-r_{f, t}=\alpha_{i}^{p}+\beta_{i}^{p} M K T_{t}+v_{i}^{p} \sum_{j \neq i} w_{j} V A L_{j, t}+m_{i}^{p} \sum_{j \neq i} w_{j} M O M_{j, t}+\varepsilon_{i, t}^{p},
$$

where $R_{i, t}^{p}$ is the time $t$ return to portfolio $p$ among the six high, middle, and low value and momentum portfolios in one of the eight asset markets $i$, for a total of 48 test assets. The time series of excess returns (in excess of the U.S. T-bill rate) of each portfolio is regressed on the excess returns of the market portfolio MKT (proxied by the MSCI World Index), and the returns to value and momentum factors in all other markets and asset classes. The latter two variables are constructed as the equal volatility weighted average of the zero cost signal weighted value and momentum factors in all other markets (where $w_{j}$ represents the equal volatility weight for each asset class), excluding the market whose tests assets are being used as the dependent variable.

We estimate equation (4) for each market and asset class separately. Figure 5 plots the actual average return of each of the test assets against the predicted expected return from the regression. The plot shows how much of the average returns to value and momentum portfolios in one market or asset class can be explained by value and momentum returns from other markets and asset classes. A 45 degree line passing through the origin is also plotted to highlight both the cross-sectional fit and the magnitude of the pricing errors across test assets. As Figure 5 shows, the average returns line up well with the predicted expected returns. The cross-sectional $R$-square is 0.55 and the average absolute value of the pricing errors (alpha) is 22.6 basis points per month. A formal statistical test of the joint significance of the pricing errors is not possible since the independent variables change across test assets for each market and asset class.

The results indicate that value and momentum returns in one market are strongly related to value and momentum returns in other markets and asset classes. Unlike many asset pricing tests conducted in a single market, here there is no overlap of securities between the test assets used as the dependent 
variable and the factors used as regressors. The dependent variable contains securities from a completely separate market or asset class than those used to comprise the factors on the right hand side of the regression. Hence, the evidence in Figure 5 makes a compelling case for common global factor structure in value and momentum returns and suggests that this common variation is economically meaningful since it captures well the cross section of average returns.

\section{B. A Global Three Factor Model}

To conduct a more formal asset pricing test, and to compare across various asset pricing models, we construct a three factor model similar to equation (4), but where the regressors are the same for every asset. This three factor model is similar in spirit to those of Fama and French (1993) and Carhart (1997), but applied globally to all markets and asset classes we study. Specifically, we estimate the following time series regression for each of the 48 high, middle, and low value and momentum portfolios across asset classes.

$$
R_{i, t}^{p}-r_{f, t}=\alpha_{i}^{p}+\beta_{i}^{p} M K T_{t}+v_{i}^{p} V A L_{t}^{\text {everywhere }}+m_{i}^{p} M O M_{t}^{\text {everywhere }}+\varepsilon_{i, t}^{p},
$$

where $V A L_{t}^{\text {everywhere }}$ and $M O M_{t}^{\text {everywhere }}$ are the across-asset-class value and momentum factors.

The first graph in Panel A of Figure 6 plots the actual sample average returns of the 48 test assets versus their predicted expected returns from equation (5) along with a 45 degree line through the origin to highlight the magnitude of the pricing errors. The cross-sectional $R$-square is 0.71 and the average absolute value of the alpha is 18 basis points, indicating slightly better fit than equation (4), which isn't surprising, since unlike equation (4), equation (5) contains some of the same securities on the left and right hand side of the regression. However, the fit is similar to equation (4), and equation (5) also allows for a formal joint test of the significance of the alphas, since the explanatory variables are the same for each test asset. Hence, we report the Gibbons, Ross, and Shanken (1989) $F$-statistic and $p$-value for a joint test of the pricing errors.

The remaining graphs in Panel A of Figure 6 plot the pricing errors of the 48 test assets under alternative asset pricing models: the global CAPM, using the MSCI World Index as the market proxy, a four factor model inspired by Carhart (1997), which is the Fama-French three factor model consisting of the U.S. stock market RMRF, a U.S. size factor $S M B$, and a U.S. value factor $H M L$, augmented with a U.S. stock momentum factor UMD, obtained from Ken French's website, which we refer to as the "Fama-French four-factor model," and a six factor model that adds the Fama and French (1993) bond return factors DEF and TERM, which capture the default and term spread for U.S. bonds, which we refer to as the "Fama-French six-factor model.” As Figure 6 shows, the global 
CAPM does not do a very good job fitting the cross section of value and momentum returns across markets and asset classes, producing the largest absolute pricing errors and smallest $R$-square. The Fama-French four and six factor specifications explain the returns a little better than the CAPM, but not nearly as well as the global three factor model. The Fama-French factors generate twice the absolute magnitude of pricing errors as the three factor global model and have much lower $R^{2}$ s.

Panel B of Figure 6 repeats the same plots for test assets derived only from U.S. stocks. Here, we use the Fama-French 25 size-value and 25 size-momentum portfolios from Ken French's website as test assets. These are, respectively, $5 \times 5$ double sorted portfolios of U.S. stocks based on size and $B E / M E$ and $5 \times 5$ portfolios sorted on size and past 2 to 12 month returns. Our three factor model derived from other markets and asset classes does a reasonable job explaining the returns to these 50 U.S. equity portfolios. The cross-sectional $R$-square is 0.64 and the average absolute pricing error is only 18 basis points. Compared to the Fama-French factors, which are derived from the same U.S. stocks as the test assets, our three factor model, which is derived from other asset classes, captures almost as much of the cross-sectional variation in returns. The Fama-French factors produce a slightly higher cross-sectional $R$-square of 0.77 and a slightly lower average absolute pricing error of 11 basis points. Hence, despite the fact that our value and momentum factors are concentrated in securities outside of U.S. equities, they capture nearly as much of the return variation of U.S. stock portfolios as the Fama-French factors, which are derived from the same set of U.S. securities.

Taken together, Panel A of Figure 6 shows that our global three factor model can explain the returns to value and momentum across markets and asset classes much better than local U.S. factors can and Panel B shows that our global factors can explain the local returns to value and momentum in U.S. stocks almost as well as the U.S. factors can. These results suggest that global value and momentum portfolios across markets and asset classes are closer to the efficient frontier than U.S. stock only value and momentum portfolios, and therefore provide a more robust set of asset pricing factors that can be used more broadly.

\section{Further Pricing Tests and Economic Magnitudes}

To further investigate the economic importance of the commonality among value and momentum strategies across asset markets, we examine their relation to macroeconomic and liquidity risks through cross-sectional and time series asset pricing tests. 


\section{C.1. Cross-Sectional Pricing Tests}

Table V reports Fama-MacBeth cross-sectional regressions of returns of the 48 value and momentum test portfolios on their betas with respect to funding liquidity risk, GDP growth, long-run consumption growth, TERM, and DEF. Regressions are run in the style of Fama and MacBeth (1973) where the cross section of monthly returns are regressed on the betas (estimated univariately using rolling windows of the past 60 months of returns) each month and the time series mean and $t$ statistic of the cross-sectional regression coefficients are reported in Table V. As the first row of Table V shows, liquidity risk betas capture part of the cross-sectional variation in average returns across the 48 portfolios, as indicated by the positive and significant coefficient on the liquidity beta. That coefficient also represents the risk premium for liquidity risk among the 48 test assets, which is 24 basis points per month or about 3\% per year. The Fama-MacBeth regressions not only test the cross-sectional relation between average returns and betas with respect to a factor, but the time series of the coefficient estimates represents the return series to a minimum variance portfolio with a unit exposure to that factor (see Fama and MacBeth (1973) and Fama (1976)). Hence, the time series of monthly coefficient estimates represents a factor mimicking portfolio for liquidity risk, which we call FP $P_{\text {liq risk. }}$

The second row of Table V shows that neither GDP growth nor long-run consumption growth capture much cross-sectional variation in returns, but TERM and DEF do, exhibiting a risk premium of 21 and 23 basis points, respectively. However, the third row of Table V adds liquidity betas to the regression, where we find that the significance of TERM and DEF are subsumed by liquidity risk. Finally, we add betas with respect to the global three factor model-the MSCI World Index and the value and momentum "everywhere" factors. While it is perhaps not too surprising that betas with respect to value and momentum factors capture average returns to value and momentum portfolios, they also subsume a significant portion of the explanatory power of liquidity risk, making it

insignificant in these cross-sectional regressions. Hence, part of what these global value and momentum factors capture appears to be exposure to global funding liquidity risk.

The next two rows of regression results in Table $\mathrm{V}$ repeat the regressions using only funding liquidity variables to capture liquidity risk and the last two rows use only market liquidity variables to measure liquidity risk. As Table V shows, only funding liquidity risk appears to be priced in the cross section of our global assets, and exposure to value and momentum common factors seems to capture part of funding liquidity risk exposure. 


\section{C.2. Time Series Pricing Tests}

To gain more insight into the economic magnitudes liquidity risk and the other factors explain, we use the factor mimicking portfolios created from the Fama-MacBeth regressions to conduct time series asset pricing tests. Specifically, we regress each of the 48 portfolio's time series of monthly returns on the factor mimicking portfolio returns for liquidity risk, GDP growth, and long-run consumption growth, as well as TERM, DEF, and the value and momentum "everywhere" factors. Because we use factor mimicking portfolios as regressors, both the dependent and independent variables are measured in returns, and hence we can conduct formal pricing tests.

Panel A of Table VI reports the results for the 48 value and momentum portfolios across markets and asset classes. We also include the market portfolio in every regression. For each factor model, we report the GRS F-statistic and $p$-value for testing the joint significance of the alphas under each model. We also report the average absolute value of the alphas to gauge the magnitude of the pricing errors under each model, the cross-sectional $R$-square of the average returns on the test assets against the predicted expected returns from each model, and the Eig\% metric from Moskowitz (2003), which is the sum of eigenvalues from the covariance matrix of the test assets implied by the model divided by the sum of eigenvalues of the sample covariance matrix, which measures how much of the covariance matrix of returns among the test assets each model can explain.

As the first row of Panel A of Table VI shows, the market portfolio alone (global CAPM) leaves substantial pricing errors - an average absolute alpha of 35 basis points per month that easily rejects the GRS test-and leaves a lot of time series and cross-sectional variation unexplained. The market portfolio captures about $57 \%$ of the covariation among the returns. The second row adds the liquidity risk factor mimicking portfolio as a regressor, and although the GRS test is still rejected, the average absolute alpha declines to 31 basis points, the cross-sectional $R^{2}$ increases, and the amount of covariation captured increases. Hence, liquidity risk adds additional explanatory power for both pricing and common variation of value and momentum portfolios globally across asset classes.

While there is a link between value and momentum and liquidity risk, only a small fraction of the return premia and covariation is captured by our proxies for these risks. We view these findings as an important starting point for possible theories related to value and momentum phenomena, but emphasize that we are far from a full explanation of these effects. We also recognize that measurement error in liquidity risk may limit what we can explain. In addition, a single liquidity risk factor alone cannot explain value and momentum since they are negatively correlated to each other but both produce positive returns, unless there is substantial time variation in liquidity risk betas and 
in the liquidity risk premium. Thus, it is not surprising that the pricing errors from this model specification remain large.

The third row of Panel A of Table VI adds factor mimicking portfolio returns for GDP growth, long-run consumption growth, and TERM and DEF. Pricing errors decline further and $R$-squares and the amount of covariation explained increase. The fourth row uses our three factor model, which provides the best fit. Here, the average absolute alpha is only 18 basis points, the cross-sectional $R^{2}$ is $72 \%$, and $84 \%$ of the covariation among the test assets is captured by these factors. The next two rows further show that having both value and momentum in the model is important, since only having value or momentum alone increases pricing errors and decreases fit considerably. This, again, is testament to the difficulty of a single factor being able to explain both value and momentum.

The last four rows of Panel A of Table VI examine models of U.S. stock factors: the U.S. market portfolio in excess of the U.S. T-bill rate, the Fama-French three factor model, the FamaFrench "four factor" model that adds the momentum factor, and the Fama-French "six factor" model that also adds TERM and DEF. As Table VI shows, the U.S. factors do not do a great job of describing the global value and momentum portfolio returns, leaving larger pricing errors, lower $R^{2} \mathrm{~s}$, and capturing a smaller fraction of their covariance matrix.

Panel B of Table VI repeats the same exercise as Panel A, but uses the 25 size BE/ME and 25 size momentum U.S. equity portfolios from Ken French's website as test assets. Not surprisingly, the Fama-French U.S. factors do a good job of capturing these returns, though the GRS test is still rejected. However, the global value and momentum "everywhere" factors, which are comprised primarily of non-U.S. equities and other asset classes, also do a good job explaining the 50 U.S. equity based test assets - the average absolute alpha is only 19 basis points, the cross-sectional $R^{2}$ is $68 \%$, and the percentage of covariation captured is $66 \%$. This is better than the Fama-French three factor model does and only slightly worse than the Fama-French four or six factor models, which are specifically designed to capture these portfolios and are constructed from the same set of securities as the test assets themselves.

Finally, Panel C of Table VI considers how well these factor models can explain hedge fund returns. Using the returns of 13 hedge fund indices from Dow Jones Credit Suisse (DJCS) and Hedge Fund Research Institute (HFRI) that include from DJCS the Market Neutral, Long-Short, Multi Strategy, Macro, Managed Futures, Currency, Emerging Markets, and Overall hedge fund indices and from HFRI the Equity Hedge, Fund of Funds, Macro, Emerging Markets, and Overall hedge fund indices, Panel C of Table VI shows that the global three factor model has smaller pricing errors than the Fama-French model and its extensions with the momentum, TERM and DEF factors. 
These results are consistent with Boyson, Stahel, and Stulz (2010), Sadka (2012), and Bali, Brown, and Caglayan (2011, 2012) who find that the Fama and French U.S. stock factors do not explain well the cross section of hedge fund returns. However, our simple value and momentum factors applied globally across asset classes do seem to capture a sizeable fraction of the returns to hedge funds.

The evidence in Table VI suggests that the global-across-asset three factor model not only captures well the returns to value and momentum globally across asset classes, but also captures the returns to size and value and size and momentum in U.S. equities, as well as the cross section of hedge fund returns, providing additional testing grounds that are created from a completely different set of securities. Conversely, while local U.S. factors capture U.S. equity returns well, they do not explain a lot of value and momentum returns globally or across asset classes and do not capture very well the returns to various hedge fund strategies. While our three factor global model does perform better in explaining all of these different test assets, the GRS test still rejects our model in all cases, suggesting that more work needs to be done in fully describing the cross section of returns.

\section{Robustness and Implementation}

Finally, we examine the robustness of our findings to implementation issues. A reader convinced of the efficacy of value and momentum strategies, particularly in combination, may well be concerned with real world implementation issues. Though well beyond the scope of this paper, in this short penultimate section we briefly discuss some of the practical concerns, including implementation costs and portfolio construction, as well as opportunities to improve upon our admittedly, and intentionally, simple approach.

Transaction costs. Like most academic studies, we focus on gross returns, which are most suitable to illuminating the relation between risk and return. However, gross returns overstate the profits earned by someone pursuing the strategies we examine in practice. A few papers have tried to examine the transaction costs and capacity of these strategies, especially momentum, perhaps due to its higher turnover. For example, Korajczyk and Sadka (2004) and Lesmond, Schill, and Zhou (2003) argue that the real world returns and capacity of equity momentum strategies are considerably lower than the theoretical results would imply. Their conclusions are based on theoretical models of transactions costs. Using live trading data, Frazzini, Israel, and Moskowitz (2012) present results showing that the real world trading costs of value, momentum, and a combination of the two in equities are much lower than implied by the calibrated models of Korajczyk and Sadka (2004) and Lesmond, Schill, and Zhou (2003), and that these strategies can be scaled considerably and still generate strong net returns. In addition, we focus on an extremely large and liquid set of equities in 
each market (approximately the largest 17\% of firms), where trading costs and price impact and capacity constraints are minimized.

Studies on trading costs also focus exclusively on individual stocks, but half of the markets that we examine are implemented with futures contracts, which typically have much lower trading costs than stocks. Hence, although our equity strategies outperform our non-equity strategies in gross returns, net of trading cost returns are likely to be much closer.

Furthermore, Garleanu and Pedersen (2012) model how portfolios can be optimally rebalanced to mitigate transaction costs and demonstrate how this improves the net performance of commodity momentum strategies, for example. In a similar spirit, Frazzini, Israel, and Moskowitz (2012) demonstrate how equity portfolios can benefit from several practical steps taken to reduce transactions costs that, while having a cost in terms of gross returns (from style drift), can improve net returns. For instance, the strategies we study here are all naively rebalanced exactly monthly no matter what the expected gain per amount traded. Varying the rebalance frequency, optimizing the portfolios for expected trading costs, and extending, or occasionally contracting, the trade horizon can all improve the basic implementation of these strategies.

Shorting. Our paper is, of course, as much about shorting assets as it is about going long. While going long vs. short is symmetric for futures, shorting involves special costs in stock markets. If our results are completely dependent on shorting and if shorting is too costly or not implementable, this would certainly raise questions about the real world efficacy of these strategies. However, Israel and Moskowitz (2012) provide evidence that the return contributions of both value and momentum strategies across the same asset classes we study here are roughly equal from the long and short sides of the portfolio and that long-only portfolios of value and momentum still produce abnormal returns. Thus, these strategies are still effective even if shorting is restricted. In addition, Frazzini, Israel, and Moskowitz (2012) provide some evidence that the trading costs of shorting stocks are not materially different than the costs of buying or selling stocks.

Portfolio formation. In this paper we intentionally keep everything as simple as possible, both for clarity and as a precaution against the pernicious effects of data mining. In fact, one of the paper's objectives is to provide a robust, out-of-sample test of ideas that have been largely tested in individual, particularly U.S., stocks and extend them to other asset classes. However, when faced with real world implementation, there are many choices to consider. For example, we look at two simple portfolio implementations in the paper: top $1 / 3$ minus bottom $1 / 3$, and a linear weighting scheme based on ranking securities. These are far from the only possibilities, and the choice of weighting scheme has an impact on not only gross returns, but also potentially transactions costs. 
While we do not claim either of these choices is optimal in either a gross or net return sense, we also explore more extreme sorts of securities into deciles and find it does not materially affect the results. Tables A6 and A7 in the Internet Appendix replicate our main results for individual equity markets in the U.S., U.K., Europe, and Japan for decile portfolios and find very similar results. Figure A1 in the Internet Appendix also plots the pricing errors of our three factor model for these 80 decile portfolios of value and momentum in each of the four equity markets (U.S., U.K., Europe, and Japan). As the figure shows and the asset pricing statistics verify, the three factor model does a good job of capturing these more extreme portfolio returns, too.

We also value weight stocks within our portfolios and equal weight the securities in other asset classes. However, other weighting schemes yield similar results and because we only focus on the largest, most liquid securities, trading costs are unlikely to be affected much by such changes. Hence, our main findings are robust across a variety of perturbations and portfolio formations.

Volatility scaling. When we aggregate our strategies across asset classes, we ensure that the different asset classes are scaled to have similar volatility. We do this by scaling each asset class by the inverse of its realized volatility over the full sample. However, since the full sample is not known in advance, a real world portfolio would need to scale by a measure of volatility that is estimated ex ante. For robustness, Table A8 in the Internet Appendix reports results for all of our value and momentum strategies scaled to the same ex ante volatility of $2 \%$ per annum using a rolling three year estimate of each portfolio's volatility from daily returns. The results are reported side by side to the original unadjusted returns. The Sharpe ratios and correlations of the strategies are very similar and yield identical conclusions.

Dollar neutral vs. beta neutral. As is standard in academic studies, our strategies are constructed to be $\$ 1$ long and \$1 short, but they need not have a zero market beta exposure (at the local or global level). However, real world portfolios can, and often do, take the step of attempting to create long-short portfolios that are ex-ante beta neutral (in addition to, or instead of, being dollar neutral). However, our inferences based on the strategies' alpha from factor regressions are not affected by market hedging.

Value and momentum measures. Finally, we use one measure for value and one for momentum for all eight markets we study. We choose the most studied or simplest measure in each case and attempt to maintain uniformity across asset classes, in order to minimize the potential for data mining. In real world implementations, data mining worries may be weighed against the potential improvements from having multiple (and perhaps better) measures of value and momentum, if for no other reason than to diversify away measurement error or noise across variables. Israel and 
Moskowitz (2012) show how other measures of value and momentum can improve the stability of returns to these styles, and most practical implementations use a variety of measures for a given style. In fact, we set out to examine value and momentum in eight different markets and asset classes using a single uniform measure for each. Although we find positive returns to value and momentum in each asset class, these returns are not always significant. In particular, our weakest results using the current measures of value and momentum pertain to bonds, which did not produce statistically significant premia. However, as shown in Table 1 Panel C, the returns can be vastly improved using other measures of value and momentum, and taking a composite average index of measures for value and momentum produces even more stable and reliable results. Hence, our use of simple, uniform value and momentum measures may understate the true returns to these strategies.

The literature on realistic implementation of these strategies is still young, and the list of choices to make when moving from an academic study like ours to implementing these strategies in practice is long. But, current evidence, research, and practical experience point to the effects we study being highly applicable to real world portfolios. Consistent with this conjecture, as shown in Table VI, our simple value and momentum global factors capture well the returns to hedge fund indices, which suggests hedge funds are engaged in similar or highly correlated strategies globally.

Evolution over time. As the hedge fund industry has grown over time and more capital is devoted to these strategies, it is interesting to consider what effect, if any, such activity has on the efficacy of value and momentum strategies. While a complete analysis of this question is beyond the scope of this paper, we offer a couple of results perhaps worthy of future investigation.

Table VII reports the Sharpe ratios and correlations among the value and momentum strategies over the first and second halves of the sample period-1972 to 1991 and 1992 to 2011. As the first row of Panel A of Table VII shows, the Sharpe ratios to both value and momentum have declined slightly over time. In addition, their correlations across markets have increased over time-the average correlation among value strategies has risen from 0.31 to 0.71 and among momentum strategies has gone from 0.46 to 0.77 . However, the correlation between value and momentum has declined from -0.44 to -0.63 , and as a result the Sharpe ratio of the combination of value and momentum has not changed much over time, since the increased correlation across markets is being offset by the more negative correlation between value and momentum. These results may be consistent with increased participation of arbitrageurs driving up correlations among value and momentum strategies globally.

The next row of Panel A of Table VII repeats the same analysis splitting the sample prior to and after August, 1998, which is roughly when the funding crisis peaked following the collapse of Long 
Term Capital Management (LTCM). The correlation among value strategies is much higher after August 1998 (0.16 pre-1998 versus 0.64 post-1998), and the correlation among momentum strategies is also higher after 1998 (0.43 versus 0.71). The next three rows of Panel A of Table VII report the same statistics for periods of worsening and improving funding liquidity, defined as negative and positive funding liquidity shocks, and are split separately into pre- and post-1998. Consistent with our previous regression results in Table IV, value strategies do worse when liquidity improves and momentum strategies do worse when liquidity declines, but these patterns appear only after 1998. Prior to the financial crisis of 1998, funding liquidity shocks seem to have little impact on either value or momentum strategies. After 1998, however, value generates a Sharpe ratio of 0.85 during periods of worsening liquidity, but only 0.28 when liquidity improves. Conversely, momentum produces only a 0.19 Sharpe ratio when liquidity worsens, but a 0.77 Sharpe ratio when liquidity improves. The 50/50 value/momentum combination is immune to liquidity risk, even after 1998.

Panel B of Table VII examines more formally how value and momentum correlations change over time and with liquidity shocks by running time series regressions, where the dependent variable is the cross product of monthly returns on the various strategies to proxy for time varying correlations. We estimate the time $t$ correlation among value strategies globally, $\rho(\mathrm{Val}, \mathrm{Val})_{\mathrm{t}}$, as the average across asset classes at time $t$ of $r_{i, t}^{V a l} \times r_{k, t}^{V a l}$, where $r_{i, t}^{V a l}$ is the return to the value strategy in market or asset class $i$ at time $t$. We define $\rho(\text { Mom,Mom })_{t}$ and $\rho(\text { Val,Mom })_{t}$ similarly. The time series of these correlations are regressed on a linear time trend, a global recession indicator, and the time series of liquidity shocks. The first three columns of Panel B of Table VII show that the average correlation among value and among momentum strategies across markets and asset classes has been significantly increasing over time and the correlation between value and momentum is significantly more negative over time. Recessions increase the correlation among both value and momentum strategies globally, controlling for the time trend. Liquidity shocks also seem to significantly increase correlations among momentum strategies, controlling for the time trend and recessions. However, the last three columns repeat the regressions adding a post-1998 dummy variable and an interaction between the post-1998 dummy and liquidity shocks. Rather than a time trend, the post-1998 dummy seems to be driving any correlation changes and the impact of liquidity shocks on correlations also appears to be exclusively a post-1998 phenomenon. These results suggest an increase in the importance of liquidity risk on the efficacy of these strategies following the events of the Summer of 1998 that appear to be more important than any time trend on the increasing popularity of value and 
momentum strategies among leveraged arbitrageurs. ${ }^{18}$ Hence, funding liquidity risk and limits to arbitrage activity may be a progressively more crucial feature of these strategies and future work may well consider these issues in understanding the returns to value and momentum.

\section{Conclusion}

We provide comprehensive evidence on the return premia to value and momentum strategies globally across asset classes, and uncover strong common factor structure among their returns. The strong correlation structure among value and momentum strategies across such diverse asset classes is difficult to reconcile under existing behavioral theories, while the high return premium and Sharpe ratio of a global-across-asset class diversified value and momentum portfolio presents an even more daunting hurdle for rational risk based models to accommodate than the more traditional approach of considering value or momentum separately in a single asset market. Although, both behavioral and rational theories for value and momentum have predominantly focused on equities, the existence of correlated value and momentum effects in other asset classes-with their different investors, institutional structures, and information environments_-argues for a more general framework.

We further find that exposure to funding liquidity risk provides a partial explanation for this correlation structure, especially following the funding crisis of 1998, but leaves much to be explained. While the relation to funding liquidity risk could imply that limited arbitrage activity may contribute to the prevalence and dynamics of these phenomena, we leave the ubiquitous evidence on the efficacy of value and momentum across the diverse asset classes we study, its strong correlation structure, and intriguing dynamics related to funding risk as a challenge for future theory and empirical work to address.

Finally, we provide a simple global three factor model which describes well a new set of 48 global-across-asset class test assets, the Fama-French portfolios, and a variety of hedge fund indices. In further investigating the underlying economic sources driving value and momentum returns, we hope this simple three factor framework can be useful for future research that is becoming increasingly concerned with pricing global assets across markets.

\footnotetext{
${ }^{18}$ Israel and Moskowitz (2012) examine the relation between size, value, and momentum profitability and aggregate trading costs and institutional investment over time and find little evidence that the returns to these strategies varies with either of these variables.
} 


\section{References}

Acharya, Viral, and Lasse Heje Pedersen, 2005, Asset pricing with liquidity risk, Journal of Financial Economics 77, 375-410.

Amihud, Yakov, 2002, Illiquidity and stock returns: Cross-section and time series effects, Journal of Financial Markets 5, 31-56.

Amihud, Yakov, Haim Mendelson, and Lasse Heje Pedersen, 2005, Liquidity and asset prices, Foundations and Trends in Finance1, 269-364.

Asness, Clifford S., 1994, Variables that explain stock returns, Ph.D. Dissertation, University of Chicago.

Asness, Clifford S., 2011, Momentum in Japan: The exception that proves the rule, Journal of Portfolio Management 37, 67-75.

Asness, Clifford S., and Andrea Frazzini, 2012, The Devil in HML's details, Working paper, AQR Capital Management.

Asness, Clifford S., John M. Liew, and Ross L. Stevens, 1997, Parallels between the cross-sectional predictability of stock and country returns, The Journal of Portfolio Management 23, 79-87.

Asness, Clifford S., R. Burt Porter, and Ross Stevens, 2000, Predicting stock returns usingindustryrelative firm characteristics, Working paper, AQR Capital Management.

Bali, Tarun G., Stephen J. Brown, and Mustafa O. Caglayan, 2011, Do hedge funds' exposures to risk factors predict their future returns? Journal of Financial Economics 101, 36-68.

Bali, Tarun G., Stephen J. Brown, and Mustafa O. Caglayan, 2012, Systematic risk and the crosssection of hedge fund returns, Journal of Financial Economics, Forthcoming.

Bansal, Ravi, and Amir Yaron, 2004, Risks for the long run: A potential resolution of asset pricing puzzles, Journal of Finance 35, 54-56.

Barberis, N., A. Shleifer and R. Vishny, 1998, A model of investor sentiment, Journal of Financial Economics 49, 307-343.

Belo, F., 2010, Production-based measures of risk for asset pricing, Journal of Monetary Economics 57, 146-163.

Berk, J., R. Green, and V. Naik,1999, Optimal investment, growth options, and security returns, Journal of Finance 54, 1153-1607.

Bessembinder, H., 1992, Systematic risk, hedging pressure, and risk premiums in futures markets, Review of Financial Studies 5, 637-667. 
Bhojraj, Sanjeev, and Bhaskaran Swaminathan, 2006, Macromomentum: Returns predictability in international equity indices, The Journal of Business 79, 429-451.

Boudoukh, Jacob, Matthew Richardson, and Robert F. Whitelaw, 1994, Industry returns and the fisher effect, The Journal of Finance 49, 1595-1615.

Boyson, Nicole, Christof W. Stahel, and Rene M. Stulz, 2010, Hedge fund contagion and liquidity shocks, Journal of Finance 65, 1789-1816.

Brunnermeier, Markus, and Lasse Heje Pedersen, 2009, Market liquidity and funding liquidity, The Review of Financial Studies 22, 2201-2238.

Carhart, M., 1997, On persistence in mutual fund performance, Journal of Finance 52, 57-82.

Chordia, Tarun, and Lakshmanan Shivakumar, 2002, Momentum, business cycle and time-varying expected returns, Journal of Finance 57, 985-1019.

Chui, Andy, Sheridan Titman, and K.C. John Wei, 2010, Individualism and momentum around the world, Journal of Finance 65, 361-392.

Daniel, K., D. Hirshleifer and A. Subrahmanyam, 1998, A theory of overconfidence, self-attribution, and security market under and over-reactions, Journal of Finance 53, 1839-1885.

DeBondt, Werner F.M., and Richard Thaler, 1985, Does the stock market overreact? The Journal of Finance 40, 793-805.

Erb, C., and C. Harvey, 2006, The strategic and tactical value of commodity futures, Financial Analysts Journal 62, 69-97.

Fama, Eugene F., 1976, Foundations of Finance (Basic Books, New York, NY).

Fama, Eugene F., and Kenneth R. French, 1992, The cross-section of expected stock returns, The Journal of Finance 47, 427-465.

Fama, Eugene F., and Kenneth R. French, 1993, Common risk factors in the returns on stocks and bonds, Journal of Financial Economics 33, 3-56.

Fama, Eugene F., and Kenneth R. French, 1996, Multifactor explanations of asset pricing anomalies, Journal of Finance 51, 55-84.

Fama, Eugene F., and Kenneth R. French, 1998, Value versus growth: The international evidence, Journal of Finance 53, 1975-1999.

Fama, Eugene F., and Kenneth R. French, 2012, Size, value, and momentum in international stock returns, Journal of Financial Economics, Forthcoming.

Fama, Eugene F., and James MacBeth, 1973, Risk, return, and equilibrium: Empirical tests, Journal of Political Economy 81(3), 607-636. 
Frazzini, Andrea, Ronen Israel, and Tobias J. Moskowitz, 2012, On the transaction costs efficiency of equity styles: What does a trillion dollars of trades tell us?, Working paper, University of Chicago.

Frazzini, Andrea, and Lasse H. Pedersen, 2010, Betting against beta, Working paper, AQR Capital Management and New York University.

Garleanu, Nicolae, and Lasse H. Pedersen, 2012, Dynamic trading with predictable returns and transaction costs, The Journal of Finance, forthcoming.

Gerakos, Joseph, and Juhani Linnainmaa, 2012, Decomposing value, Working paper, University of Chicago.

Gibbons, Michael R., Stephen A. Ross, and Jay Shanken, 1989, A test of the efficiency of a given portfolio, Econometrica 57, 1121-1152.

Gomes, Joao F., Leonid Kogan, and Lu Zhang, 2003, Equilibrium cross section of returns, Journal of Political Economy 111, 693-732.

Gorton, Gary B., Fumio Hayashi, and K. Geert Rouwenhorst, 2008, The fundamentals of commodity futures returns, Working paper, University of Pennsylvania.

Goyal, Amit, and Sunil Wahal, 2012, Is momentum an echo? Working paper, Arizona State University.

Griffin, John, Susan Ji, and Spencer Martin, 2003, Momentum investing and business cycle risk: Evidence from Pole to Pole, Journal of Finance 58, 1515-1547.

Grinblatt, Mark, and Tobias J. Moskowitz, 2004, Predicting stock price movements from past returns: The role of consistency and tax-loss selling, Journal of Financial Economics 71, 541-579.

Hansen, Lars P., John Heaton, and Nan Li, 2008, Consumption strikes back?: Measuring long run risk, Journal of Political Economy 116(2), 260-302.

Hansen, Lars P., and Ravi Jagannathan, 1997, "Assessing Specification Errors in Stochastic Discount Factor Models," Journal of Finance 52(2), 557-590.

Hong, H., Lim, T., and Stein, J., 2000, Bad news travels slowly: Size, analyst coverage, and the profitability of momentum strategies, Journal of Finance 55, 265-295.

Hong, H., and J. Stein, 1999, A unified theory of underreaction, momentum trading, and overreaction in asset markets, Journal of Finance 54, 2143-2184.

Israel, Ronen, and Tobias J. Moskowitz, 2012, The role of shorting, firm size, and time on market anomalies, Journal of Financial Economics, Forthcoming.

Jegadeesh, Narasimhan, 1990, evidence of predictable behavior of security returns, The Journal of Finance 45, 881-898. 
Jegadeesh, Narasimhan, and Sheridan Titman, 1993, Returns to buying winners and selling losers: Implications for stock market efficiency, The Journal of Finance 48, 65-91.

Johnson, T., 2002, Rational momentum effects, Journal of Finance 57, 585-608.

Kho, B.C., 1996, Time-varying risk premia, volatility, and technical trading rule profits: Evidence from foreign currency futures markets, Journal of Financial Economics 41, 249-290.

Koijen, Ralph, Tobias Moskowitz, Lasse H. Pedersen, and Evert Vrugt, 2012, Carry, Working paper, University of Chicago.

Korajczyk, Robert A., and Ronnie Sadka, 2004, Are momentum profits robust to trading costs? The Journal of Finance 59, 1039-1082.

Korajczyk, Robert A., and Ronnie Sadka, 2008, Pricing the commonality across alternative measures of liquidity, Journal of Financial Economics 87, 45-72.

Krishnamurthy, A., 2002, The bond/old-bond spread, Journal of Financial Economics 66, 463-506.

Lakonishok, Josef, Andrei Shleifer, and Robert W. Vishny, 1994, Contrarian investment, extrapolation, and risk, Journal of Finance 49, 1541-1578.

Lebaron, B., 1999, Technical trading rule profitability and foreign exchange intervention, Journal of International Economics, 49, 125-143.

Lesmond, David A., Michael J. Schill, and Chunsheng Zhou, 2003, The illusory nature of momentum profits, Journal of Financial Economics 71, 349-380.

Li, Dongmei, and Lu Zhang, 2010, Does q-theory with investment frictions explain anomalies in the cross-section of returns? Journal of Financial Economics 98, 297-314.

Li, Erica X. N., Dmitry Livdan, and Lu Zhang, 2009, Anomalies, Review of Financial Studies 22, 4301-4334.

Liew, Jimmy, and Maria Vassalou, 2000, Can book-to-market, size and momentum be risk factors that predict economic growth? Journal of Financial Economics 57, 221-245.

Liu, Laura Xiaolei, Toni M. Whited, and Lu Zhang, 2009, Investment-based expected stock returns, Journal of Political Economy 117, 1105-1139.

Liu, Laura Xiaolei, and Lu Zhang, 2008, Momentum profits, factor pricing, and macroeconomic risk, Review of Financial Studies 21, 2417-2448.

Lo, Andrew W., and A. Craig MacKinaly, 1990, When are contrarian profits due to stock market overreaction? Review of Financial Studies 3, 175-205. 
Malloy, Christopher, Tobias J. Moskowitz, and Annette Vissing-Jorgensen, 2009, Long-run stockholder consumption risk and asset returns, Journal of Finance 64, 2427-2479.

Moskowitz, Tobias J., 2003, An analysis of covariance risk and pricing anomalies, Review of Financial Studies 16, 417-457.

Moskowitz, Tobias J., Yao Hua Ooi, and Lasse Heje Pedersen, 2012, Time series momentum, Journal of Financial Economics 104, 228-250.

Moskowitz, Tobias J., and Lasse Heje Pedersen, 2012, Global market and funding liquidity, Working paper, University of Chicago.

Novy-Marx, Robert, 2011, Is momentum really momentum? Journal of Financial Economics, Forthcoming.

Parker, Jonathan A., and Christian Julliard, 2005, Consumption risk and the cross section of expected returns, Journal of Political Economy 113, 185-222.

Pastor, Lubos, and Robert F. Stambaugh, 2003, Liquidity risk and expected stock returns, Journal of Political Economy 111, 642-685.

Pedersen, Lasse, 2009, When everyone runs for the exit, The International Journal of Central Banking 5, 177-199.

Piotroski, Joseph, 2000, Value investing: The use of historical financial statement information to separate winners from losers, Journal of Accounting Research, 38, 1-41.

Roon, F.A. de, Nijman, T.E., \& Veld, C.H., 2000. Hedging pressure effects in futures markets. Journal of Finance, 55, 1437-1456.

Rosenberg, Barr, Kenneth Reid, and Ronald Lanstein, 1985, Persuasive evidence of market inefficiency, Journal of Portfolio Management, 11, 9-16.

Rouwenhorst, K. Geert, 1998, International momentum strategies, The Journal of Finance 53, 267284.

Sadka, Ronnie, 2006, Momentum and post-earnings-announcement drift anomalies: The role of liquidity risk, Journal of Financial Economics 80, 309-349.

Sadka, Ronnie, 2012, Hedge-fund performance and liquidity risk, Journal of Investment Management 10, 60-72.

Sagi, Jacob, and Mark Seasholes, 2007, Firm-specific attributes and the cross-section of momentum, Journal of Financial Economics 84, 389-434.

Shleifer, Andrei and Lawrence H. Summers, 1990, The noise trader approach to finance. Journal of Economic Perspectives 4, 19-33. 
Stattman, Dennis, 1980, Book values and stock returns, Chicago MBA: A Journal of Selected Papers 5, 25-45.

Vayanos, Dimitri, and Paul Woolley, 2012, An institutional theory of momentum and reversal, Working paper, London School of Econmics.

Zhang, Lu, 2005, The value premium, Journal of Finance 60, 67-103. 


\section{Figure 1: First Principal Component for Value and Momentum Strategies}

Plotted are the eigenvector values associated with the largest eigenvalue of the covariance matrix of returns to value and momentum strategies. The top graph plots the first principal component of value and momentum strategies in individual stocks in four international markets: U.S., U.K., Europe (excluding the U.K.), and Japan and the bottom graph plots the first principal component for value and momentum strategies in five asset classes: individual stocks globally, country equity index futures, currencies, sovereign bonds, and commodities. Also reported is the percentage of the covariance matrix explained by the first principal component.

First PC of Global Equity Value and Momentum Portfolios

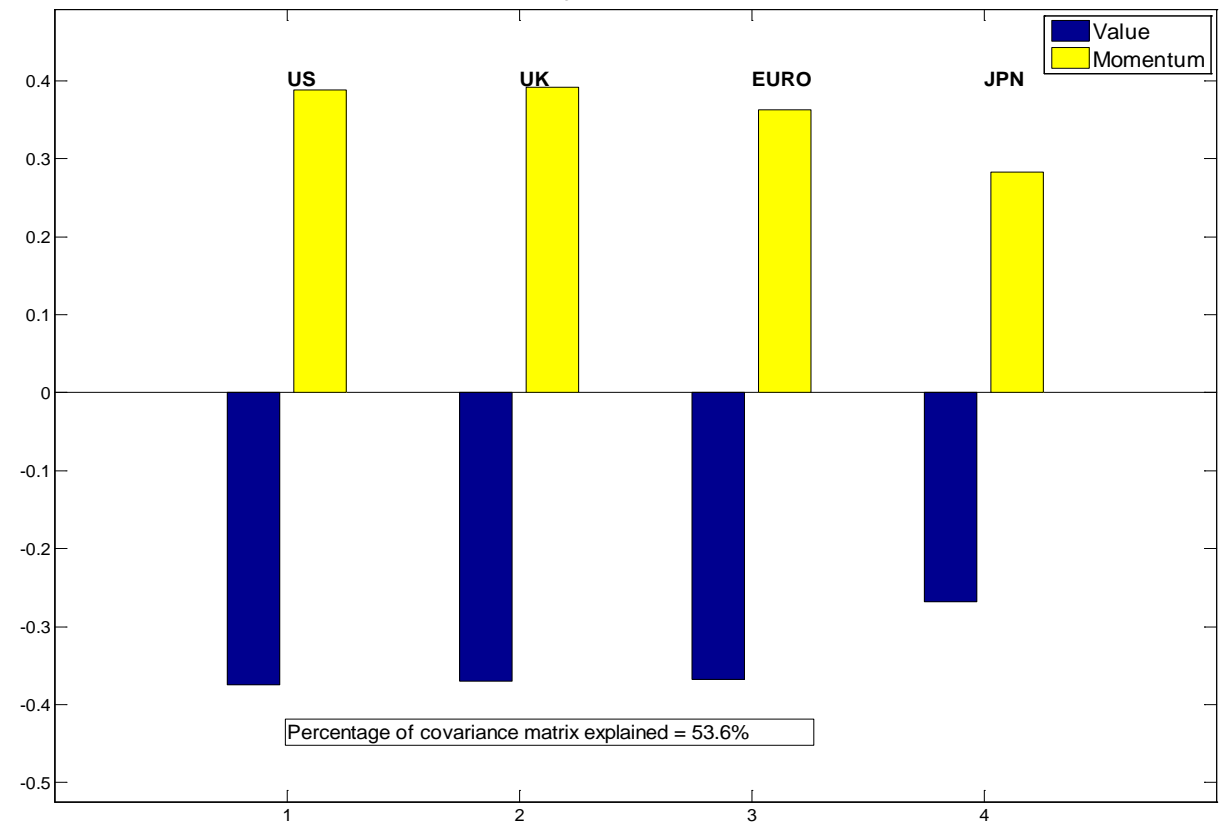

First PC of All Asset Classes Value and Momentum Portfolios

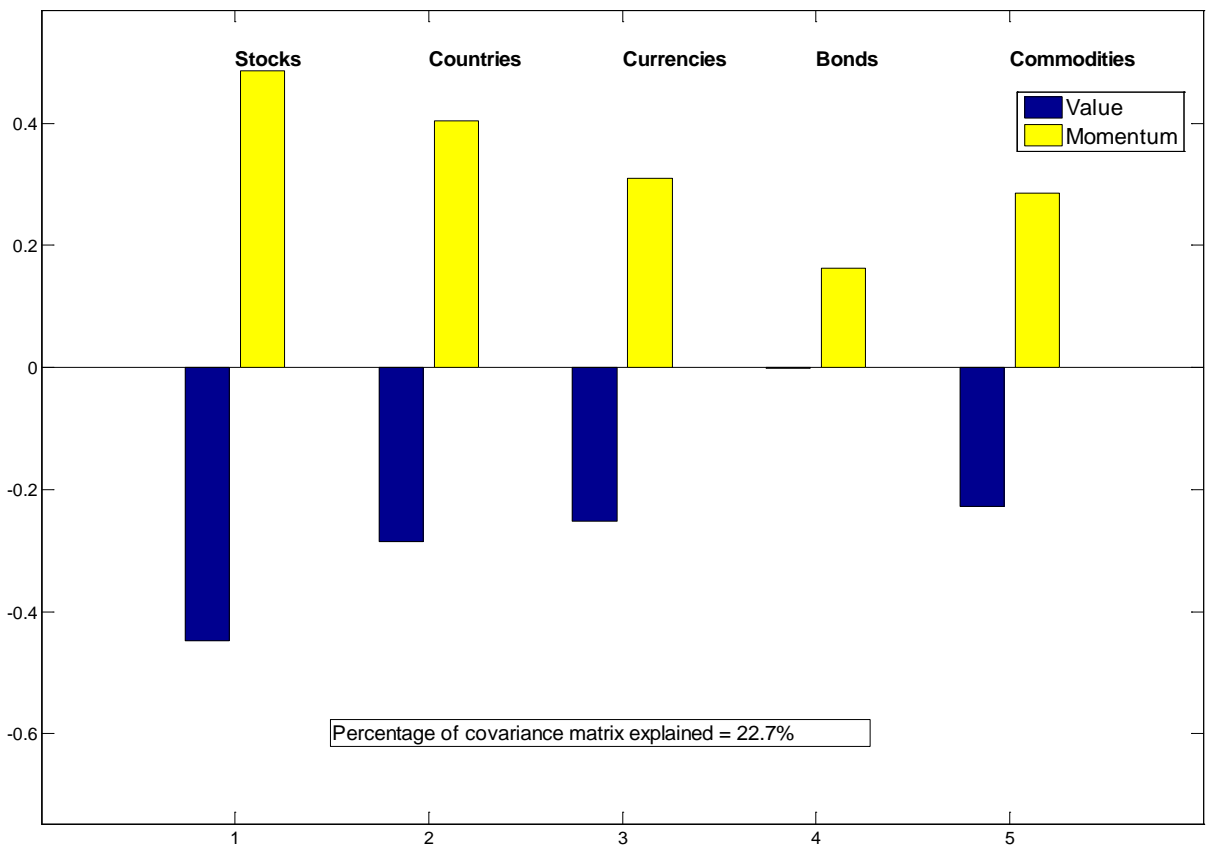




\section{Figure 2: Cumulative Returns to Value and Momentum Strategies Across Markets and Asset Classes}

Plotted are the cumulative (sum of log) returns to value, momentum, and their 50/50 combination strategies in each of the eight asset markets considered: equities in the U.S.,

U.K., Europe, and Japan, equity index futures, currencies, bonds, and commodities. Returns are plotted for the rank weighted factor portfolios which are zero-investment portfolios that weight each asset in proportion to its rank based on either value or momentum, following equation (1). Results are also reported for an average of all individual stock strategies across all stock markets (“Global stocks”), across all non-stock asset classes ("Global other asset classes”), and across all markets and asset classes (“Global all asset classes”), where average return series are computed using equal volatility weights across the markets and asset classes to account for the differences in volatility across asset classes. Reported on each graph are the annualized Sharpe ratios for each strategy as well as the correlation between value and momentum in each market.
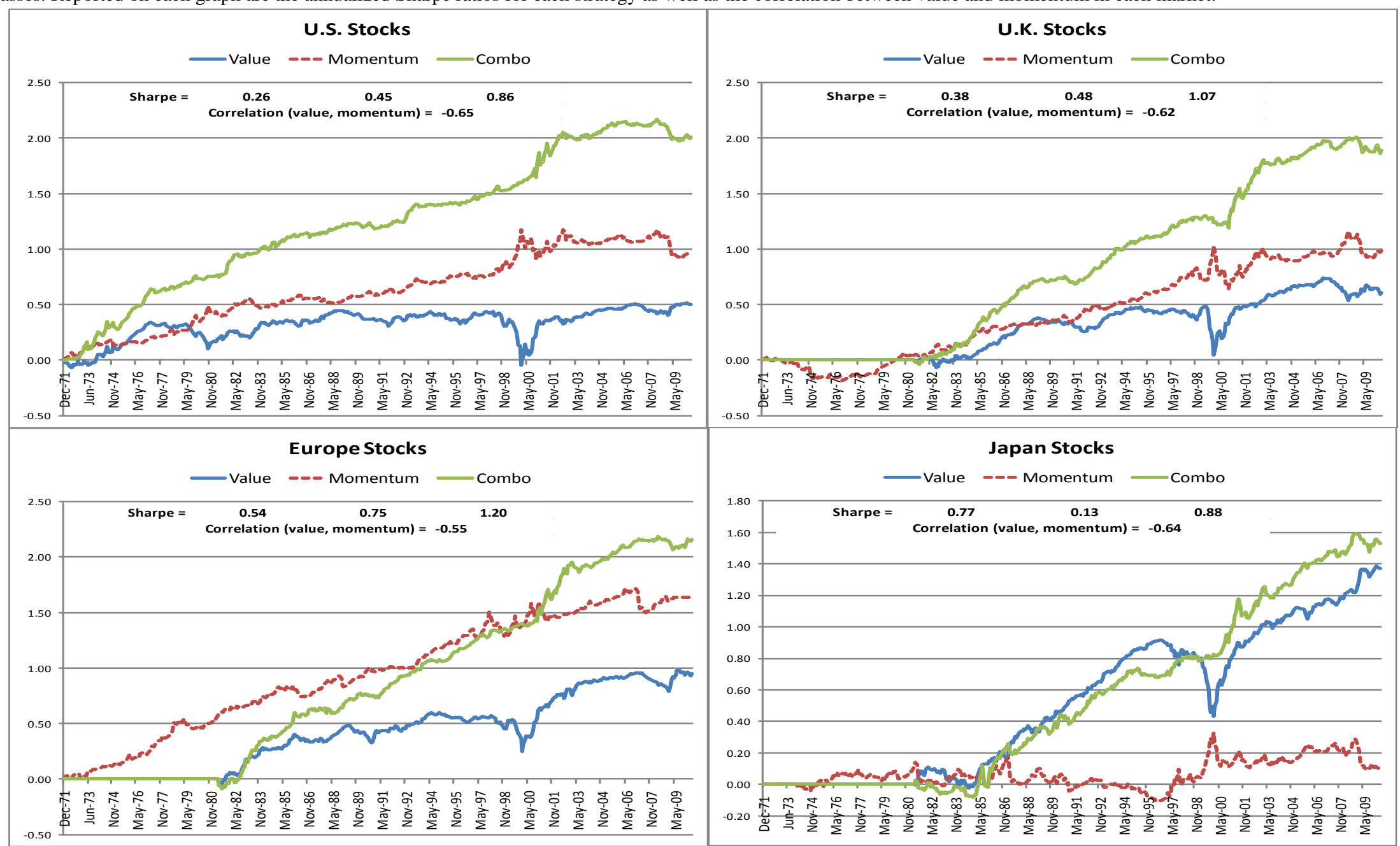


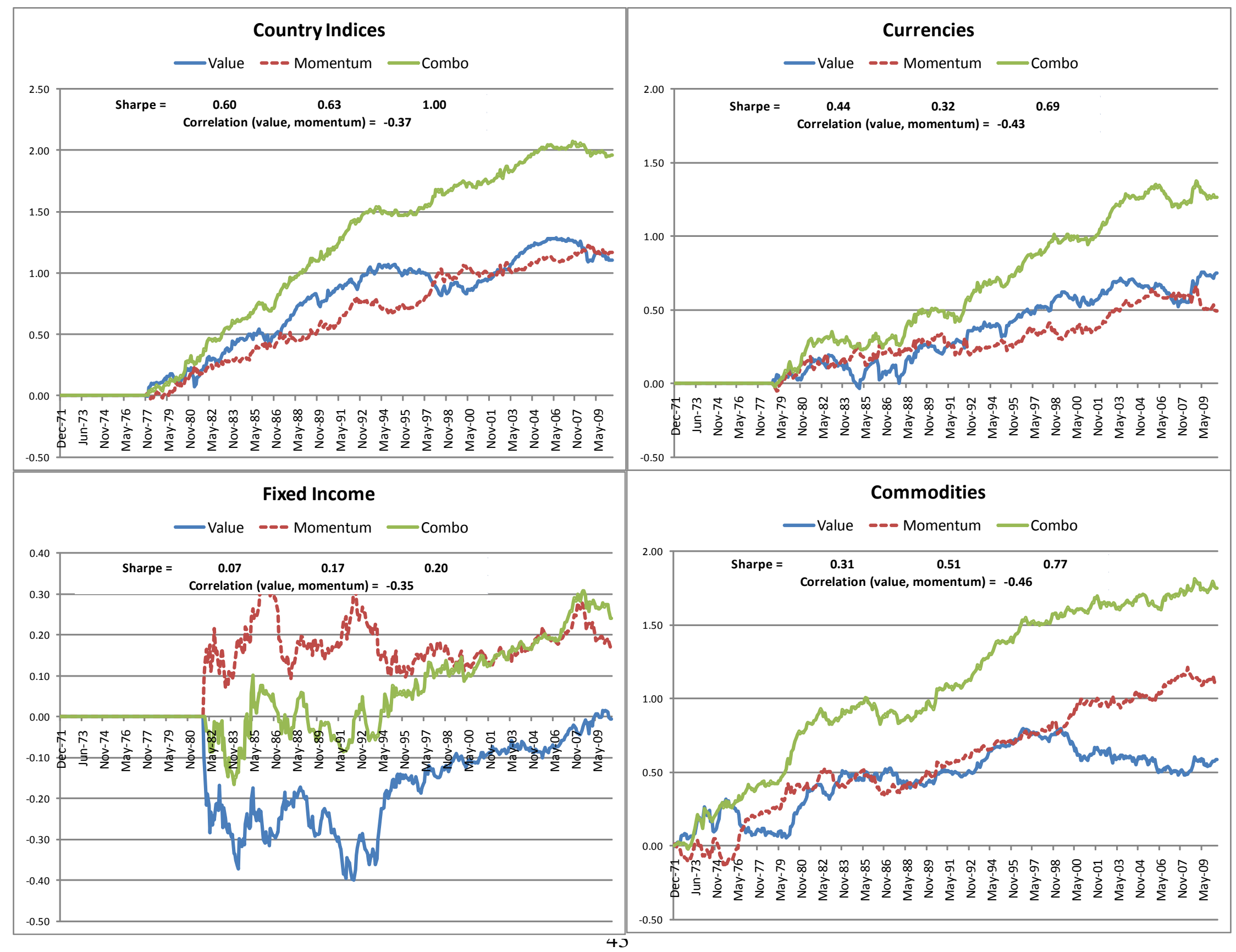



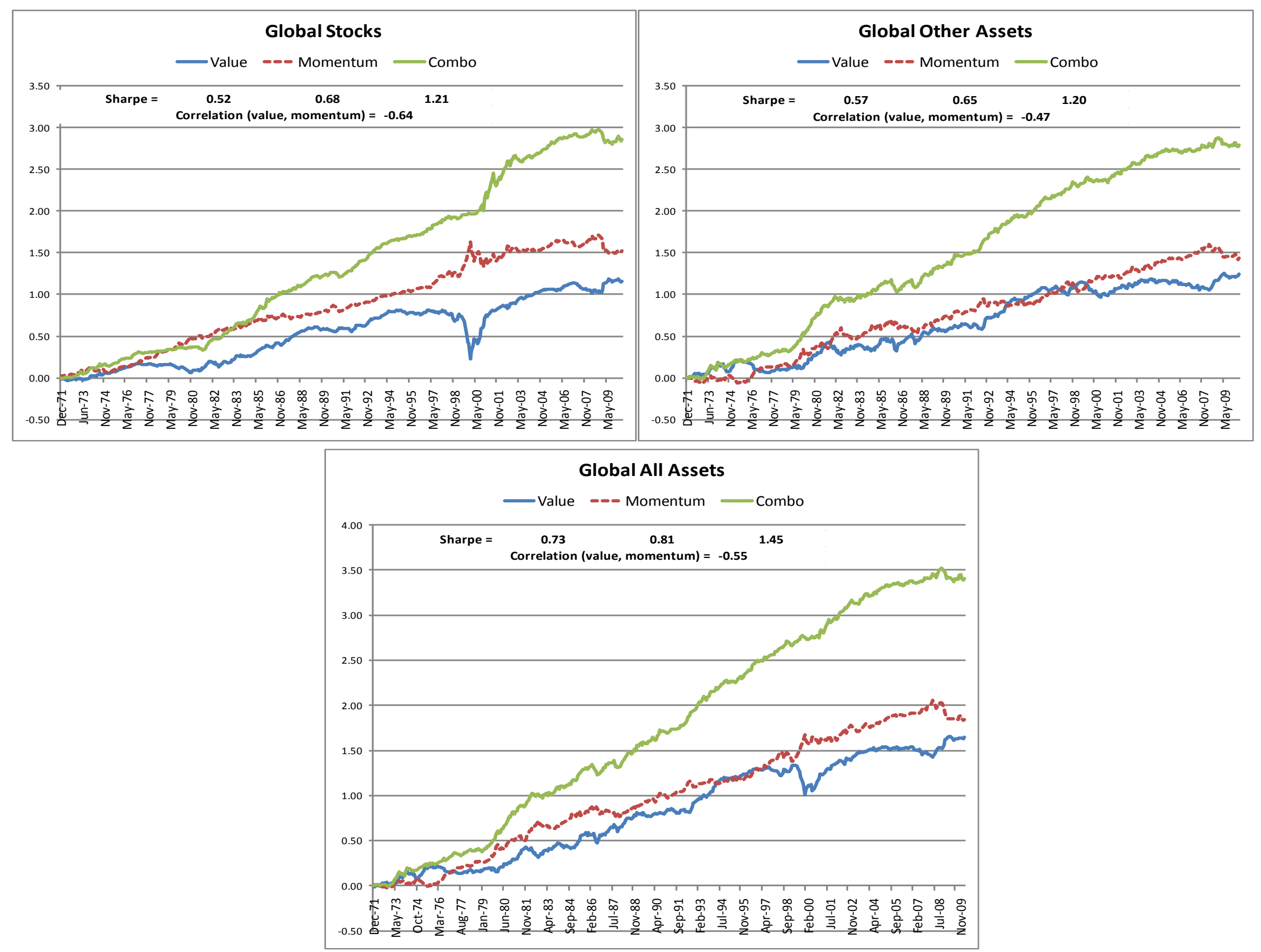


\section{Figure 3: Time Series of Global Liquidity Shocks}

The time series of global liquidity shocks is plotted from January 1987 to June 2010, where global liquidity shocks are as defined in Section III. Global liquidity shocks are the residuals from an AR(2) of the global liquidity index, which is a principal component weighted average of all market and funding liquidity variables across all markets (U.S., U.K., Europe, and Japan) as described in Section III. Also highlighted on the graph are episodes known to have generated movements in aggregate liquidity.

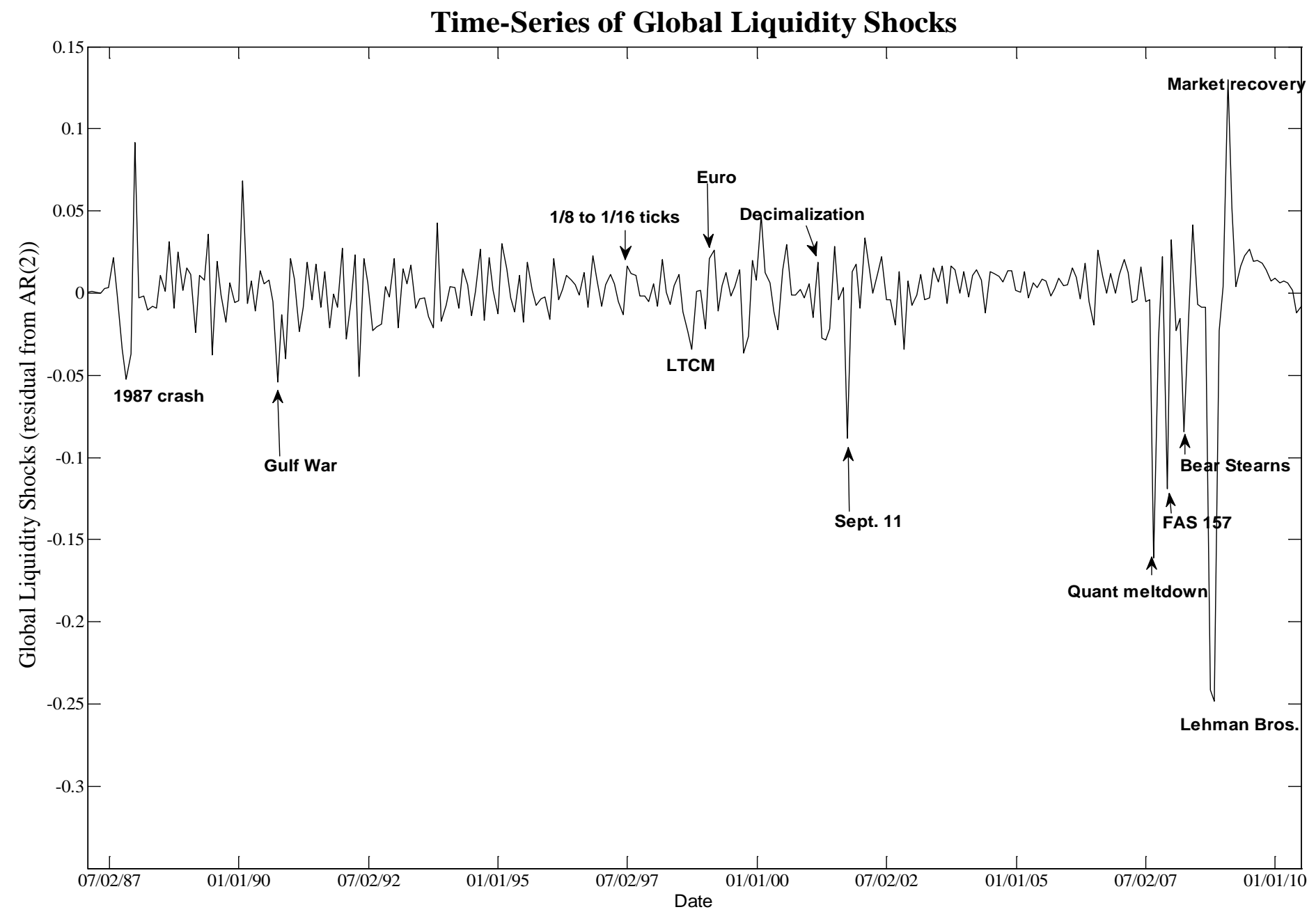




\section{Figure 4: Liquidity Risk Beta t-statistics}

Plotted are the $t$-statistics of the liquidity risk beta estimates of value and momentum strategies in each asset class using shocks to the global liquidity index as described in Section III. Also reported is the cross-sectional average $t$-statistic of value and momentum strategies across the asset classes ("average") as well as the $t$-statistic of the average return series across all asset classes for value and momentum (“all asset classes”).

- Value $\square$ Momentum

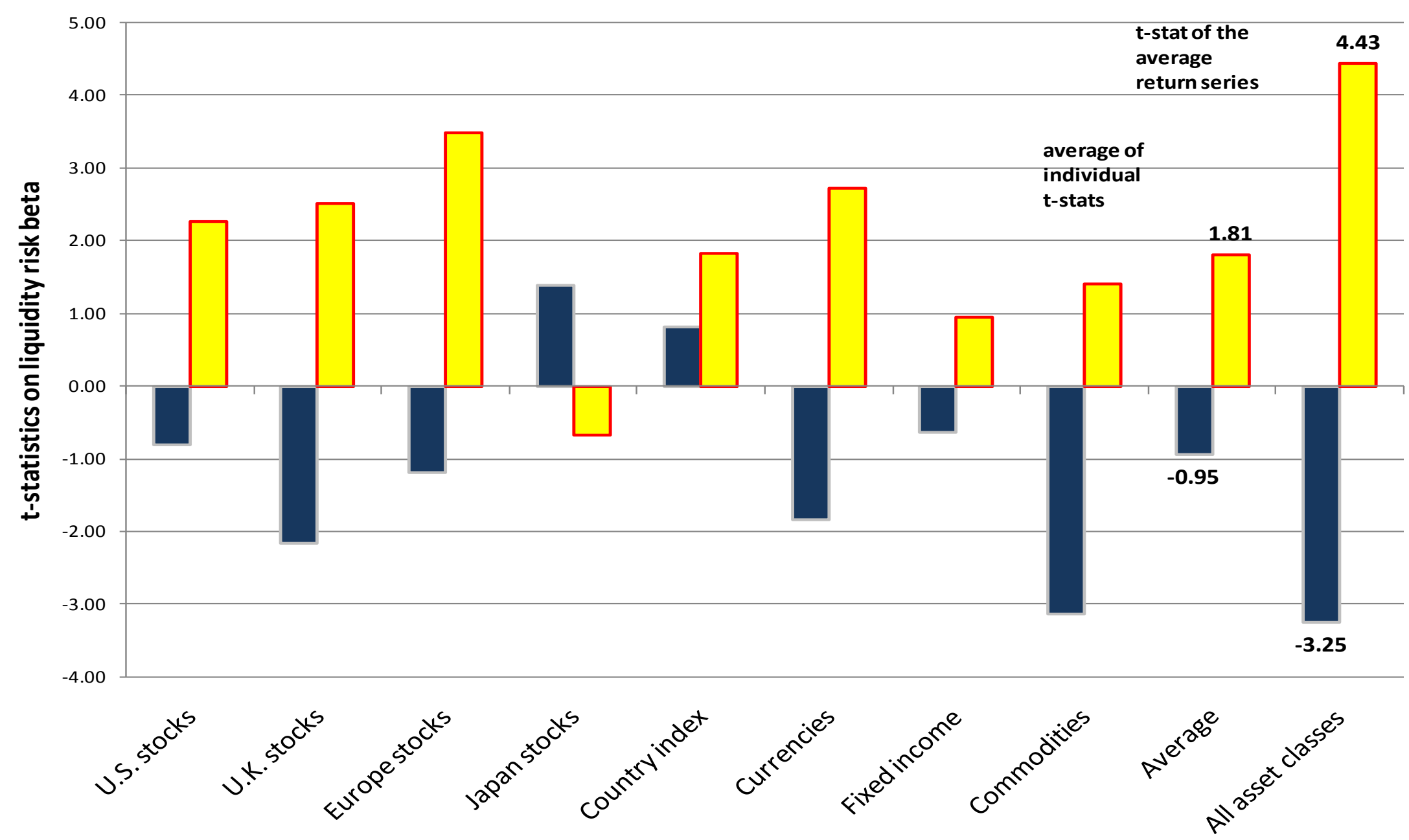




\section{Figure 5: Explaining Value and Momentum in One Market with Value and Momentum in Other Markets}

Plotted are the actual average returns (in excess of the U.S. one month T-bill rate) of the 48 value and momentum low, middle, and high portfolios in each market and asset class against their predicted expected returns using their betas with respect to value and momentum strategies in all other markets globally. Specifically, for each of the eight markets we consider (U.S. stocks, U.K. stocks, Europe stocks, Japan stocks, country index futures, currencies, government bonds, commodities) we estimate the betas of value and momentum low, middle, and high portfolios in each market with respect to a value and momentum factor across all other markets by running a time series regression of each value and momentum portfolio in one market on the (equal volatility weighted) average of the value and momentum factors across all other markets, excluding the market being analyzed. The predicted value from this regression is the predicted expected return of the strategy which we plot against the average actual average return over the sample period. The average absolute value of the alphas from these regressions and the cross-sectional $R^{2}$ of the actual average returns against the predicted expected returns are also reported. To highlight both the alphas and cross-sectional fit, a 45 degree line is plotted through the origin.

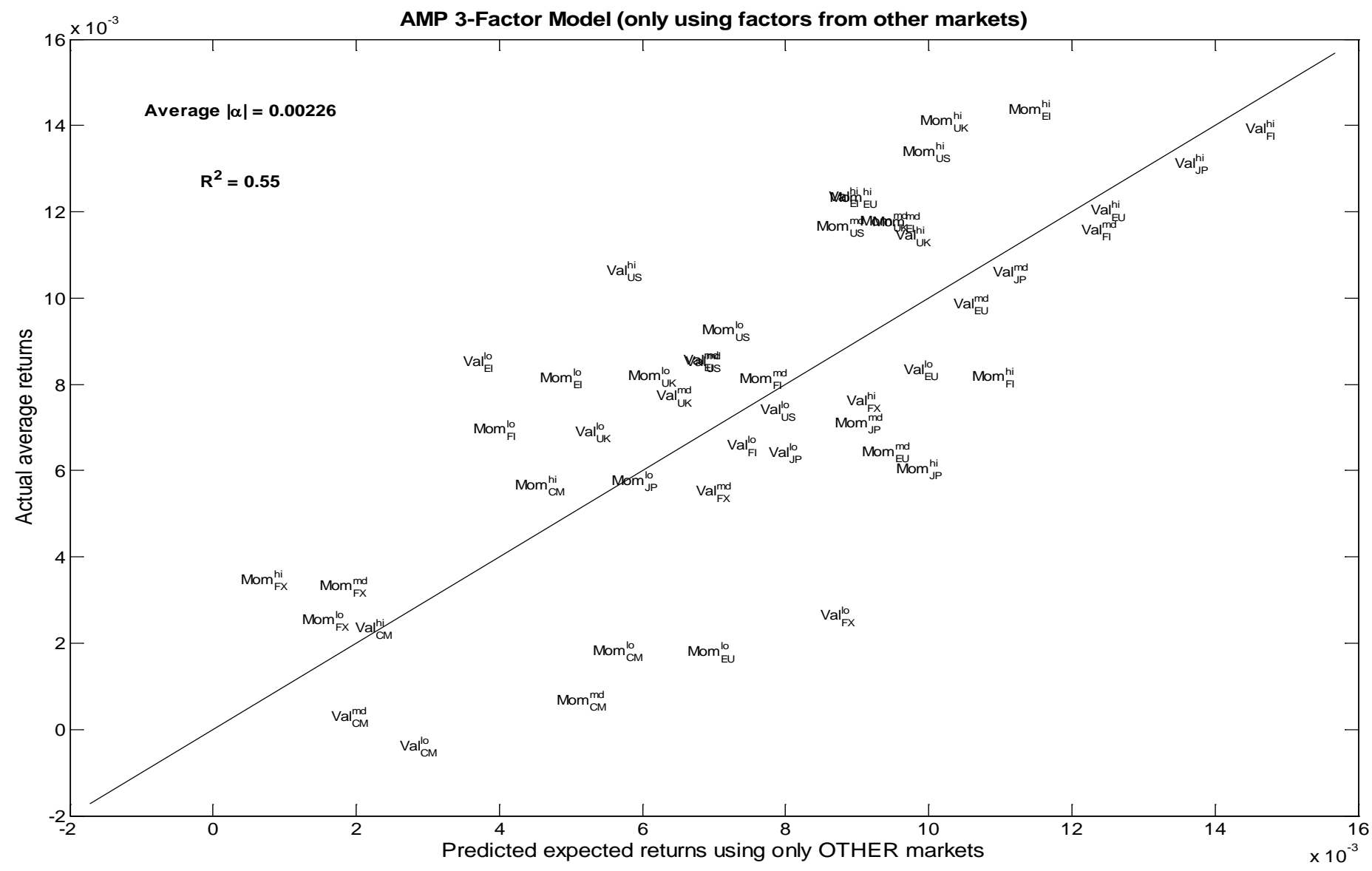




\section{Figure 6: Asset Pricing Tests of the Cross Section of Expected Returns}

Plotted are the pricing errors of the 48 value and momentum low, middle, and high portfolios in each market and asset class under the global CAPM (MSCI World Index), Fama and French four factor model consisting of U.S. market, size, value, and momentum factors: RMRF, SMB, HML, and UMD, Fama and French six factor model which adds TERM and DEF to the four factor model to capture term and default risk premia, and the AMP three factor model consisting of a global market factor (MSCI World Index), a value "everywhere" factor, and a momentum "everywhere" factor, which are value and momentum long-short portfolios diversified across the eight asset classes we consider, where each asset class is weighted by the inverse of its in-sample volatility. The pricing errors are alphas from time series regressions of each of the 48 portfolios on the various factor models, plotted below as the actual average return on each portfolio relative to their predicted expected returns under each model. A 45 degree line which passes through the origin is added to highlight the pricing errors (vertical distances to the 45 degree line) where each model is forced to also price the equity premium. Also reported on each graph are the average absolute value of the alphas, $F$-statistic and $p$-value from the GRS test, and the cross-sectional $R^{2}$ under each asset pricing model.

\section{PANEL A: 48 Value and Momentum Portfolios Across Markets and Asset Classes}
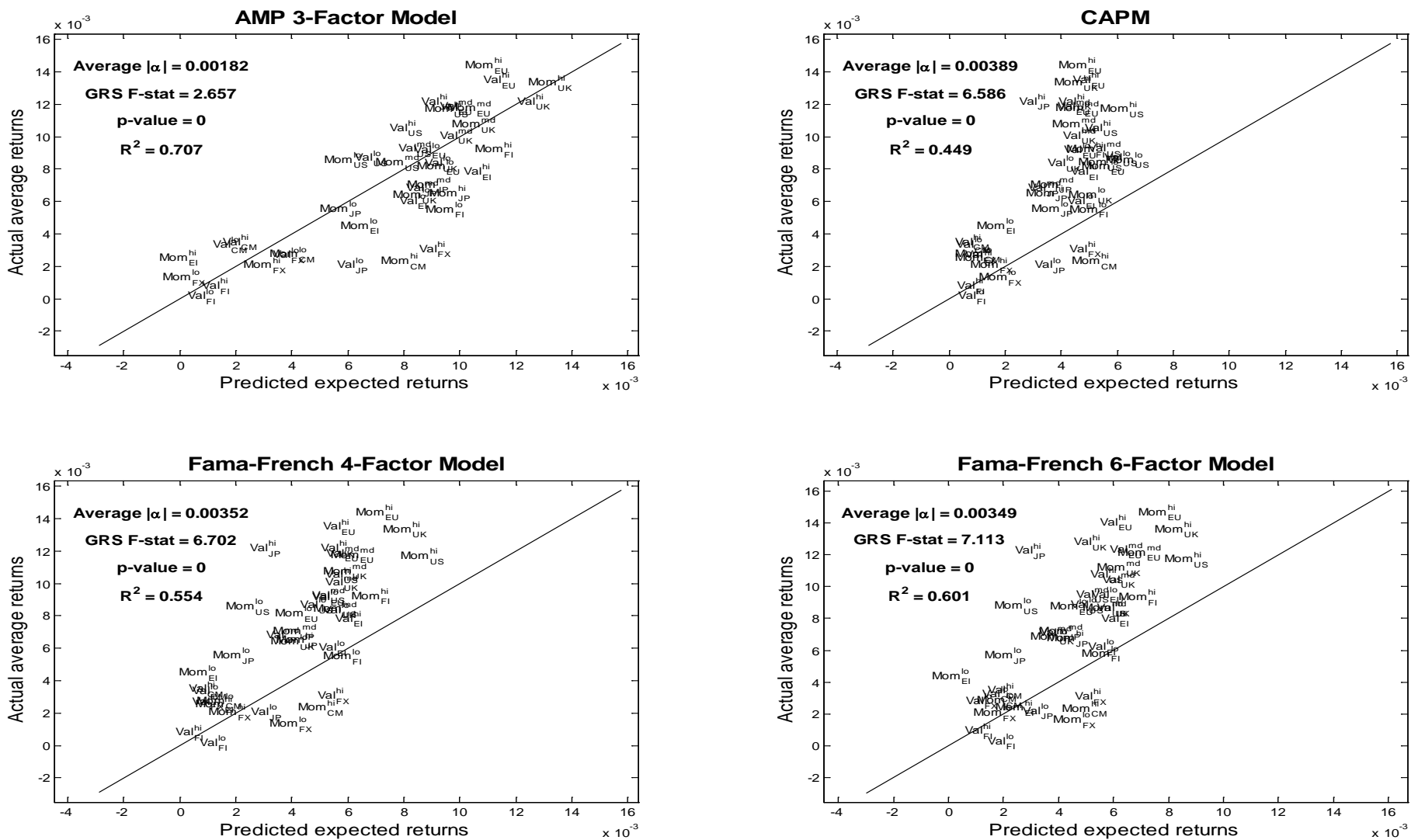
PANEL B: Fama-French 25 Size-Value and 25 Size-Momentum Portfolios (U.S. Stocks)
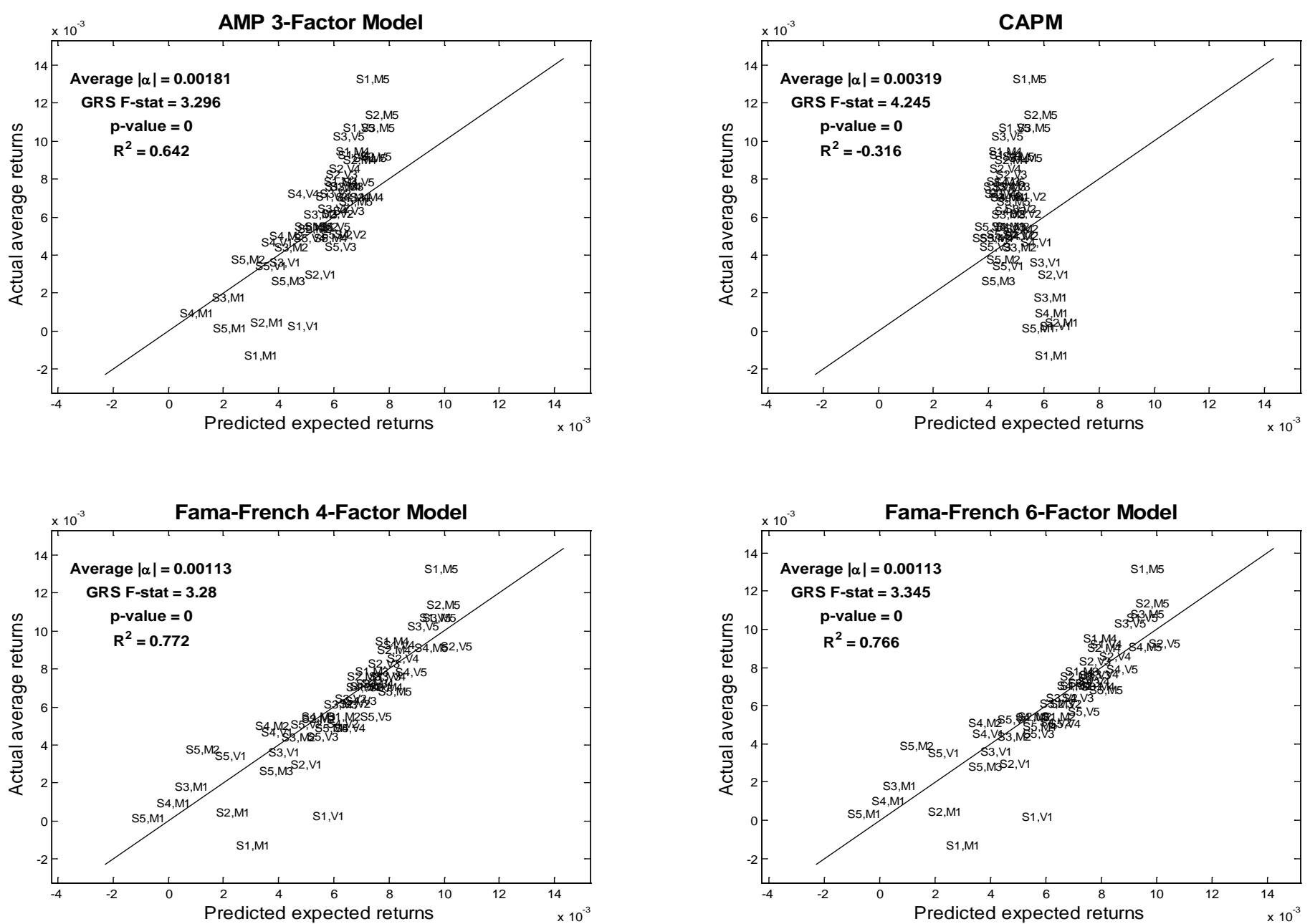


\section{Table I:}

\section{Performance of Value and Momentum Portfolios Across Markets and Asset Classes}

Reported are the average raw excess (of the 1 month U.S. T-bill rate) return, $t$-statistic of the average return (in parentheses), standard deviation of returns, and Sharpe ratio of each value, momentum, and equal weighted 50/50 value and momentum combination strategy in each market and asset class we study: U.S. stocks, U.K. stocks, Europe stocks, Japan stocks, country index futures, currencies, fixed income government bonds, and commodities. Also reported are the intercepts or alphas, and their $t$-statistics (in parentheses) from a time series regression of each return series on the return of the market index for each asset class. The market index for the stock strategies is the MSCI equity index for each country for all of the individual stock strategies. The MSCI world index is used as the benchmark for strategies of country index futures. For currencies, fixed income, and commodities, the benchmark index is an equal weighted basket of the securities in each asset class. In each market or asset class the universe of securities is first sorted by either value or momentum and then broken into three equal groups based on those sorts to form three portfolios_low, middle, and high_corresponding to portfolios P1, P2, and P3, respectively. For individual stock strategies (Panel A), stocks within the three portfolios are value weighted by their beginning of month capitalization and for non-stock asset classes (Panel B), securities are equal weighted in the portfolios. Also reported is the high minus low spread in returns (P3-P1) as well as a rank weighted factor portfolio ("Factor") which is a zero-investment portfolio that weights each asset in proportion to its rank based on either value or momentum, following equation (1). The 50/50 value/momentum combination strategies are an equal weighted average of the value and momentum spread strategies (P3-P1 and Factor) for each market/asset class. Results are also reported for an average of all individual stock strategies across all stock markets (“Global stocks”), across all non-stock asset classes ("Global other asset classes”), and across all markets and asset classes ("Global all asset classes”), where average return series are computed using equal volatility weights across the markets and asset classes to account for the large differences in volatility across asset classes (e.g., fixed income versus commodities). Panel C also reports results for alternative measures of value for fixed income securities. Finally, the last row for each asset class reports the correlation between value and momentum zero cost residual returns from the benchmark in each market or asset class. Statistics are computed from monthly return series but are reported as annualized numbers.

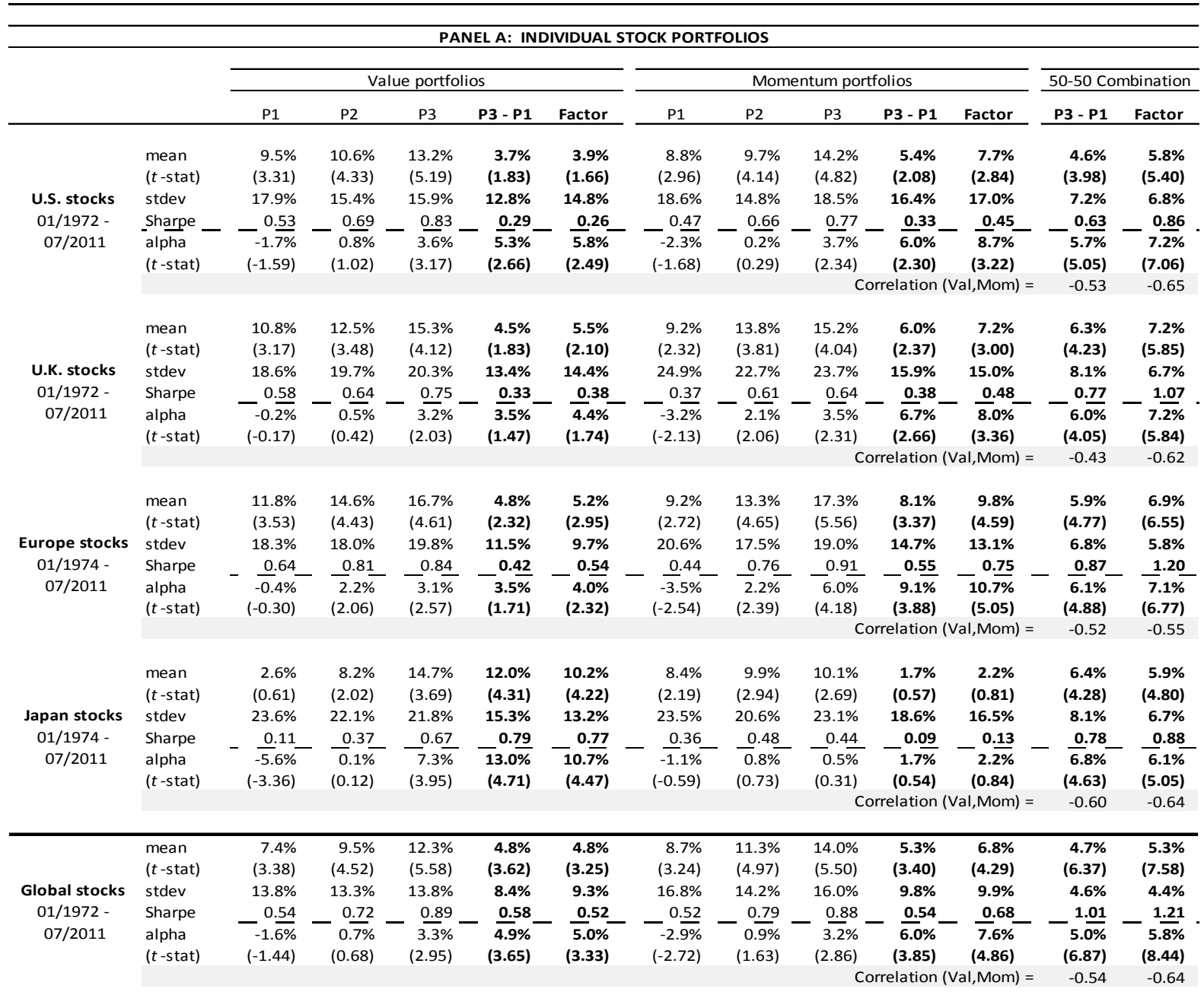




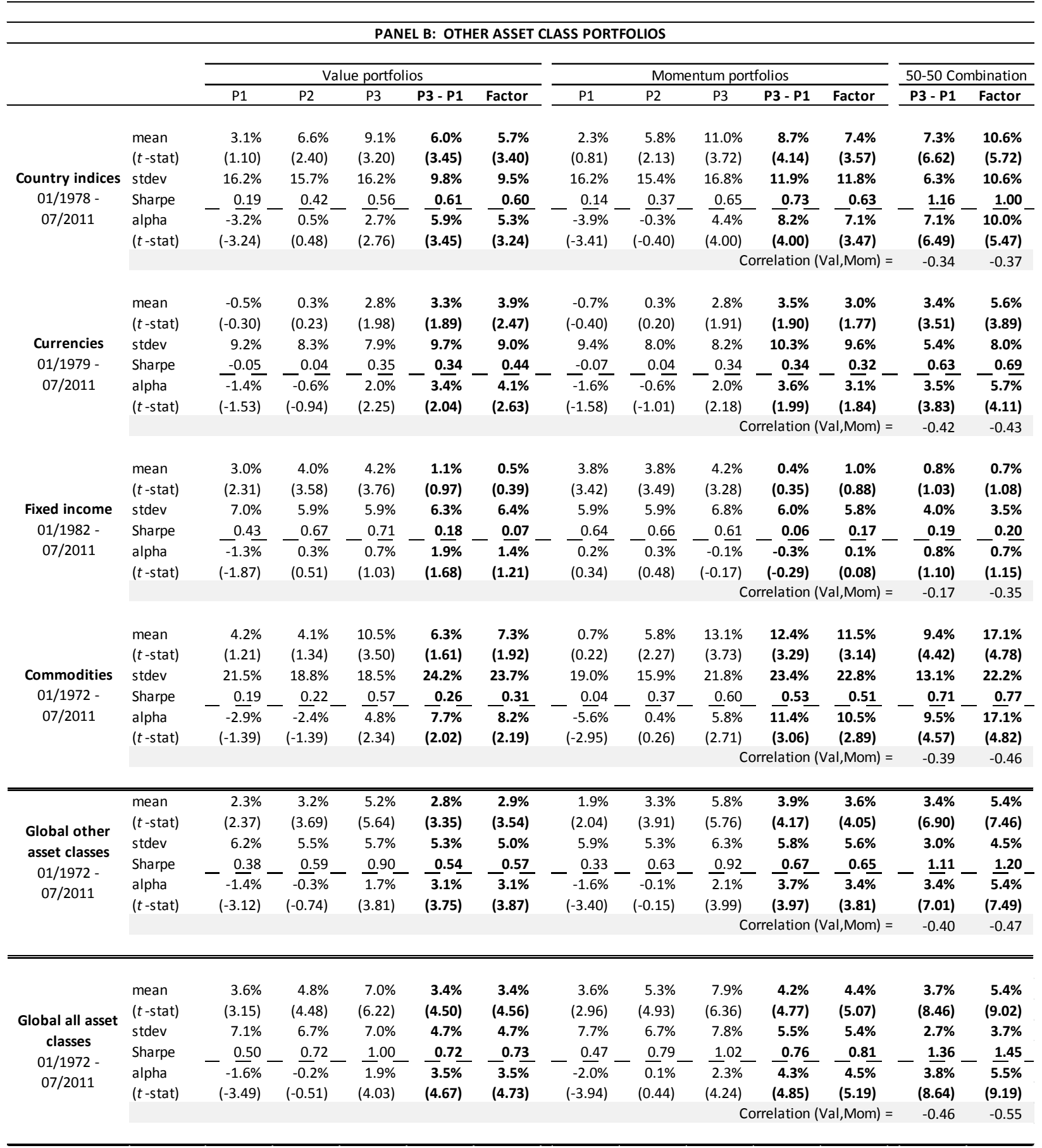




\begin{tabular}{|c|c|c|c|c|c|c|c|c|}
\hline \multicolumn{9}{|c|}{ PANEL C: ALTERNATIVE VALUE MEASURES FOR FIXED INCOME } \\
\hline \multirow{3}{*}{$\begin{array}{c}\text { Fixed income } \\
01 / 1983- \\
07 / 2011 \\
\end{array}$} & & & & & & & & \\
\hline & & \multicolumn{5}{|c|}{ Value portfolios } & \multicolumn{2}{|c|}{ 50-50 Combination } \\
\hline & & P1 & $\mathrm{P} 2$ & P3 & P3 - P1 & Factor & P3 - P1 & Factor \\
\hline \multirow{7}{*}{$\begin{array}{l}\text { Value = } 5 \text { year } \\
\text { yield change } \\
\text { (yield - yield } 5 \\
\text { years ago) }\end{array}$} & mean & $3.0 \%$ & $4.0 \%$ & $4.2 \%$ & $1.1 \%$ & $0.5 \%$ & $0.8 \%$ & $0.7 \%$ \\
\hline & ( $t$-stat) & $(2.31)$ & $(3.58)$ & $(3.76)$ & $(0.97)$ & (0.39) & $(1.03)$ & $(1.08)$ \\
\hline & stdev & $7.0 \%$ & $5.9 \%$ & $5.9 \%$ & $6.3 \%$ & $6.4 \%$ & $4.0 \%$ & $3.5 \%$ \\
\hline & Sharpe & 0.43 & $0 . \underline{67}$ & 0.71 & 0.18 & $\underline{0.07}$ & 0.19 & 0.20 \\
\hline & alpha & $-1.3 \%$ & $0 . \overline{3 \%}$ & $0 . \overline{7 \%}$ & $1 . \overline{9 \%}$ & $\overline{1.4 \%}$ & $0.8 \%$ & $0.7 \%$ \\
\hline & ( $t$-stat) & $(-1.87)$ & $(-0.51)$ & $(1.03)$ & (1.68) & (1.21) & (1.10) & (1.15) \\
\hline & \multicolumn{6}{|c|}{ Correlation $(\mathrm{Val}, \mathrm{Mom})=$} & -0.17 & -0.35 \\
\hline \multirow{7}{*}{$\begin{array}{c}\text { Value }=\text { real } \\
\text { bond yield } \\
\text { (10 year yield - } \\
5 \text { year inflation } \\
\text { forecast) }\end{array}$} & mean & $0.9 \%$ & $2.1 \%$ & $2.9 \%$ & $2.0 \%$ & $1.9 \%$ & $0.9 \%$ & $1.4 \%$ \\
\hline & (t-stat) & $(1.84)$ & (3.36) & $(4.17)$ & (3.78) & (3.58) & (2.44) & $(2.63)$ \\
\hline & stdev & $2.6 \%$ & $3.2 \%$ & $3.6 \%$ & $2.7 \%$ & $2.8 \%$ & $1.9 \%$ & $2.9 \%$ \\
\hline & Sharpe & 0.36 & 0.65 & 0.81 & 0.73 & $\underline{0.70}$ & 0.46 & $0 . \underline{49}$ \\
\hline & alpha & $-0.6 \%$ & $-0.1 \%$ & $0 . \overline{4 \%}$ & $1 . \overline{0 \%}$ & $\overline{0.9 \%}$ & $0.4 \%$ & $0.6 \%$ \\
\hline & (t-stat) & $(-2.02)$ & $(-0.15)$ & $(1.09)$ & $(2.36)$ & (2.09) & (1.17) & $(1.25)$ \\
\hline & \multicolumn{6}{|c|}{ Correlation $($ Val,Mom) $=$} & -0.09 & -0.03 \\
\hline \multirow{7}{*}{$\begin{array}{l}\text { Value }=\text { term } \\
\text { spread } \\
\text { (10 year yield - } \\
\text { short rate) }\end{array}$} & mean & $0.8 \%$ & $1.5 \%$ & $2.3 \%$ & $1.5 \%$ & $1.7 \%$ & $0.6 \%$ & $1.1 \%$ \\
\hline & (t-stat) & $(1.25)$ & (2.37) & $(3.60)$ & (2.69) & (3.22) & (1.47) & (1.96) \\
\hline & stdev & $3.2 \%$ & $3.2 \%$ & $3.2 \%$ & $2.8 \%$ & $2.5 \%$ & $2.2 \%$ & $2.9 \%$ \\
\hline & Sharpe & $\underline{0.25}$ & 0.48 & 0.73 & 0.55 & 0.65 & $\underline{0.28}$ & $\underline{0.37}$ \\
\hline & alpha & $-1.2 \%$ & $-0.7 \%$ & $0.1 \%$ & $1.3 \%$ & $1.4 \%$ & $0.5 \%$ & $0.8 \%$ \\
\hline & (t-stat) & $(-3.03)$ & $(-1.79)$ & $(0.28)$ & (2.78) & (3.31) & $(1.22)$ & (1.55) \\
\hline & \multicolumn{6}{|c|}{ Correlation $($ Val, Mom $)=$} & 0.22 & 0.28 \\
\hline \multirow{7}{*}{$\begin{array}{c}\text { Value }= \\
\text { composite } \\
\text { average of all } \\
\text { three measures }\end{array}$} & mean & $0.3 \%$ & $1.6 \%$ & $3.0 \%$ & $2.6 \%$ & $2.9 \%$ & $1.3 \%$ & $2.2 \%$ \\
\hline & ( $t$-stat) & $(0.58)$ & $(2.56)$ & $(4.63)$ & (4.88) & (5.89) & (3.17) & $(4.30)$ \\
\hline & stdev & $3.2 \%$ & $3.4 \%$ & $3.4 \%$ & $2.9 \%$ & $2.6 \%$ & $2.1 \%$ & $2.7 \%$ \\
\hline & Sharpe & $-\quad \underline{0.11}$ & $\underline{0.48}$ & 0.87 & 0.91 & 1.10 & 0.59 & 0.81 \\
\hline & alpha & $-1 . \overline{5} \%$ & $-\overline{0.3} \%$ & $\overline{0.8 \%}$ & $2.3 \%$ & $2.6 \%$ & $\overline{1.0} \%$ & $\overline{1.8} \%$ \\
\hline & $(t$-stat) & $(-4.01)$ & $(-0.80)$ & $(2.25)$ & $(4.40)$ & (5.48) & $(2.55)$ & $(3.66)$ \\
\hline & \multicolumn{6}{|c|}{ Correlation $(\mathrm{Val}, \mathrm{Mom})=$} & 0.03 & 0.04 \\
\hline
\end{tabular}




\section{Table II:}

\section{Correlation of Value and Momentum Strategies Across Markets and Asset Classes}

Reported are the average correlations among all value and momentum strategies across markets and asset classes. Panel A reports the correlations of the average return series, where we first compute the average return series for a group (e.g., all individual stock value strategies across all markets and all non-stock value strategies across all non-stock asset classes) and then compute the correlation between the two average return series. The diagonal elements in Panel A are computed as the average correlation between each market's return series and the average of all other return series in other markets, excluding the market itself. For example, we compute the correlation between U.S. stock value returns and the average value returns across stocks in the U.K., Europe, and Japan. We then do the same for U.K. value returns with the average of value returns across the U.S., Europe, and Japan, and repeat this for Europe value and Japan value strategies as well. We then take the average of these correlations and report them as the first diagonal element of Panel A. We exclude the correlation of each strategy with itself (e.g., removing the 1's) and exclude the correlation of each strategy with all other strategies within the same market (e.g., exclude U.S. momentum when examining U.S. value's correlation with other strategies). Correlations are computed from quarterly returns to mitigate the influence of non-synchronous trading across markets. Panel B breaks down the correlations of the individual stock value and momentum strategies series with each of the non-stock value and momentum strategies. An F-test for the joint significance of the individual correlations within each group is performed, where $*$ indicates the correlations are significantly different from zero.

\begin{tabular}{|c|c|c|c|c|c|c|c|c|}
\hline & \multicolumn{4}{|c|}{ PANEL A: CORRELATION OF AVERAGE RETURN SERIES } & & & & \\
\hline & Stock value & $\begin{array}{l}\text { Non-stock } \\
\text { value }\end{array}$ & $\begin{array}{c}\text { Stock } \\
\text { momentum }\end{array}$ & $\begin{array}{l}\text { Non-stock } \\
\text { momentum }\end{array}$ & & & & \\
\hline Stock value & $0.68 *$ & 0.15 & $-0.53^{*}$ & $-0.26 *$ & & & & \\
\hline Non-stock value & & 0.07 & $-0.16^{*}$ & $-0.13^{*}$ & & & & \\
\hline Stock momentum & & & $0.65^{*}$ & $0.37 *$ & & & & \\
\hline \multirow[t]{3}{*}{ Non-stock momentum } & & & & $0.21 *$ & & & & \\
\hline & \multicolumn{8}{|c|}{ PANEL B: CORRELATION OF AVERAGE STOCK SERIES WITH EACH NON-STOCK SERIES } \\
\hline & $\begin{array}{c}\text { Country Index } \\
\text { value }\end{array}$ & $\begin{array}{c}\text { Currency } \\
\text { value }\end{array}$ & $\begin{array}{c}\text { Fixed Income } \\
\text { value }\end{array}$ & $\begin{array}{c}\text { Commodity } \\
\text { value }\end{array}$ & $\begin{array}{c}\text { Country Index } \\
\text { momentum }\end{array}$ & $\begin{array}{c}\text { Currency } \\
\text { momentum }\end{array}$ & $\begin{array}{c}\text { Fixed Income } \\
\text { momentum }\end{array}$ & $\begin{array}{l}\text { Commodity } \\
\text { momentum }\end{array}$ \\
\hline Global Stock value & $0.27 *$ & $0.13^{*}$ & -0.03 & 0.01 & $-0.28 *$ & $-0.20 *$ & -0.01 & $-0.17^{*}$ \\
\hline Global Stock momentum & $-0.19 *$ & $-0.12 *$ & -0.05 & -0.06 & $0.40 *$ & $0.28 *$ & 0.09 & $0.20 *$ \\
\hline
\end{tabular}




\section{Table III:}

\section{Macroeconomic Risk Exposures}

Reported are coefficient estimates, $t$-statistics (in parentheses), and $R$-squares from time series regressions of the value and momentum strategy returns in U.S. individual stocks, Global individual stocks (across the U.S., U.K., Europe, and Japan), non-stock asset classes, and across all asset classes (stock and non-stock) on various measures of macroeconomic risks. The macroeconomic variables are a measure of long-run consumption growth, which is the three year future growth rate in per capita nondurable real consumption (quarterly), a recession dummy ( 0 = peak, 1 = trough) obtained from NBER dates for the U.S. and ECRI dates outside of the U.S., contemporaneous GDP growth rates (from NIPA for the U.S. and from ECRI outside of the U.S.), the MSCI world equity index return in excess of the U.S. T-bill rate, and the bond factor returns of Fama and French (1993) TERM and DEF, which represent the term spread on U.S. government bonds and the default spread between U.S. corporate bonds and U.S. Treasuries, respectively. For U.S. stock return regressions, only U.S. macroeconomic variables are used as independent variables. For the global, non-stock, and all asset class return regressions, the macroeconomic variables are averaged across all countries (U.S., U.K., Europe, and Japan) weighting each country in proportion to its GDP. The intercepts from the regressions are not reported for brevity.

\begin{tabular}{|c|c|c|c|c|c|c|c|c|c|c|}
\hline & & \multicolumn{2}{|c|}{ U.S. stocks } & & \multicolumn{2}{|c|}{ Global stocks } & \multicolumn{2}{|c|}{ Non-stock assets } & \multicolumn{2}{|c|}{ All asset classes } \\
\hline & & Value & Momentum & & Value & Momentum & Value & Momentum & Value & Momentum \\
\hline & Long-run consumption growth & $\begin{array}{r}0.0004 \\
(2.06)\end{array}$ & $\begin{array}{r}0.0001 \\
(0.33)\end{array}$ & & $\begin{array}{r}0.0001 \\
(0.93)\end{array}$ & $\begin{array}{r}0.0001 \\
(0.92)\end{array}$ & $\begin{array}{r}0.0001 \\
(0.68)\end{array}$ & $\begin{array}{r}0.0001 \\
(0.03)\end{array}$ & $\begin{array}{r}0.0001 \\
(1.01)\end{array}$ & $\begin{array}{r}0.0001 \\
(0.43)\end{array}$ \\
\hline & Recession dummy & $\begin{array}{r}-0.0068 \\
(-1.06)\end{array}$ & $\begin{array}{r}-0.0056 \\
(-0.73)\end{array}$ & Global values & $\begin{array}{r}0.0037 \\
(0.66)\end{array}$ & $\begin{array}{r}-0.0044 \\
(-0.75)\end{array}$ & $\begin{array}{r}0.0045 \\
(1.48)\end{array}$ & $\begin{array}{r}-0.0081 \\
(-2.44)\end{array}$ & $\begin{array}{r}0.0043 \\
(1.55)\end{array}$ & $\begin{array}{r}-0.0072 \\
(-2.26)\end{array}$ \\
\hline $\begin{array}{c}\text { U.S. values } \\
\text { for }\end{array}$ & GDP growth & $\begin{array}{r}-0.0050 \\
(-1.75)\end{array}$ & $\begin{array}{r}0.0019 \\
(0.57)\end{array}$ & $\begin{array}{c}\text { for } \\
\text { independent }\end{array}$ & $\begin{array}{r}-0.0011 \\
(-0.39)\end{array}$ & $\begin{array}{r}0.0023 \\
(0.80)\end{array}$ & $\begin{array}{r}-0.0005 \\
(-0.32)\end{array}$ & $\begin{array}{r}-0.0034 \\
(-2.08)\end{array}$ & $\begin{array}{r}-0.0006 \\
(-0.45)\end{array}$ & $\begin{array}{r}-0.0020 \\
(-1.29)\end{array}$ \\
\hline $\begin{array}{c}\text { independent } \\
\text { variables }\end{array}$ & Market return & $\begin{array}{r}-0.3435 \\
(-7.46)\end{array}$ & $\begin{array}{r}0.0219 \\
(0.40)\end{array}$ & $\begin{array}{c}\text { variables } \\
\text { (GDP- }\end{array}$ & $\begin{array}{r}-0.0615 \\
(-1.41)\end{array}$ & $\begin{array}{r}-0.0709 \\
(-1.55)\end{array}$ & $\begin{array}{r}0.0101 \\
(0.44)\end{array}$ & $\begin{array}{r}-0.0083 \\
(-0.32)\end{array}$ & $\begin{array}{r}-0.0068 \\
(-0.32)\end{array}$ & $\begin{array}{r}-0.0231 \\
(-0.93)\end{array}$ \\
\hline & TERM & $\begin{array}{r}0.2038 \\
(2.64)\end{array}$ & $\begin{array}{r}-0.0234 \\
(-0.25)\end{array}$ & weighted) & $\begin{array}{r}0.0523 \\
(1.04)\end{array}$ & $\begin{array}{r}0.0141 \\
(0.27)\end{array}$ & $\begin{array}{r}-0.0885 \\
(-3.30)\end{array}$ & $\begin{array}{r}0.0370 \\
(1.25)\end{array}$ & $\begin{array}{r}-0.0551 \\
(-2.23)\end{array}$ & $\begin{array}{r}0.0316 \\
(1.11)\end{array}$ \\
\hline & DEF & $\begin{array}{r}0.7439 \\
(5.25)\end{array}$ & $\begin{array}{r}-0.7733 \\
(-4.57)\end{array}$ & & $\begin{array}{r}0.2650 \\
(2.86)\end{array}$ & $\begin{array}{r}-0.3752 \\
(-3.87)\end{array}$ & $\begin{array}{r}-0.0510 \\
(-1.03)\end{array}$ & $\begin{array}{r}-0.0787 \\
(-1.44)\end{array}$ & $\begin{array}{r}0.0240 \\
(0.53)\end{array}$ & $\begin{array}{r}-0.1490 \\
(-2.84)\end{array}$ \\
\hline & $R$-square & $13.1 \%$ & $5.9 \%$ & & $2.3 \%$ & $6.4 \%$ & $3.4 \%$ & $2.9 \%$ & $2.9 \%$ & $4.7 \%$ \\
\hline
\end{tabular}




\section{Table IV: \\ Liquidity Risk Exposures}

Reported are coefficient estimates and $t$-statistics (in parentheses) from time series regressions of the value and momentum strategy returns across all asset classes on a host of liquidity shocks to measure liquidity risk exposure. The liquidity shocks are estimated as residuals from an $\operatorname{AR}(2)$ of a set of funding liquidity variables and market liquidity variables. The funding liquidity variables are the Treasury-Eurodollar (TED) spread, the LIBOR minus term repo spread, and the interest rate swap minus T-bill spread. We also compute a principal component weighted average index of the funding liquidity shocks ("Funding liquidity PC") from the correlation matrix of the liquidity shocks and use this as another regressor. The market liquidity variables are the on-therun minus off-the-run 10 year government Treasury note spread, the Pastor and Stambaugh (2003) liquidity measure, and the illiquidity measure of Acharya and Pedersen (2005). All variables are signed so that they represent liquidity, hence we take the negative of the Acharya and Pedersen (2005) measure. A principal component weighted average index of the market liquidity shocks from the correlation matrix of the liquidity shocks is also used. Finally, we also use a principal component weighted average index of all liquidity shocks (funding and market) from the correlation matrix of those liquidity shocks as a regressor. Panel A reports results using only U.S. liquidity risk variables and Panel B reports results using global liquidity risk measures, where the global liquidity risks are estimated by taking the average of all the liquidity measures across countries-U.S., U.K., Europe, and Japan - weighted by the principal component of each country's contribution to the correlation matrix of each liquidity measure across the four markets. TED spreads, LIBOR — term repo rates, swap — T-bill rates, and on-the-run minus off-the-run spreads for each country are quoted using each country's government bond rates. The Pastor and Stambaugh (2003) and Acharya and Pedersen (2005) measures are computed outside of the U.S. following the same methodology outlined in those papers to individual stocks in each of the other markets-U.K., Europe, and Japan. All regressions include the set of macroeconomic variables from Table III as controls (coefficient estimates not reported). The intercepts from the regressions are not reported for brevity. 


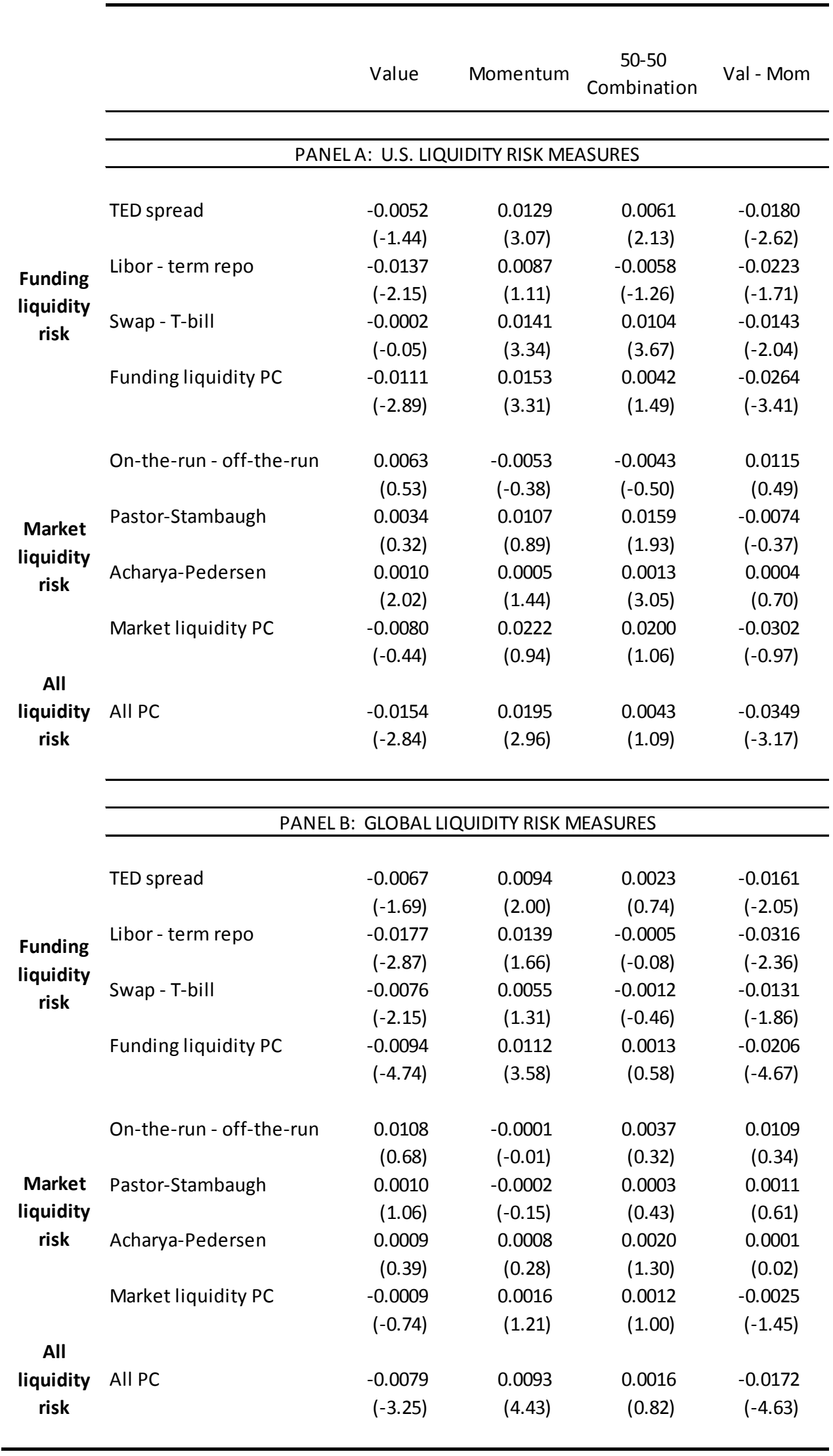




\section{Table V:}

\section{Cross-Sectional Asset Pricing Tests of Global Value and Momentum Strategies}

Reported are Fama-MacBeth (1973) regression coefficient estimates and $t$-statistics of the cross section of average returns to the 48 value and momentum portfolios across the eight markets and asset classes we consider are reported. The dependent variable is the cross section of returns on the low, middle, and high value and momentum portfolios of individual stocks in the U.S., U.K., Europe, Japan, country index futures, currencies, government bonds, and commodities. The regressors are beta estimates of these portfolios with respect to the "All” liquidity risk measure from Table IV (the principal component weighted average index of all liquidity shock measures across all markets globally), GDP growth, long-run consumption growth, the MSCI world index ("market"), the "value everywhere" factor, consisting of an equal volatility weighted average of value strategies across all markets and asset classes and a "momentum everywhere" factor defined similarly. The last four rows report results using only funding and market liquidity variables separately to measure liquidity risk, where the principal component weighted average index of funding and market liquidity shocks are used separately to measure funding liquidity risk and market liquidity risk. Betas are estimated in a univariate regression with respect to each of the factors using a rolling window of the past 60 months of returns, with a Dimson correction to account for possible non-synchronous trading effects, where each portfolio's returns are estimated on the contemporaneous value of the factor plus two month lags of factor realizations and the beta is the sum of the three coefficients on the contemporaneous, one and two month lags of the factor. The cross-sectional regressions are estimated in the style of Fama and MacBeth (1973), where the cross section of returns on the 48 portfolios are regressed each month on the cross section of beta estimates and the time series mean and $t$-statistics of the monthly regression coefficients are reported.

\begin{tabular}{|c|c|c|c|c|c|c|c|}
\hline \multicolumn{8}{|c|}{ Fama-MacBeth Cross-Sectional Regressions } \\
\hline$\beta_{\text {Liquidity risk }}$ & $\beta_{\mathrm{GDP} \text { growth }}$ & $\beta_{\text {LRCG }}$ & $\beta_{\text {TERM }}$ & $\beta_{\text {DEF }}$ & $\beta_{\mathrm{Mkt}}$ & $\beta_{\text {Value }}$ & $\beta_{\text {Momentum }}$ \\
\hline \multicolumn{8}{|c|}{ Dependent variable: Cross-section of 48 value and momentum portfolios } \\
\hline \multicolumn{8}{|l|}{$\begin{array}{r}0.0024 \\
(3.05)\end{array}$} \\
\hline & $\begin{array}{r}0.0003 \\
(0.43)\end{array}$ & $\begin{array}{r}0.0005 \\
(0.42)\end{array}$ & $\begin{array}{r}0.0021 \\
(2.19)\end{array}$ & $\begin{array}{r}0.0023 \\
(2.18)\end{array}$ & & & \\
\hline $\begin{array}{r}0.0023 \\
(2.29)\end{array}$ & $\begin{array}{r}-0.0001 \\
(-0.13)\end{array}$ & $\begin{array}{r}0.0012 \\
(1.01)\end{array}$ & $\begin{array}{r}0.0014 \\
(1.59)\end{array}$ & $\begin{array}{r}0.0001 \\
(0.11)\end{array}$ & & & \\
\hline $\begin{array}{r}0.0016 \\
(1.38) \\
\end{array}$ & $\begin{array}{r}0.0018 \\
(2.87) \\
\end{array}$ & $\begin{array}{r}-0.0001 \\
-(-0.03) \\
\end{array}$ & $\begin{array}{r}0.0033 \\
(2.87) \\
\end{array}$ & $\begin{array}{r}0.0014 \\
-(1.12) \\
\end{array}$ & $\begin{array}{r}-0.0006 \\
-(-0.38) \\
\end{array}$ & $\begin{array}{r}0.0031 \\
-(3.96) \\
\end{array}$ & $\begin{array}{r}0.003 \\
(3.53) \\
\end{array}$ \\
\hline \multicolumn{8}{|c|}{ Funding liquidity variables only } \\
\hline $\begin{array}{r}0.0022 \\
(2.06)\end{array}$ & $\begin{array}{r}-0.0002 \\
(-0.30)\end{array}$ & $\begin{array}{r}0.0019 \\
(1.45)\end{array}$ & $\begin{array}{r}0.0011 \\
(1.05)\end{array}$ & $\begin{array}{r}0.0015 \\
(1.30)\end{array}$ & & & \\
\hline $\begin{array}{r}0.0012 \\
(1.80)\end{array}$ & $\begin{array}{r}0.0019 \\
(3.28)\end{array}$ & $\begin{array}{r}0.0003 \\
(0.17)\end{array}$ & $\begin{array}{r}0.0027 \\
(2.19)\end{array}$ & $\begin{array}{r}0.0011 \\
(0.84)\end{array}$ & $\begin{array}{r}0.0008 \\
(0.58)\end{array}$ & $\begin{array}{r}0.0034 \\
(4.40)\end{array}$ & $\begin{array}{r}0.0031 \\
(3.50)\end{array}$ \\
\hline \multicolumn{8}{|c|}{ Market liquidity variables only } \\
\hline $\begin{array}{r}0.0001 \\
(0.07)\end{array}$ & $\begin{array}{r}0.0003 \\
(0.48)\end{array}$ & $\begin{array}{r}0.0005 \\
(0.44)\end{array}$ & $\begin{array}{r}0.0021 \\
(2.67)\end{array}$ & $\begin{array}{r}0.0022 \\
(2.63)\end{array}$ & & & \\
\hline $\begin{array}{r}-0.0013 \\
(-0.88)\end{array}$ & $\begin{array}{r}0.0019 \\
(3.19)\end{array}$ & $\begin{array}{l}-0.001 \\
(-0.77)\end{array}$ & $\begin{array}{r}0.0045 \\
(5.05)\end{array}$ & $\begin{array}{l}0.003 \\
(2.73)\end{array}$ & $\begin{array}{r}0.0004 \\
(0.31)\end{array}$ & $\begin{array}{r}0.0038 \\
(5.94)\end{array}$ & $\begin{array}{l}0.004 \\
(5.82)\end{array}$ \\
\hline
\end{tabular}


Table VI:

Time Series Asset Pricing Tests of Global Value and Momentum Strategies

Panel A reports results from time series asset pricing tests of the 48 value and momentum portfolios across markets and asset classes on a set of global and U.S. only asset pricing models. The global models include a global CAPM (MSCI World index), a two-factor model of the global market portfolio plus a factor mimicking portfolio for a global liquidity risk factor (estimated from the cross-sectional regression coefficients in Table IV), a six-factor model that includes the global market and factor mimicking portfolios for global liquidity risk, GDP growth, long-run consumption growth (each estimated from the cross-sectional regression coefficients in Table IV), and TERM and DEF, the three-factor AMP model of the global market plus all-asset-class value and momentum factors, as well as two-factor versions that include the market and just one of either all-asset-class value or momentum. The U.S. only factor models include the U.S. CAPM (U.S. CRSP value weighted index), Fama and French three-factor model that adds size and value factors to the market, Fama-French four-factor model that adds a momentum factor, and Fama-French six-factor model that adds TERM and DEF as additional factors. Panel B reports results for time series tests using the same asset pricing models on the 25 Fama-French size and BE/ME portfolios and 25 size and momentum portfolios that pertain only to U.S. individual stocks. Panel C reports results for 13 hedge fund indices obtained from DJCS and HFRI. All panels report the GRS (1989) F-statistic on the joint significance of the alphas under each model from the time series regressions, the $p$-value of the $F$-statistic, the average absolute alpha, the average time series $R^{2}$, the cross-sectional $R^{2}$ of average returns on the predicted expected return from each model, and the percentage of the covariance matrix captured by each model using the Eig\% metric of Moskowitz (2003) and described in Section IV. Regressions are estimated from monthly returns.

\begin{tabular}{|c|c|c|c|c|c|c|c|}
\hline & Asset Pricing Models & GRS F-stat & $p$-value & average $|\alpha|$ & $\begin{array}{c}\text { average } \\
\text { time-series } \\
R^{2} \\
\end{array}$ & $\begin{array}{c}\text { Cross- } \\
\text { sectional } R^{2}\end{array}$ & $\begin{array}{c}\% \text { of } \\
\text { covariances }\end{array}$ \\
\hline & \multicolumn{7}{|c|}{ PANEL A: 48 Value and Momentum Portfolios Globally Across Asset Classes } \\
\hline & Mkt (Global CAPM) & 6.02 & 0.000 & 0.0035 & 0.40 & 0.52 & $57 \%$ \\
\hline Global & Mkt, $\mathrm{FP}_{\text {liq risk }}$ & 5.02 & 0.000 & 0.0031 & 0.48 & 0.54 & $64 \%$ \\
\hline Asset & Mkt, $\mathrm{FP}_{\text {liq risk, }} \mathrm{FP}_{\mathrm{GDPg}}, \mathrm{FP}_{\mathrm{LRCG}}, \mathrm{TERM}, \mathrm{DEF}$ & 4.09 & 0.000 & 0.0027 & 0.59 & 0.56 & $80 \%$ \\
\hline \multirow{3}{*}{$\begin{array}{l}\text { Pricing } \\
\text { Factors }\end{array}$} & Mkt, VAL $L_{\text {everywhere, }} \mathrm{MOM}_{\text {everywhere }}$ & 2.66 & 0.000 & 0.0018 & 0.68 & 0.72 & $74 \%$ \\
\hline & Mkt, $V A L_{\text {everywhere }}$ & 3.72 & 0.000 & 0.0028 & 0.42 & 0.43 & $68 \%$ \\
\hline & Mkt, MOM everywhere & 3.80 & 0.000 & 0.0022 & 0.42 & 0.57 & $70 \%$ \\
\hline \multirow{4}{*}{$\begin{array}{l}\text { U.S. } \\
\text { Asset } \\
\text { Pricing } \\
\text { Factors }\end{array}$} & Mkt (U.S. CAPM) & 6.59 & 0.000 & 0.0039 & 0.30 & 0.44 & $47 \%$ \\
\hline & FF 3-Factor & 7.18 & 0.000 & 0.0036 & 0.31 & 0.50 & $53 \%$ \\
\hline & FF 4-Factor & 6.70 & 0.000 & 0.0035 & 0.33 & 0.55 & $63 \%$ \\
\hline & FF 6-factor & 7.11 & 0.000 & 0.0035 & 0.39 & 0.62 & $64 \%$ \\
\hline
\end{tabular}




\begin{tabular}{|c|c|c|c|c|c|c|c|}
\hline \multirow{3}{*}{ Global } & Asset Pricing Models & GRS F-stat & $p$-value & average $|\alpha|$ & $\begin{array}{c}\text { average } \\
\text { time-series } \\
R^{2}\end{array}$ & $\begin{array}{c}\text { Cross- } \\
\text { sectional } R^{2}\end{array}$ & $\begin{array}{c}\% \text { of } \\
\text { covariances }\end{array}$ \\
\hline & \multicolumn{7}{|c|}{ PANEL B: Fama-French 25 Size-Value and 25 Size-Momentum Portfolios } \\
\hline & Mkt (Global CAPM) & 4.09 & 0.000 & 0.0030 & 0.41 & 0.20 & $48 \%$ \\
\hline Asset & Mkt, $\mathrm{FP}_{\text {liq risk }}$ & 4.12 & 0.000 & 0.0030 & 0.42 & 0.20 & $49 \%$ \\
\hline \multirow{2}{*}{$\begin{array}{l}\text { Pricing } \\
\text { Factors }\end{array}$} & Mkt, $\mathrm{FP}_{\text {liq risk, }}, \mathrm{FP}_{\mathrm{GDPg}}, \mathrm{FP}_{\mathrm{LRCG}}, \mathrm{TERM}, \mathrm{DEF}$ & 4.76 & 0.000 & 0.0035 & 0.57 & 0.38 & $61 \%$ \\
\hline & Mkt, $\mathrm{VAL}_{\text {everywhere, }} \mathrm{MOM}_{\text {everywhere }}$ & 3.22 & 0.000 & 0.0019 & 0.70 & 0.68 & $66 \%$ \\
\hline \multirow{4}{*}{$\begin{array}{c}\text { U.S. } \\
\text { Asset } \\
\text { Pricing } \\
\text { Factors }\end{array}$} & Mkt (U.S. CAPM) & 4.25 & 0.000 & 0.0032 & 0.73 & 0.17 & $82 \%$ \\
\hline & FF 3-Factor & 3.81 & 0.000 & 0.0023 & 0.87 & 0.30 & $93 \%$ \\
\hline & FF 4-Factor & 3.28 & 0.000 & 0.0011 & 0.91 & 0.77 & $97 \%$ \\
\hline & FF 6-factor & 3.35 & 0.000 & 0.0011 & 0.91 & 0.77 & $97 \%$ \\
\hline \multirow{5}{*}{$\begin{array}{l}\text { Global } \\
\text { Asset } \\
\text { Pricing } \\
\text { Factors }\end{array}$} & \multicolumn{7}{|c|}{ PANEL C: 13 Hedge Fund Indexes } \\
\hline & Mkt (Global CAPM) & 12.14 & 0.000 & 0.0032 & 0.30 & 0.20 & $43 \%$ \\
\hline & Mkt, $\mathrm{FP}_{\text {liq risk }}$ & 12.36 & 0.000 & 0.0025 & 0.34 & 0.30 & $47 \%$ \\
\hline & Mkt, $\mathrm{FP}_{\text {liq risk, }}, \mathrm{FP}_{\mathrm{GDPg}}, \mathrm{FP}_{\mathrm{LRCG}}$ TERM, DEF & 11.86 & 0.000 & 0.0022 & 0.46 & 0.17 & $53 \%$ \\
\hline & Mkt, $\mathrm{VAL}_{\text {everywhere, }} \mathrm{MOM}_{\text {everywhere }}$ & 7.26 & 0.000 & 0.0018 & 0.41 & 0.47 & $54 \%$ \\
\hline \multirow{4}{*}{$\begin{array}{l}\text { U.S. } \\
\text { Asset } \\
\text { Pricing } \\
\text { Factors }\end{array}$} & Mkt (U.S. CAPM) & 12.14 & 0.000 & 0.0028 & 0.30 & 0.18 & $43 \%$ \\
\hline & FF 3-Factor & 12.64 & 0.000 & 0.0026 & 0.35 & 0.19 & $47 \%$ \\
\hline & FF 4-Factor & 13.03 & 0.000 & 0.0022 & 0.37 & 0.36 & $49 \%$ \\
\hline & FF 6-factor & 12.25 & 0.000 & 0.0021 & 0.44 & 0.36 & $51 \%$ \\
\hline
\end{tabular}




\section{Table VII:}

\section{Dynamics of Value and Momentum Returns}

Panel A reports Sharpe ratios and correlations among the value, momentum, and 50/50 value/momentum combination strategies across different economic environments. The first three columns report the Sharpe ratios of the all-asset-class value, momentum, and 50/50 combination strategies and the last three columns report the average correlations among value strategies globally, among momentum strategies globally, and among 50/50 value/momentum combinations globally. These statistics are reported for the two halves of the sample period, prior to and after August 1998 for the top and bottom half of observations based on our global index of liquidity shocks from Table III ("improving" and "worsening” liquidity, respectively), and the same split of improving versus worsening liquidity pre- and post-August 1998. Panel B reports time series regressions of conditional correlations among value strategies globally, among momentum strategies globally, and between value and momentum strategies globally on a time trend, a global recession indicator (as defined in Table III), global liquidity shocks (as defined in Table III), a post-August 1998 dummy and an interaction between the post-August 1998 dummy and liquidity shocks. The conditional correlations used as the dependent variables are estimated as the average pairwise correlations among the strategies each month using the cross product of monthly returns to each strategy as described in Section IV.

\begin{tabular}{|c|c|c|c|c|c|c|}
\hline \multicolumn{7}{|c|}{ PANEL A: DYNAMICS OF SHARPE RATIOS AND CORRELATIONS } \\
\hline & \multicolumn{3}{|c|}{ Sharpe ratios } & \multicolumn{3}{|c|}{ Correlations } \\
\hline & Value & Momentum & $\begin{array}{c}50-50 \\
\text { Combination }\end{array}$ & $\rho($ Val, Val $)$ & $\rho($ Mom, Mom) & $\rho($ Val,Mom) \\
\hline 1st half-1972 to 1991 & 0.78 & 0.90 & 1.40 & 0.31 & 0.46 & -0.44 \\
\hline 2nd half-1992 to 2010 & 0.68 & 0.71 & 1.43 & 0.71 & 0.77 & -0.63 \\
\hline Pre-08/1998 & 0.68 & 1.02 & 1.49 & 0.16 & 0.43 & -0.51 \\
\hline Post-08/1998 & 0.75 & 0.72 & 1.39 & 0.64 & 0.71 & -0.55 \\
\hline Worsening liquidity & 0.95 & 0.57 & 1.36 & 0.54 & 0.72 & -0.53 \\
\hline Improving liquidity & 0.59 & 0.87 & 1.45 & 0.77 & 0.79 & -0.56 \\
\hline Worsening liquidity (pre-1998) & 1.10 & 1.00 & 1.76 & 0.40 & 0.59 & -0.30 \\
\hline Improving liquidity (pre-1998) & 1.09 & 1.27 & 2.04 & 0.36 & 0.49 & -0.29 \\
\hline Worsening liquidity (post-1998) & 0.85 & 0.19 & 0.88 & 0.65 & 0.81 & -0.71 \\
\hline Improving liquidity (post-1998) & 0.28 & 0.77 & 1.07 & 0.87 & 0.87 & -0.65 \\
\hline \multicolumn{7}{|c|}{ PANEL B: DYNAMICS OF VALUE AND MOMENTUM CORRELATIONS } \\
\hline Dependent variable $=$ & $\rho(\text { Val, Val })_{\mathrm{t}}$ & $\rho(\text { Mom, Mom })_{t}$ & $\rho(\text { Val,Mom })_{t}$ & $\rho(\text { Val, Val })_{\mathrm{t}}$ & $\rho(\text { Mom, Mom })_{t}$ & $\rho(\text { Val,Mom })_{t}$ \\
\hline Time trend & $\begin{array}{r}0.0067 \\
(2.21)\end{array}$ & $\begin{array}{r}0.0181 \\
(3.26)\end{array}$ & $\begin{array}{r}-0.0320 \\
(-4.22)\end{array}$ & $\begin{array}{r}-0.0011 \\
(0.20)\end{array}$ & $\begin{array}{r}0.0045 \\
(0.52)\end{array}$ & $\begin{array}{r}-0.0197 \\
(-1.37)\end{array}$ \\
\hline Recession & $\begin{array}{r}0.0828 \\
(1.88)\end{array}$ & $\begin{array}{r}0.0971 \\
(2.31)\end{array}$ & $\begin{array}{r}0.0195 \\
(0.31)\end{array}$ & $\begin{array}{r}0.0823 \\
(2.05)\end{array}$ & $\begin{array}{r}0.0938 \\
(2.30)\end{array}$ & $\begin{array}{r}0.0206 \\
(0.34)\end{array}$ \\
\hline Liquidity shocks & $\begin{array}{r}0.0131 \\
(0.98)\end{array}$ & $\begin{array}{r}0.0519 \\
(2.58)\end{array}$ & $\begin{array}{r}-0.0303 \\
(-1.62)\end{array}$ & $\begin{array}{r}0.0458 \\
(1.80)\end{array}$ & $\begin{array}{r}-0.0048 \\
(-0.11)\end{array}$ & $\begin{array}{r}-0.0717 \\
(-1.64)\end{array}$ \\
\hline Post-08/1998 & & & & $\begin{array}{r}0.1212 \\
(1.70)\end{array}$ & $\begin{array}{r}0.2136 \\
(1.82)\end{array}$ & $\begin{array}{r}-0.1928 \\
(-0.99)\end{array}$ \\
\hline Liquidity shocks X post-08/1998 & & & & $\begin{array}{r}-0.0379 \\
(-1.20)\end{array}$ & $\begin{array}{r}0.0929 \\
(2.11)\end{array}$ & $\begin{array}{r}0.0161 \\
(0.34)\end{array}$ \\
\hline
\end{tabular}




\section{Internet Appendix for "Value and Momentum Everywhere"*}

\section{Table A1:}

Correlation of Returns between $B E / M E$ versus Past Five Year Return Sorted Portfolios

Reported are the pair-wise correlations between the zero cost signal weighted value strategy returns formed on book-tomarket equity ratios $(B E / M E)$ and the negative of the past five year return for each stock market (U.S., U.K., Europe, Japan) as well as globally across all equity markets.

\begin{tabular}{ll}
\hline & \\
\cline { 2 - 2 } & Correlation (BE/ME returns, $-1,60$ returns) \\
\hline U.S. stocks & 0.83 \\
U.K. stocks & 0.78 \\
Europe stocks & 0.68 \\
Japan stocks & 0.82 \\
Global stocks & 0.86 \\
\hline
\end{tabular}

\footnotetext{
*Asness, Cliff, Tobias J. Moskowitz, and Lasse H. Pedersen, 2012, Internet Appendix to "Value and Momentum Everywhere,” Journal of Finance, vol. , ???, http://www.afajof.org/IA/[year].asp.
} 


\section{Figure A1: Global Value and Momentum Decile Portfolios}

Plotted are the pricing errors of value decile and momentum decile portfolios in each of the four international stock markets we study: U.S., U.K., Europe, and Japan under the three-factor global model, consisting of a global market factor (MSCI stock index), a value "everywhere" factor, and a momentum "everywhere" factor. The pricing errors of the 80 portfolios are alphas from time series regressions of each of the portfolios on the factor models, plotted below as the actual average return on each portfolio relative to their predicted expected returns from the model. A 45 degree line passing through the origin is added to highlight the pricing errors (vertical distances to the 45 degree line) where each model is forced to also price the equity premium. Also reported on each graph are the average absolute value of the alphas, $F$-statistic and $p$-value from the GRS test, and the crosssectional $R^{2}$.

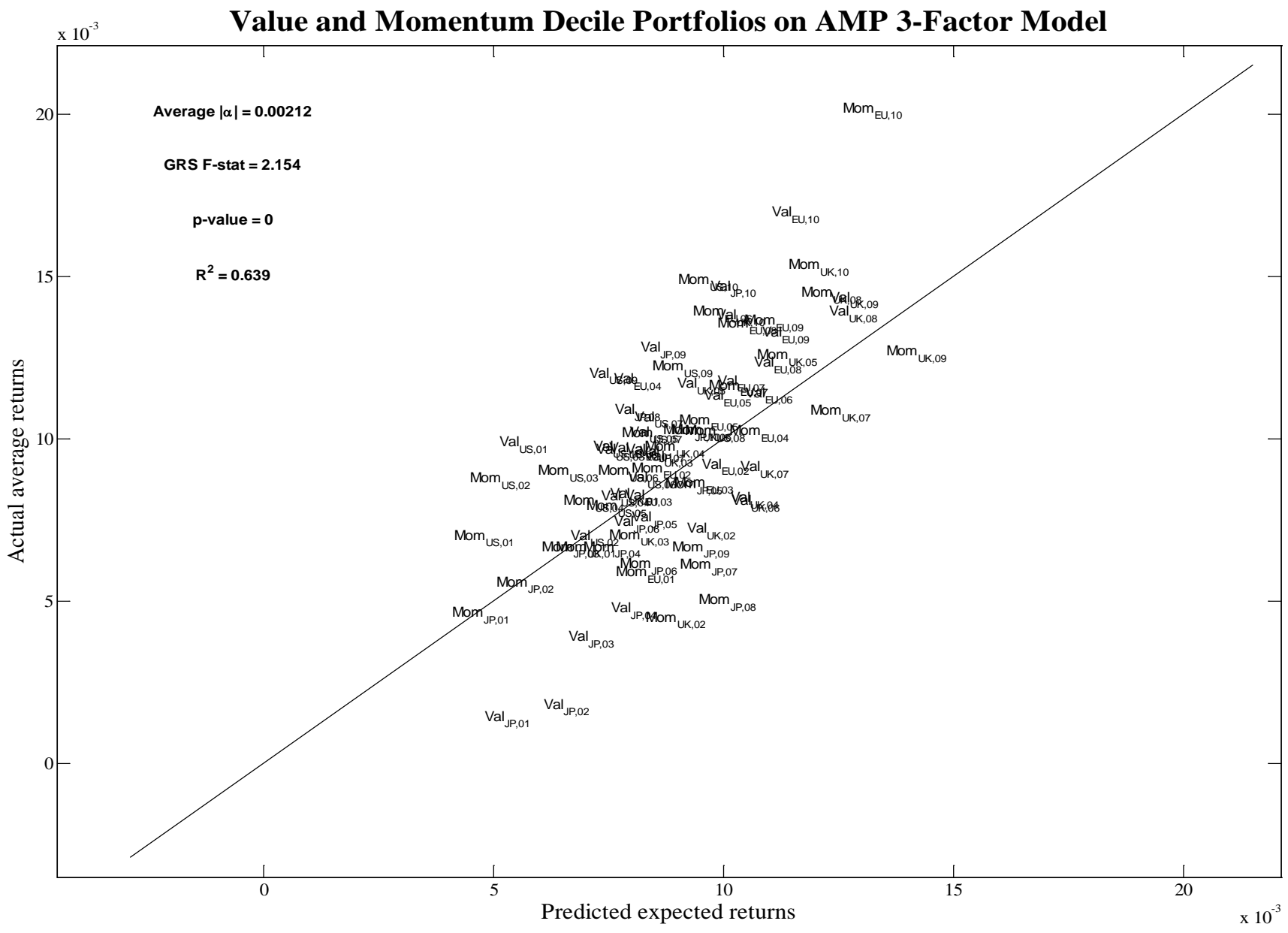




\section{Table A2:}

\section{Correlation of Value and Momentum Strategies-Average of Individual Correlations}

Reported are the average of the individual correlations of value and momentum strategies across markets and asset classes, where we first compute the pairwise correlation of all individual strategies (e.g., U.S. individual stock value strategy returns with Japan individual stock value strategy returns) and then take the average of these pairwise correlations for each group. Excluded are the correlation of each strategy with itself (e.g., removing the 1's) and the correlation of each strategy with all other strategies within the same market. Correlations are computed from quarterly returns to mitigate the influence of non-synchronous trading across markets.

\begin{tabular}{lcccc}
\hline & \multicolumn{3}{c}{ AVERAGE OF INDIVIDUAL CORRELATIONS } \\
\cline { 2 - 5 } & Stock value & $\begin{array}{c}\text { Non-stock } \\
\text { value }\end{array}$ & $\begin{array}{c}\text { Stock } \\
\text { momentum }\end{array}$ & $\begin{array}{c}\text { Non-stock } \\
\text { momentum }\end{array}$ \\
\cline { 2 - 5 } Stock value & $0.57^{*}$ & 0.12 & $-0.46^{*}$ & -0.17 \\
Non-stock value & & & $-0.13^{*}$ & -0.11 \\
Stock momentum & & & $0.54^{*}$ & $0.25^{*}$ \\
Non-stock momentum & & & $0.15^{*}$ \\
\hline
\end{tabular}




\section{Table A3:}

\section{Correlation of Value and Momentum Strategies Across Markets and Asset Classes-Value Lagged a Year}

Reported are the results of Table II in the paper for the average correlations among all value and momentum strategies across markets and asset classes, where the value measure $B E / M E$ is lagged an additional year (i.e., market value is lagged to coincide with book value and both are taken from the most recent year end rather than quarter end). Panel A reports the average of the individual correlations, where we first compute the pairwise correlation of all individual strategies and then take the average of these pairwise correlations for each group. Panel B reports the correlations of the average return series, where we first compute the average return series for a group and then compute the correlation between the two average return series. The diagonal elements in Panel B are computed as the average correlation between each market's return series and the average of all other return series in other markets, excluding the market itself. Both panels exclude the correlation of each strategy with itself (e.g., removing the 1's) and exclude the correlation of each strategy with all other strategies within the same market. Correlations are computed from quarterly returns to mitigate the influence of non-synchronous trading across markets.

\begin{tabular}{|c|c|c|c|c|c|c|c|c|}
\hline & \multicolumn{4}{|c|}{ PANEL A: AVERAGE OF INDIVIDUAL CORRELATIONS } & \multicolumn{4}{|c|}{ PANEL B: CORRELATION OF AVERAGE RETURN SERIES } \\
\hline & $\begin{array}{l}\text { Stock } \\
\text { value }\end{array}$ & $\begin{array}{c}\text { Non-stock } \\
\text { value }\end{array}$ & $\begin{array}{c}\text { Stock } \\
\text { momentum }\end{array}$ & $\begin{array}{l}\text { Non-stock } \\
\text { momentum }\end{array}$ & $\begin{array}{l}\text { Stock } \\
\text { value }\end{array}$ & $\begin{array}{c}\text { Non-stock } \\
\text { value }\end{array}$ & $\begin{array}{c}\text { Stock } \\
\text { momentum }\end{array}$ & $\begin{array}{l}\text { Non-stock } \\
\text { momentum }\end{array}$ \\
\hline Stock value & 0.50 & 0.06 & -0.28 & -0.06 & 0.62 & 0.05 & -0.28 & -0.08 \\
\hline Non-stock value & & 0.03 & -0.13 & -0.11 & & 0.07 & -0.20 & -0.15 \\
\hline Stock momentum & & & 0.54 & 0.25 & & & 0.65 & 0.41 \\
\hline Non-stock momentum & & & & 0.15 & & & & 0.21 \\
\hline
\end{tabular}




\section{Table A4:}

Correlation of Value and Momentum Strategies Across Markets and Asset Classes—Value Measured as Past five year Return

Reported are the results of Table II in the paper for the average correlations among all value and momentum strategies across markets and asset classes, where the value measure is the past five year (60 months) return on the security for every asset class. Panel A reports the average of the individual correlations, where we first compute the pairwise correlation of all individual strategies and then take the average of these pairwise correlations for each group. Panel B reports the correlations of the average return series, where we first compute the average return series for a group and then compute the correlation between the two average return series. The diagonal elements in Panel B are computed as the average correlation between each market's return series and the average of all other return series in other markets, excluding the market itself. Both panels exclude the correlation of each strategy with itself (e.g., removing the 1's) and exclude the correlation of each strategy with all other strategies within the same market. Correlations are computed from quarterly returns to mitigate the influence of non-synchronous trading across markets.

\begin{tabular}{|c|c|c|c|c|c|c|c|c|}
\hline & \multicolumn{4}{|c|}{ PANEL A: AVERAGE OF INDIVIDUAL CORRELATIONS } & \multicolumn{4}{|c|}{ PANEL B: CORRELATION OF AVERAGE RETURN SERIES } \\
\hline & $\begin{array}{l}\text { Stock } \\
\text { value }\end{array}$ & $\begin{array}{c}\text { Non-stock } \\
\text { value }\end{array}$ & $\begin{array}{c}\text { Stock } \\
\text { momentum }\end{array}$ & $\begin{array}{l}\text { Non-stock } \\
\text { momentum }\end{array}$ & $\begin{array}{l}\text { Stock } \\
\text { value }\end{array}$ & $\begin{array}{c}\text { Non-stock } \\
\text { value }\end{array}$ & $\begin{array}{c}\text { Stock } \\
\text { momentum }\end{array}$ & $\begin{array}{l}\text { Non-stock } \\
\text { momentum }\end{array}$ \\
\hline Stock value & 0.48 & 0.18 & -0.42 & -0.23 & 0.60 & 0.27 & -0.48 & -0.38 \\
\hline Non-stock value & & 0.08 & -0.10 & -0.13 & & 0.13 & -0.21 & -0.23 \\
\hline Stock momentum & & & 0.54 & 0.27 & & & 0.65 & 0.45 \\
\hline Non-stock momentum & & & & 0.15 & & & & 0.21 \\
\hline
\end{tabular}




\section{Table A5:}

\section{Correlation of Value/Momentum Combination Strategies Across Markets and Asset Classes}

Reported are the results of Table II in the paper for the average correlations among the value/momentum 50/50 combination strategies across markets and asset classes. Panel A reports the average of the individual correlations, where we first compute the pairwise correlation of all individual strategies and then take the average of these pairwise correlations for each group. Panel B reports the correlations of the average return series, where we first compute the average return series for a group and then compute the correlation between the two average return series. The diagonal elements in Panel B are computed as the average correlation between each market's return series and the average of all other return series in other markets, excluding the market itself. Both panels exclude the correlation of each strategy with itself (e.g., removing the 1's). Correlations are computed from quarterly returns to mitigate the influence of non-synchronous trading across markets.

\begin{tabular}{|c|c|c|c|c|}
\hline & \multicolumn{2}{|c|}{$\begin{array}{c}\text { PANEL A: } \\
\text { AVERAGE OF INDIVIDUAL } \\
\text { CORRELATIONS }\end{array}$} & \multicolumn{2}{|c|}{$\begin{array}{l}\text { PANEL B: CORRELATION OF } \\
\text { AVERAGE RETURN SERIES }\end{array}$} \\
\hline & Stock combo & Non-stock combo & Stock combo & Non-stock combo \\
\hline Stock combo & 0.43 & 0.10 & 0.55 & 0.22 \\
\hline Non-stock combo & & 0.00 & & 0.04 \\
\hline
\end{tabular}


Table A6:

\section{Performance of Value and Momentum Portfolios Across Markets and Asset Classes- Decile Portfolios}

Reported are the average raw excess (of the 1 month U.S. T-bill rate) return, $t$-statistic of the average return (in parentheses), standard deviation of returns, and Sharpe ratio of each value, momentum, and equal weighted 50/50 value and momentum combination strategy in each equity market we study: U.S. stocks, U.K. stocks, Europe stocks, and Japan stocks. Also reported are the intercepts or alphas, and their $t$-statistics (in parentheses) from a time series regression of each return series on the return of the market index for each asset class. The market index for the stock strategies is the MSCI equity index for each country for all of the individual stock strategies. In each market the universe of securities is first sorted by either value or momentum and then broken into ten equal groups based on those sorts to form decile portfolios P1, P2, . . P10. Stocks within the portfolios are value weighted by their beginning of month capitalization. Reported are the returns to P1, P5, and P10 as well as the high minus low spread in returns (P10-P1). For comparison, the rank weighted factor portfolio ("Factor"), which is a zero-investment portfolio that weights each asset in proportion to its rank based on either value or momentum, following equation (1) is also reported (same numbers as in Table I of the paper). The 50/50 value/momentum combination strategies are an equal weighted average of the value and momentum spread strategies (P10-P1 and Factor) for each market. Results are also reported for an average of all individual stock strategies across all stock markets (“Global stocks”), where average return series are computed using equal volatility weights across the markets to account for differences in volatility. Finally, the last row for each market reports the correlation between value and momentum zero cost residual returns from the benchmark in each market or asset class. Statistics are computed from monthly return series but are reported as annualized numbers.

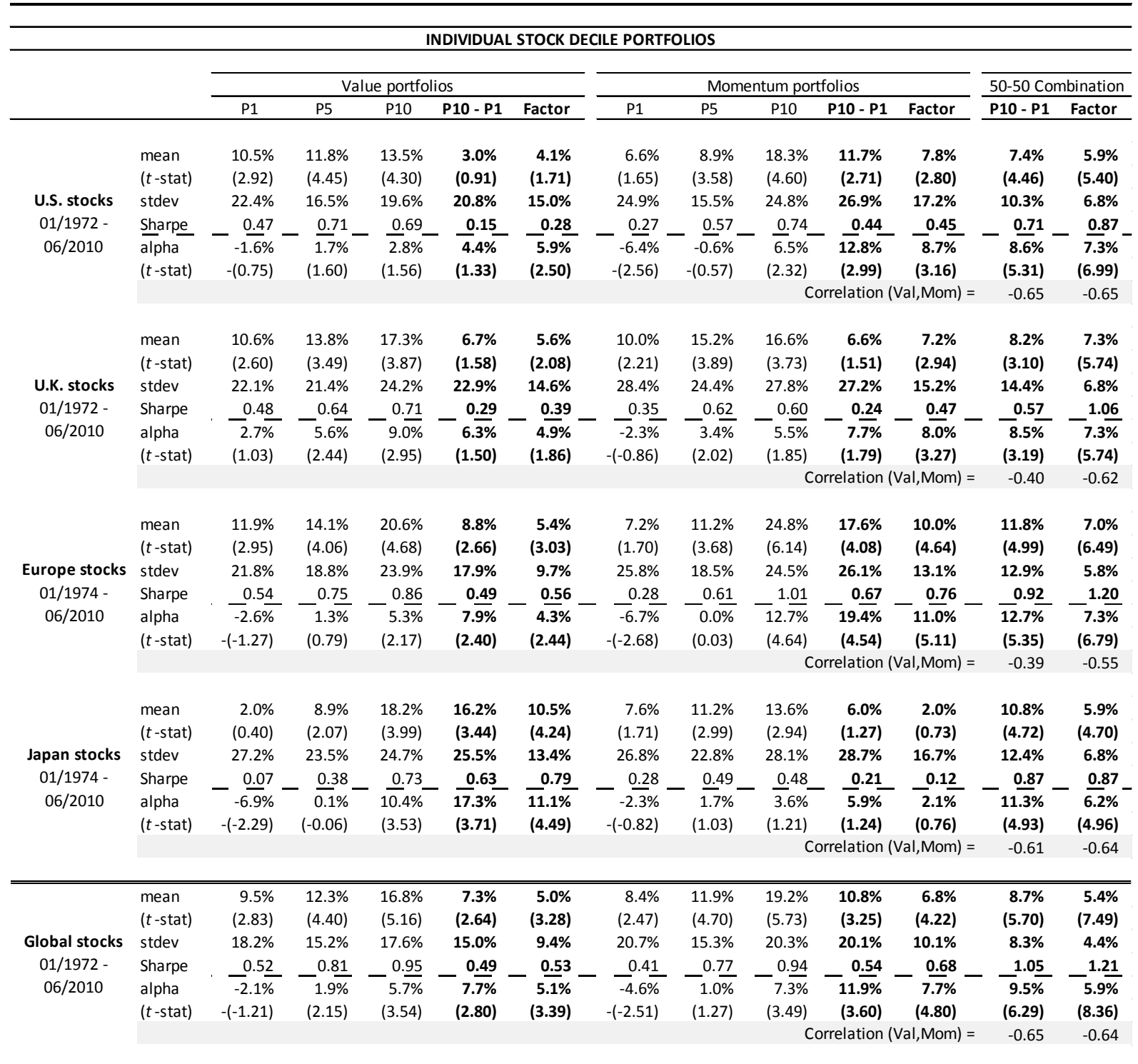


Table A7:

\section{Correlation of Value and Momentum Strategies Across Markets and Asset Classes-Decile Portfolios}

Reported are the results of Table II in the paper for the average correlations among all value and momentum strategies across markets and asset classes, where value and momentum strategies in equities are the difference in returns between the top and bottom decile portfolios (P10-P1) sorted on value and momentum measures. Panel A reports the average of the individual correlations, where we first compute the pairwise correlation of all individual strategies and then take the average of these pairwise correlations for each group. Panel B reports the correlations of the average return series, where we first compute the average return series for a group and then compute the correlation between the two average return series. The diagonal elements in Panel B are computed as the average correlation between each market's return series and the average of all other return series in other markets, excluding the market itself. Both panels exclude the correlation of each strategy with itself (e.g., removing the 1's) and exclude the correlation of each strategy with all other strategies within the same market. Correlations are computed from quarterly returns to mitigate the influence of non-synchronous trading across markets.

\begin{tabular}{|c|c|c|c|c|c|c|c|c|}
\hline & \multicolumn{4}{|c|}{ PANEL A: AVERAGE OF INDIVIDUAL CORRELATIONS } & \multicolumn{4}{|c|}{ PANEL B: CORRELATION OF AVERAGE RETURN SERIES } \\
\hline & $\begin{array}{l}\text { Stock } \\
\text { value }\end{array}$ & $\begin{array}{c}\text { Non-stock } \\
\text { value }\end{array}$ & $\begin{array}{c}\text { Stock } \\
\text { momentum }\end{array}$ & $\begin{array}{l}\text { Non-stock } \\
\text { momentum }\end{array}$ & $\begin{array}{l}\text { Stock } \\
\text { value }\end{array}$ & $\begin{array}{c}\text { Non-stock } \\
\text { value }\end{array}$ & $\begin{array}{c}\text { Stock } \\
\text { momentum }\end{array}$ & $\begin{array}{l}\text { Non-stock } \\
\text { momentum }\end{array}$ \\
\hline Stock value & 0.51 & 0.12 & -0.47 & -0.17 & 0.68 & 0.20 & -0.54 & -0.28 \\
\hline Non-stock value & & 0.03 & -0.11 & -0.11 & & 0.07 & -0.19 & -0.13 \\
\hline Stock momentum & & & 0.50 & 0.25 & & & 0.65 & 0.38 \\
\hline Non-stock momentum & & & & 0.15 & & & & 0.21 \\
\hline
\end{tabular}




\section{Performance of Value and Momentum Portfolios Across Markets and Asset Classes- Volatility Adjusted Portfolios}

Reported are the average raw excess (of the 1 month U.S. T-bill rate) return, $t$-statistic of the average return (in parentheses), standard deviation of returns, and Sharpe ratio of the zero cost the high minus low spread in returns (P3-P1) as well as a rank weighted factor portfolio ("Factor") which is a zero-investment portfolio that weights each asset in proportion to its rank based on either value or momentum, following equation (1) for each market and asset class we study: U.S. stocks, U.K. stocks, Europe stocks, Japan stocks, country index futures, currencies, fixed income government bonds, and commodities. Also reported are the intercepts or alphas, and their $t$-statistics (in parentheses) from a time series regression of each return series on the return of the market index for each asset class, which is the MSCI equity index for each country for all of the individual stock strategies, the MSCI world index for strategies of country index futures, and an equal weighted basket of securities in each asset class for currencies, fixed income, and commodities. The 50/50 value/momentum combination strategies are an equal weighted average of the value and momentum spread strategies. The first two columns in each panel report results for the volatility adjusted portfolios, where portfolios are scaled to have an ex ante volatility of $2 \%$ per annum using a rolling volatility estimate of daily returns data over the past three years. The second two columns in each panel report the results for the unadjusted portfolios from Table I. Results are also reported for an average of all individual stock strategies across all stock markets (“Global stocks”), across all non-stock asset classes ("Global other asset classes”), and across all markets and asset classes ("Global all asset classes”), where average return series are computed using equal volatility weights across the markets and asset classes to account for the large differences in volatility across asset classes. The last row for each asset class reports the correlation between value and momentum zero cost residual returns from the benchmark in each market or asset class. Statistics are computed from monthly return series but are reported as annualized numbers.

\begin{tabular}{|c|c|c|c|c|c|c|c|c|c|c|c|c|c|}
\hline \multicolumn{14}{|c|}{ PANEL A: INDIVIDUAL STOCK PORTFOLIOS } \\
\hline & & \multicolumn{4}{|c|}{ Value } & \multicolumn{4}{|c|}{ Momentum } & \multicolumn{4}{|c|}{ 50-50 Combination } \\
\hline & & \multicolumn{2}{|c|}{ Volatility Adjusted } & \multicolumn{2}{|c|}{ Unadjusted } & \multicolumn{2}{|c|}{ Volatility Adjusted } & \multicolumn{2}{|c|}{ Unadjusted } & \multicolumn{2}{|c|}{ Volatility Adjusted } & \multicolumn{2}{|c|}{ Unadjusted } \\
\hline & & P3 - P1 & Factor & P3 - P1 & Factor & P3 - P1 & Factor & P3 - P1 & Factor & P3 - P1 & Factor & P3 - P1 & Factor \\
\hline & mean & $\begin{array}{r}0.2 \% \\
(0.55)\end{array}$ & $0.1 \%$ & $\begin{array}{r}3.7 \% \\
(1.83)\end{array}$ & $\begin{array}{r}3.9 \% \\
(166)\end{array}$ & $0.8 \%$ & $\begin{array}{r}1.3 \% \\
(3.34)\end{array}$ & $\begin{array}{r}5.4 \% \\
(2.08)\end{array}$ & $\begin{array}{r}7.7 \% \\
(2.84)\end{array}$ & $\begin{array}{r}1.0 \% \\
(2.87)\end{array}$ & $\begin{array}{r}1.8 \% \\
(4.87)\end{array}$ & $\begin{array}{r}4.6 \% \\
(3.98)\end{array}$ & $\begin{array}{r}5.8 \% \\
(5.40)\end{array}$ \\
\hline U.S. stocks & stdev & $2.2 \%$ & $2.3 \%$ & $12.8 \%$ & $14.8 \%$ & $2.2 \%$ & $2.3 \%$ & $16.4 \%$ & $17.0 \%$ & $2.2 \%$ & $2.2 \%$ & $7.2 \%$ & $6.8 \%$ \\
\hline $01 / 1972-$ & Sharpe & 0.09 & 0.06 & 0.29 & 0.26 & 0.38 & 0.55 & 0.33 & 0.45 & 0.48 & 0.81 & 0.63 & 0.86 \\
\hline \multirow[t]{5}{*}{$07 / 2011$} & alpha & $\overline{0.5 \%}$ & $\overline{0.5 \%}$ & $\overline{5.3 \%}$ & $5.8 \%$ & $0 . \overline{7 \%}$ & $1 . \overline{2 \%}$ & $6 . \overline{0 \%}$ & $8 . \overline{7 \%}$ & $\overline{1.3} \%$ & $2.2 \%$ & $\overline{5.7} \%$ & $\overline{7.2} \%$ \\
\hline & $(t$-stat $)$ & (1.43) & (1.28) & (2.66) & (2.49) & (1.95) & (3.04) & $(2.30)$ & (3.22) & (3.62) & (6.06) & (5.05) & (7.06) \\
\hline & & & & & & & & & & -0.58 & -0.72 & -0.53 & -0.65 \\
\hline & mean & $0.4 \%$ & $0.7 \%$ & $4.5 \%$ & $5.5 \%$ & $1.1 \%$ & $1.7 \%$ & $6.0 \%$ & $7.2 \%$ & $1.7 \%$ & $2.5 \%$ & $6.3 \%$ & $7.2 \%$ \\
\hline & ( $t$-stat) & $(0.89)$ & $(1.66)$ & $(1.83)$ & $(2.10)$ & $(2.98)$ & $(4.40)$ & $(2.37)$ & $(3.00)$ & (3.95) & (5.58) & $(4.23)$ & $(5.85)$ \\
\hline U.K. stocks & stdev & $2.1 \%$ & $2.3 \%$ & $13.4 \%$ & $14.4 \%$ & $2.2 \%$ & $2.3 \%$ & $15.9 \%$ & $15.0 \%$ & $2.2 \%$ & $2.3 \%$ & $8.1 \%$ & $6.7 \%$ \\
\hline $01 / 1972$ & Sharpe & 0.17 & 0.32 & 0.33 & 0.38 & 0.49 & 0.73 & 0.38 & 0.48 & 0.76 & 1.07 & 0.77 & 1.07 \\
\hline \multirow{5}{*}{$07 / 2011$} & alpha & $0.2 \%$ & $0.5 \%$ & $3.5 \%$ & $4.4 \%$ & $1 . \overline{2 \%}$ & $1 . \overline{9 \%}$ & $6 . \overline{7 \%}$ & $8 . \overline{0}$ & $\overline{1.6} \%$ & $\overline{2.4} \%$ & $\overline{6.0} \%$ & $7.2 \%$ \\
\hline & $(t$-stat) & $(0.45)$ & (1.10) & (1.47) & (1.74) & (3.39) & (5.07) & (2.66) & (3.36) & (3.75) & (5.47) & $(4.05)$ & (5.84) \\
\hline & & & & & & & & & & -0.39 & -0.62 & -0.43 & -0.62 \\
\hline & mean & $0.5 \%$ & $0.5 \%$ & $4.8 \%$ & $5.2 \%$ & $1.6 \%$ & $2.1 \%$ & $8.1 \%$ & $9.8 \%$ & $1.9 \%$ & $2.6 \%$ & $5.9 \%$ & $6.9 \%$ \\
\hline & $(t$-stat) & (1.15) & (1.07) & $(2.32)$ & (2.95) & (4.05) & (5.19) & (3.37) & (4.59) & $(4.37)$ & (6.06) & $(4.77)$ & (6.55) \\
\hline Europe stocks & stdev & $2.5 \%$ & $2.4 \%$ & $11.5 \%$ & $9.7 \%$ & $2.3 \%$ & $2.4 \%$ & $14.7 \%$ & $13.1 \%$ & $2.2 \%$ & $2.3 \%$ & $6.8 \%$ & $5.8 \%$ \\
\hline 01/1974 - & Sharpe & 0.22 & 0.21 & 0.42 & 0.54 & 0.69 & 0.89 & 0.55 & 0.75 & 0.84 & 1.17 & 0.87 & 1.20 \\
\hline \multirow[t]{5}{*}{$07 / 2011$} & alpha & $0 . \overline{1 \%}$ & $0 . \overline{1 \%}$ & $3 . \overline{5 \%}$ & $4 . \overline{0 \%}$ & $\overline{1.7} \%$ & $\overline{2.2} \%$ & $\overline{9.1} \%$ & $1 \overline{0.7} \%$ & $1.9 \%$ & $2.6 \%$ & $6.1 \%$ & $7.1 \overline{\%}$ \\
\hline & $(t$-stat) & $(0.32)$ & $(0.27)$ & (1.71) & (2.32) & (4.24) & (5.43) & (3.88) & (5.05) & (4.43) & (6.08) & (4.88) & (6.77) \\
\hline & & & & & & & & & & -0.56 & -0.64 & -0.52 & -0.55 \\
\hline & mean & $1.7 \%$ & $1.9 \%$ & $12.0 \%$ & $10.2 \%$ & $0.2 \%$ & $0.2 \%$ & $1.7 \%$ & $2.2 \%$ & $2.0 \%$ & $2.2 \%$ & $6.4 \%$ & $5.9 \%$ \\
\hline & ( $t$-stat) & (3.88) & $(4.27)$ & $(4.31)$ & $(4.22)$ & (0.59) & $(0.64)$ & $(0.57)$ & $(0.81)$ & $(4.56)$ & $(4.86)$ & $(4.28)$ & $(4.80)$ \\
\hline Japan stocks & stdev & $2.3 \%$ & $2.3 \%$ & $15.3 \%$ & $13.2 \%$ & $2.3 \%$ & $2.2 \%$ & $18.6 \%$ & $16.5 \%$ & $2.2 \%$ & $2.3 \%$ & $8.1 \%$ & $6.7 \%$ \\
\hline $01 / 1974$ & Sharpe & 0.75 & 0.82 & 0.79 & 0.77 & 0.10 & 0.11 & 0.09 & 0.13 & 0.88 & 0.93 & 0.78 & 0.88 \\
\hline \multirow[t]{5}{*}{$07 / 2011$} & alpha & $1 . \overline{8 \%}$ & $1 . \overline{9 \%}$ & $13 . \overline{0 \%}$ & $10 . \overline{7 \%}$ & $\overline{0.3} \%$ & $0.3 \%$ & $1.7 \%$ & $2.2 \%$ & $2.1 \%$ & $2.3 \%$ & $6.8 \%$ & $6 . \overline{1 \%}$ \\
\hline & $(t$-stat) & (4.11) & $(4.30)$ & (4.71) & (4.47) & $(0.65)$ & $(0.76)$ & $(0.54)$ & $(0.84)$ & (4.98) & (5.32) & (4.63) & (5.05) \\
\hline & & & & & & & & & & -0.59 & -0.64 & -0.60 & -0.64 \\
\hline & mean & $0.5 \%$ & $0.6 \%$ & $4.8 \%$ & $4.8 \%$ & $0.9 \%$ & $1.3 \%$ & $5.3 \%$ & $6.8 \%$ & $1.3 \%$ & $1.8 \%$ & $4.7 \%$ & $5.3 \%$ \\
\hline & ( $t$-stat) & (2.18) & $(2.22)$ & (3.62) & (3.25) & $(3.60)$ & $(4.81)$ & $(3.40)$ & $(4.29)$ & (5.70) & $(7.26)$ & (6.37) & (7.58) \\
\hline Global stocks & stdev & $1.4 \%$ & $1.5 \%$ & $8.4 \%$ & $9.3 \%$ & $1.6 \%$ & $1.7 \%$ & $9.8 \%$ & $9.9 \%$ & $1.3 \%$ & $1.5 \%$ & $4.6 \%$ & $4.4 \%$ \\
\hline 01/1972 - & Sharpe & 0.36 & 0.37 & 0.58 & 0.52 & 0.60 & 0.80 & 0.54 & 0.68 & 0.94 & 1.20 & 1.01 & 1.21 \\
\hline \multirow{3}{*}{$07 / 2011$} & alpha & $0.4 \%$ & $0.5 \%$ & $4.9 \%$ & $5.0 \%$ & $0 . \overline{9 \%}$ & $1.3 \%$ & $6 . \overline{0 \%}$ & $7.6 \%$ & $1.2 \%$ & $1.8 \%$ & $5.0 \%$ & $5.8 \%$ \\
\hline & $(t$-stat) & (1.97) & $(2.00)$ & (3.65) & (3.33) & (3.73) & (5.02) & (3.85) & $(4.86)$ & (6.08) & (7.89) & (6.87) & (8.44) \\
\hline & & & & & & & & & & -0.63 & -0.73 & -0.54 & -0.64 \\
\hline
\end{tabular}




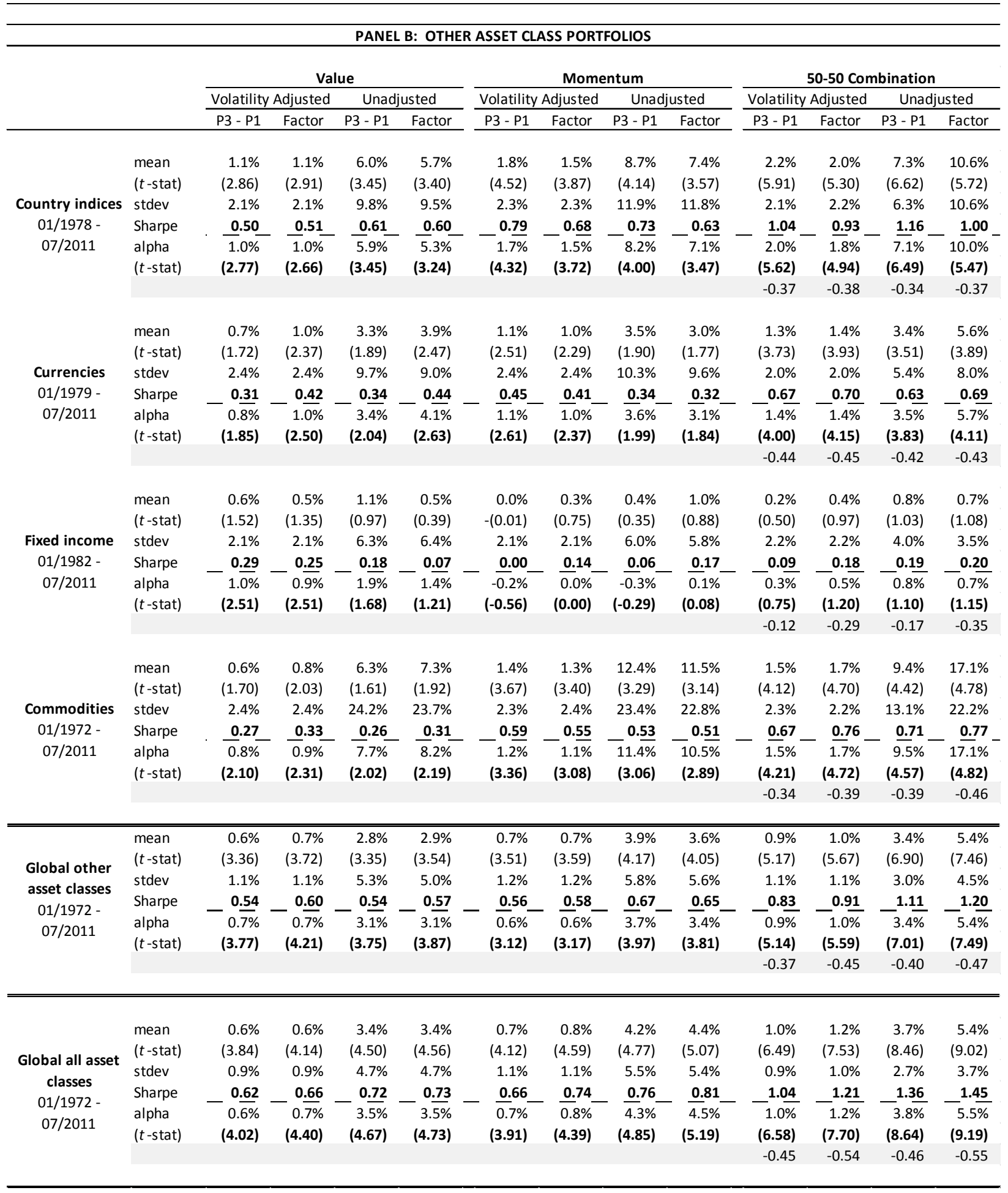

